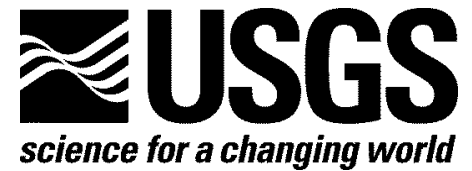

\title{
Report on the Aseismic Slip, Tremor, and Earthquakes Workshop
}

By Joan Gomberg, Evelyn Roeloffs, Anne Trehu, Herb Dragert, and Charles Meertens
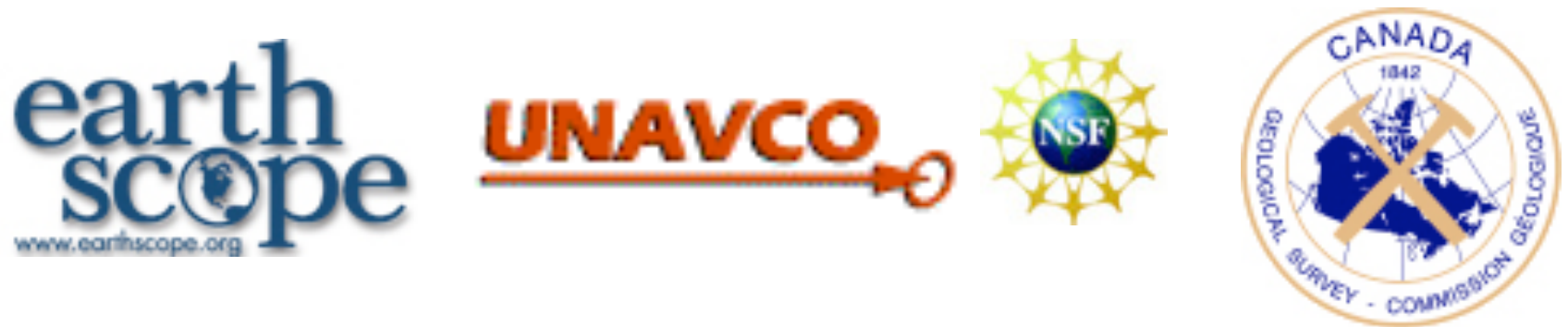

Open-File Report 2008-1343

U.S. Department of the Interior

U.S. Geological Survey 


\title{
U.S. Department of the Interior \\ DIRK KEMPTHORNE, Secretary
}

\author{
U.S. Geological Survey \\ Mark D. Myers, Director
}

U.S. Geological Survey, Reston, Virginia 2008

For product and ordering information:

World Wide Web: http://www.usgs.gov/pubprod

Telephone: 1-888-ASK-USGS

For more information on the USGS - the Federal source for science about the Earth, its natural and living resources, natural hazards, and the environment:

World Wide Web: http://www.usgs.gov

Telephone: 1-888-ASK-USGS

Suggested citation:

Gomberg, Joan, Roeloffs, Evelyn, Trehu, Anne, Dragert, Herb, and Meertens, Charles, 2008, Report on the Aseismic Slip, Tremor, and Earthquakes workshop: U.S. Geological Survey Open-File Report 2008-1343, 72 p. [http://pubs.usgs.gov/of/2008/1343/].

Any use of trade, product, or firm names is for descriptive purposes only and does not imply endorsement by the U.S. Government.

Although this report is in the public domain, permission must be secured from the individual copyright owners to reproduce any copyrighted material contained within this report.

Abstracts authored entirely by non-USGS authors do not represent the views or positions of the U.S. Geological Survey or the U.S. Government and are published solely as part of the proceedings volume. 


\section{Contents}

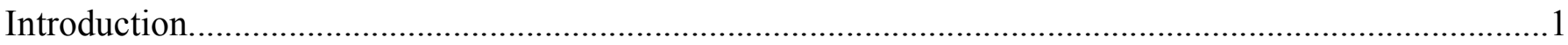

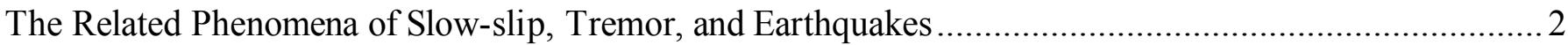

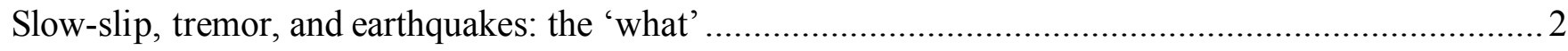

Slow-slip, tremor, and earthquakes: the 'when and where' ............................................................... 3

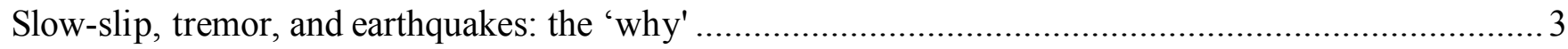

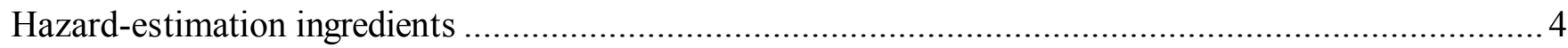

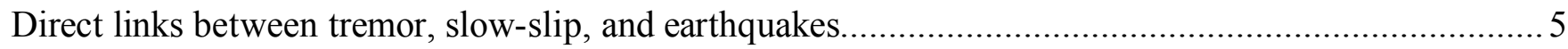

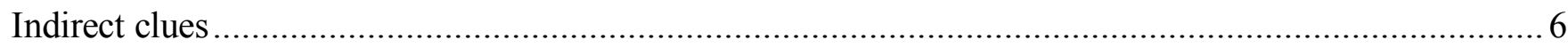

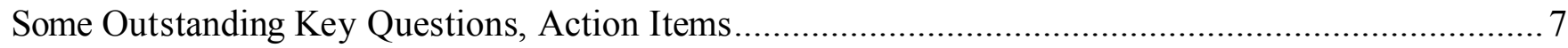

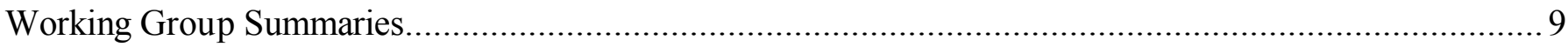

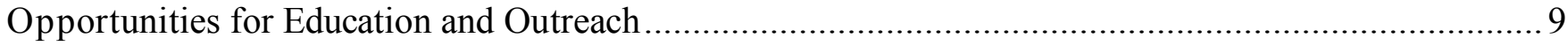

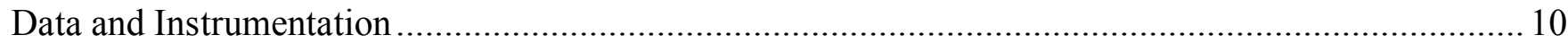

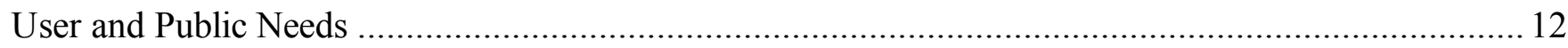

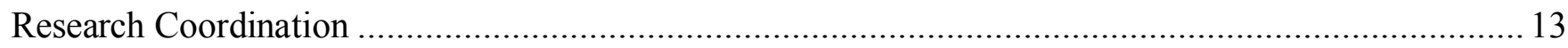

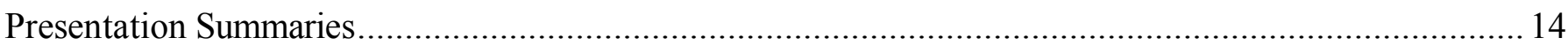

The phenomenology; the observations of aseismic slip, tremor, related (temporally and spatially)

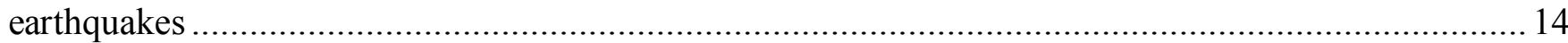

Long-term and short-term slow-slip events inferred from GEONET GPS data and the NIED Hi-net tiltmeter data, Shinichi Miyazaki (Earthquake Research Institute, Japan), Paul Segall, Jeffery J. McGuire,Hitoshi Hirose, Shutaro Sekine, Kazushige Obara ……………......................................... 14 The mechanics of subduction zone tremor and transient slip in southwest Japan, David Shelly (University of California, Berkeley), Greg Beroza, Satoshi Ide, Sho Nakamula, Takahiko Uchide...... 14 Spatial-Temporal Patterns of ETS Tremors in Northern Cascadia: 10 Years of Observations from 1997 to 2007, Honn Kao (Geol. Survey of Canada, Shao-Ju Shan, Garry

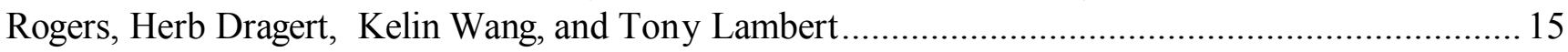

GPS observations of Cascadia ETS, Tim Melbourne (Central Washington University) .....................15

Nonvolcanic Tremor on the San Andreas Fault: Why?, Bill Ellsworth

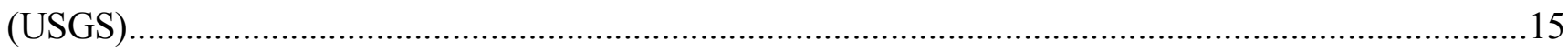

The underlying physical processes; observational constraints, theoretical models................................ 16

The environment of Episodic Tremor and Slip: Temperature, rock composition, and water,

Roy Hyndman (Geol. Survey of Canada) ....................................................................................... 16

Mechanical models for slow-slip with focus on dilatant strengthening plus speculation on tremor and triggered earthquakes, Paul Segall (Stanford University), Allan Rubin, Jim

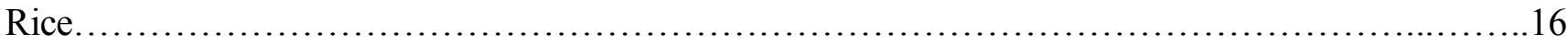

What can thermal-petrologic models and field studies of subduction zones tell us about episodic tremor and slip? Simon Peacock (University of British Columbia)....................................... 17

Studies on the physical origin of aseismic deformation transients in the framework of rate and

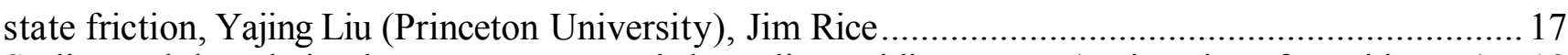

Scaling and the relation between tremor and slow-slip, Heidi Houston (University of Washington)...18 
Implications for earthquake hazards; what do users need/want to know and what do we need to do $t$ deliver this?

Seismic hazard implications of ETS - no canary in the gold mine yet. John Vidale (University of

Washington)

The California Earthquake Advisory Plan,Jim Goltz (California Office of Emergency

Services)....

The Challenges of Communicating About Earthquake Hazards and Their Uncertainties, Ivan Wong, (URS Corp)

ETS and Regional Earthquakes: Looking for the Links Herb Dragert (Geol.

Survey of Canada) Garry Rogers, Kelin Wang, John Cassidy, and Stephane Mazzotti ....................20

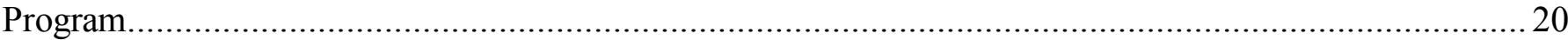

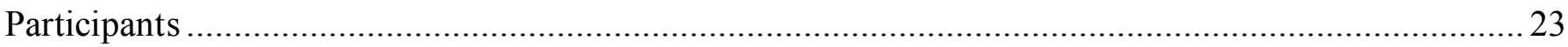

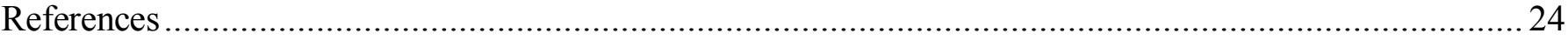

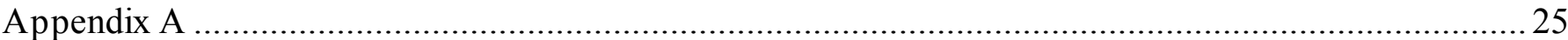




\section{Report on the Aseismic Slip, Tremor, and Earthquakes Workshop}

By Joan Gomberg, Evelyn Roeloffs, Anne Trehu, Herb Dragert, and Charles Meertens

\section{Introduction}

This report summarizes the discussions and information presented during the workshop on Aseismic Slip, Tremor, and Earthquakes. Workshop goals included improving coordination among those involved in conducting research related to these phenomena, assessing the implications for earthquake hazard assessment, and identifying ways to capitalize on the education and outreach opportunities presented by these phenomena. Research activities of focus included making, disseminating, and analyzing relevant measurements; the relationships among tremor, aseismic or "slow-slip", and earthquakes; and discovering the underlying causative physical processes. More than 52 participants contributed to the workshop, held February 25-28, 2008 in Sidney, British Columbia. The workshop was sponsored by the U.S. Geological Survey, the National Science Foundation's Earthscope Program and UNAVCO Consortium, and the Geological Survey of Canada.

This report has five parts. In the first part, we integrate the information exchanged at the workshop as it relates to advancing our understanding of earthquake generation and hazard. In the second part, we summarize the ideas and concerns discussed in workshop working groups on Opportunities for Education and Outreach, Data and Instrumentation, User and Public Needs, and Research Coordination. The third part presents summaries of the oral presentations. The oral presentations are grouped as they were at the workshop in the categories of phenomenology, underlying physical processes, and implications for earthquake hazards. The fourth part contains the meeting program and the fifth part lists the workshop participants. References noted in parentheses refer to the authors of presentations made at the workshop, and published references are noted in square brackets and listed in the Reference section. Appendix A contains abstracts of all participant presentations and posters, which also have been posted online, along with 
presentations and author contact information at http://www.earthscope.org/science/cascadia.

\section{The Related Phenomena of Slow-slip, Tremor, and Earthquakes}

We begin this section by introducing the phenomena of aseismic or "slow-slip", tremor, and earthquakes, and briefly summarizing the relevant components needed to assess earthquake hazards. When viewed retrospectively, the workshop presentations and discussions revealed a number of exciting, likely causal connections between slow-slip and tremor and earthquake generation and hazard. We review those conclusions that are evident directly in observations of slow-slip, tremor, and earthquakes, as well as indirectly from model predictions and clues provided by more peripheral observations and analyses. The section concludes with a summary of outstanding questions and suggested approaches to answering them. Note that information in this report is based on workshop presentations and discussions. References in parentheses refer to the authors of relevant presentations (abstracts and presentation materials also are online), with published references noted in square brackets and listed in the References section.

\section{Slow Slip, Tremor, and Earthquakes: The "What"}

"Slow-slip" refers to deviations from constant-rate, long-term fault displacement, usually modeled as a slow (but not necessarily complete) release of the strain energy that accumulates due to relative plate motions. These deviations last days to years and are typically observed in GPSdetermined positions, as well as strainmeter and tiltmeter data. Generally, the slip occurs so slowly that almost no seismic waves radiate, although very low frequency waves have been recorded on seismometers from "slow earthquakes" or slow-slip events. "Tremor" is a seismic phenomenon, observed as emergent wavetrains lacking distinct phase arrivals and having amplitudes that are limited regardless of their durations, which may be from minutes to hours. Tremor is depleted in high frequencies relative to earthquakes of comparable moment or magnitude. In this context, the term tremor is often preceded by "nonvolcanic" to distinguish it from similar signals long observed

on and near volcanoes. We do not make this distinction herein because, while the source of the loading deformations may differ near and away from volcanoes, we cannot rule out the possibility that analogous mechanisms underlie the tremor-source processes in all environments. Whether 
tremor is radiated by rapid shear slip, as in earthquakes, or by some other process remains a matter of debate.

\section{Slow Slip, Tremor, and Earthquakes: The "When and Where"}

Slow-slip may have tremor coincident with it, both spatially and temporally, clearly suggesting a causal relationship. In some places these apparently coupled phenomena recur, sometimes at regular intervals (for example, in Cascadia), and thus have been termed 'episodic tremor and slip' (ETS). Tremor has been observed without detectable slow-slip, but because it grows more vigorous when slow-slip is observed, it is possible that small magnitude, undetectable slip may accompany all tremor. Tremor can also result from loading by large-amplitude seismic waves, and in some cases, this 'triggered tremor' happens without detectable concurrent slow-slip. Slow-slip is not always accompanied by tremor, but rather in some cases by increased earthquake activity, and in others by no seismic radiation at all. These differing behaviors seem linked to specific geographic or tectonic environments, and thus far have been studied primarily in subduction zones (for example Japan; the Pacific Northwest, Alaska, and Hawaii in the United States; New Zealand; Mexico; Costa Rica; and Taiwan). Slow-slip and tremor have also been observed along the transform-plate boundary in California; tremor alone has been observed in the New Madrid region of the central United States; and one or the other, or both, have been observed in other types of natural systems (for example, glaciers and landslides).

\section{Slow Slip, Tremor, and Earthquakes: The "Why"}

Quantitative, predictive physical models of tremor have yet to be developed. The prevailing models explaining slow-slip and earthquakes appeal to frictional sliding mechanisms constrained primarily from laboratory experiments. In these frictional models, earthquakes occur where strain energy accumulates on a nearly motionless or "locked" fault until some critical state is reached, after which the energy is released as the fault surfaces slide so rapidly that seismic waves radiate. This "stick-slip" behavior is predicted for frictional properties roughly consistent with those expected to depths reaching the base of the seismogenic zone. Well below this depth, fault zones slip continuously or "stably", without accumulating moment deficits. This stable-sliding regime 
also may occur at shallow or near-surface depths, consistent with the frictional properties of some loosely consolidated shallow materials. The transitional region between the stably sliding and stickslip regimes is where slow-slip is thought to occur. This conceptual model was developed initially for subduction zones, but could plausibly apply to other environments as well.

\section{Hazard-Estimation Ingredients}

Earthquake hazard herein refers to the potential ground motions caused by earthquakegenerated seismic waves. Assessments of this hazard may be for single 'scenario' earthquakes or for some ensemble of earthquakes weighted by their likelihoods. The latter probabilistic assessments, as well as time-dependent forecasts, require knowledge of the recurrence of earthquakes on the posited seismogenic faults, and thus, the temporal behavior of stress accumulation and release. Indeed, slow-slip on parts of major faults (for example, the subduction interface) may affect the rate of stress accumulation and release elsewhere on the same fault, or on other faults, but as currently understood the impact appears small.

Current calculated changes in earthquake probabilities are based on simple stress transfer ideas: specifically, that slow-slip on all or part of a fault brings neighboring locked sections of fault(s) closer to failure by incrementing the stresses acting on them. Calculations for the recurring slowslip events in northern Cascadia, inferred to occur on the subduction interface beneath the locked section, show the stress changes to be $<\sim 0.01 \mathrm{MPa}$ per slow-slip event, or fractions of a percent of most earthquake stress drops (Dragert and others). Studies elsewhere indicate that such small stress changes can stimulate increased seismicity, but to date there is no evidence that thrust earthquakes on the Cascadia subduction interface have occurred in response to the slow-slip events. However, as stresses on the locked sections of the subduction interface approach near-failure levels due to tectonic loading, it is conceivable that these slow-slip generated stress changes may trigger failure.

The slow-slip can be translated into enhanced cumulative weekly probabilities of a major earthquake. For example, the increased loading rates during the northern Cascadia slow-slip events amount to a change from $1 / 200,000$ to $1 / 4,000$ at this point of time in the interseismic period, that is, 300 years into a 550-year cycle (Dragert and others) [Mazzotti and Adams, 2004]. While this is a 50-fold increase, this latter probability was viewed by the workshop participants from the emergency management community as too low to precipitate public action. Moreover, the 
predictive value of the slow-slip events appears further limited by their frequent occurrence; slow slip events occur somewhere along the Cascadia forearc about every 3 months. Opinions expressed at the workshop indicated that only significant departure from established patterns of slow-slip events in Cascadia would provide cause to revisit these calculations.

Detailed understanding of slow-slip and tremor may prove significant for constraining other characteristics of rupture scenarios needed for hazard assessments. These include the dimensions and distribution of the seismogenic (locked) portions of faults, estimates of their failure strength, and conditions on and around faults such as the presence of fluids and the magnitudes of confining stresses. All these characteristics control the size of earthquakes and the amplitudes and frequency content of radiated seismic waves. Many of these parameters have been proven difficult to constrain by other means.

\section{Direct links between Tremor, Slow-Slip, and Earthquakes.}

Temporal and spatial relationships between tremor, slow-slip, and earthquakes have begun to emerge from the growing number of studies around the globe. Slow-slip and tremor now appear to delineate the down-dip limit of the locked zone. This limit is evident in independently determined rupture zones of megathrust earthquakes, including the 1944 and 1946 Nankai earthquakes and anticipated Tonankai and Tokai rupture zones in Japan (Miyazki and others), and the great 1964 Alaska earthquake (Christensen and others). An example from New Zealand illustrates that it already appears possible to map the locked portions of the subduction interface with unprecedented resolution by accounting for both steady-plate motion and slow-slip events, with the latter relaxing accumulated plate-motion stresses at the down-dip edge of the locked zone (McCaffrey and others).

An apparent anticorrelation between slow-slip, tremor, and small-magnitude earthquakes also suggests that each reflects differing frictional regimes and/or modes of stress relaxation and failure. In Cascadia, small-magnitude ambient seismicity appears spatially anticorrelated with the distribution of tremor sources (Kao and others), and the largest historical crustal earthquakes on Vancouver Island locate within a persistent gap of tremor-source locations (Dragert and others). While examined in only a few cases, this anticorrelation also is evident in the spatial distribution of 
triggered tremor and earthquakes (Peng and others, Gomberg and others). Moreover, observations of small- and moderate-magnitude earthquake rates and slow-slip and tremor also are beginning to reveal interactions that manifest over extended times, as well as distances. For example, in Mexico, Liu and others suggest the rate of moderate-magnitude earthquakes increases around the time of slow-slip events, although not in the same places. Similarly, modulation of crustal seismicity rates by interplate slow-slip events has been noted in the Tokai region of Japan [Yoshida and others, 2006] and in Cascadia [T. Pratt, unpub. data, 2006].

In some environments, increased earthquake rates, rather than tremor, appear to be the dominant or only response to slow-slip. For example, in Hawaii (Segall and others, Brooks and others) and New Zealand (Delahaye and others) slow-slip is not accompanied by tremor, but by increased rates of small to moderate earthquakes. While the Mw7.8 Denali, Alaska earthquake waves triggered tremor at numerous places in California, in geothermal areas they only triggered earthquakes. Similarly, increased earthquake rates have been observed concurrent with shallow slow-slip events along the San Juan Bautista section of the San Andreas fault [Pollitz and Johnston, 2006] and preliminary examination shows no evidence of tremor. These regional variations undoubtedly provide clues about the properties of faults in different environments, including those faults capable of producing damaging earthquakes. Once better understood, these fault properties will be key ingredients for models of forecasted earthquake shaking and hazard (Wong).

\section{Indirect Clues}

The results of more model-dependent studies are beginning to lead to more focused questions and answers. One example considers the scaling of moment release with duration of slow-slip and tremor events. Preliminary analyses of tremor in Cascadia indicate that the slow-slip is not simply a sum of tremor events because the moment released in tremor is much less than that released in slow-slip, and that scaling differs for earthquakes and tremor, with earthquakes durations growing approximately as $\mathrm{M}_{0}^{1 / 3}$ and tremor as $\mathrm{M}_{0}^{0.85}$ (Houston). Ide and others [2008] study data mostly from Japan and find a similar moment exponent close to unity, but in contrast to Cascadia, for Japan they find that slow-slip may be a sum of tremor events. This is corroborated by more recently observed seismic radiation with $20-100$ sec periods in Japan that appears to partially fill a 
gap between geodetic and seismic observations (Shelly and others).

A single moment-duration scaling for both tremor and slow-slip events appears consistent with theoretical frictional modeling (Liu), although the full range of model predictions has not yet been explored. In addition to the above mentioned apparent regional differences, it is surprising that we do not observe events that have moment-duration scaling exponents between those inferred for earthquakes and for tremor events, given the complexity of the Earth; fortunately with the growth of new data acquisition and analysis results it should soon be possible to confirm or dispel this apparent distinction.

Perhaps the most definitive conclusion to emerge, from a variety of independent lines of evidence, is that the effective stress (the difference between the normal stress and pore pressure) must be very low in the source regions of slow-slip and tremor. Theoretical models for friction on the plate interface indicate that low effective stress favors the generation of slow-slip (Liu, Rice). Similar inferences are made from observations of tremor modulated by small stress changes from passing surface waves and tidal forces (Vidale and others). High pore pressure appears to be the simplest, most plausible way to achieve low effective stresses. Petrologic and thermal models of subduction zones predict high pore pressures due to dehydration of the subducting plate (Peacock). Seismic-velocity analysis in southwestern Japan reveals an increase in the P-to-S wave-speed ratio consistent with higher fluid pressures in the crust underlying locations of slow-slip and tremor, and new results reveal a similar feature in Cascadia (Bostock). Frictional models taking into account the high fluid pressures and a dilatancy stabilization effect, whereby viscous resistance increases with the rate of shear, can explain how frictional-slip instabilities may nucleate at slow speeds but become quenched before reaching the fast slip speeds of earthquakes (Segall, and others).

\section{Some Outstanding Key Questions, Action Items}

While quantitative models that predict and explain slow-slip exist, the mechanisms underlying the generation of tremor are speculative and qualitative. The same can be said about the causal connections between tremor and slow-slip. The location of tremor sources is a key discriminant among even the speculative models, particularly whether they coincide with the faults that slip slowly, or instead are distributed in the volume adjacent to or including these faults. While a 
significant fraction of tremor appears to occur on or close to slowly slipping faults, another significant fraction may have an extensive depth distribution. Vigorous debate exists on whether the derived source locations for tremor depend on the particular location method employed. Carefully designed comparisons that test the nonuniquenesses and biases of various location methods need to be developed and implemented. These should be conducted for data sets and algorithms from Japan and Cascadia, where differences in both tremor distributions and algorithms are most striking.

One view of the relationship between tremor and slow-slip is that the slow-slip is comprised of sums of tiny tremor events that are themselves distributed shear-slip failures on the slipping faults. A different hypothesis attributes tremor to unspecified failures related to the presence of fluids through large volumes of crust and upper mantle. In addition to more accurate locations of tremor and slow-slip, measurements of the scaling of both slow-slip and tremor events may elucidate the causal connection between these phenomena and earthquakes. Objective measures of tremor-event sizes and durations need to be developed and applied identically in a variety of regions, and observational limitations and biases must be carefully assessed. Although frictional models are now providing testable predictions about how various earth materials should behave, little laboratory work has been conducted on frictional behavior of materials at conditions representative of the slow-slip and tremor-source regions. In addition to laboratory experiments, new approaches to measuring frictional properties in place are much needed.

As the number of slow-slip and tremor observations increases, and as understanding of the causative mechanisms grows, better defining the relationship to regional seismicity should be a scientific priority. We need more crustal-deformation instrumentation and continuous seismic data in areas where destructive earthquakes might happen so that we are prepared to establish whether a temporal relationship exists. We might examine the along-strike segmentation of slow-slip and tremor events and corresponding features of the seismogenic zone (Brudzinski and others) to establish whether these can be used to better define where great earthquakes are likely to start and stop. These initiatives will entail a concerted effort to better monitor major fault zones globally with continuous recording of seismic and geodetic information, particularly in subduction zones where great events are most frequent. Additionally, observations from natural processes other than crustal or subduction-zone fault systems, such as glaciers or landslides, and from theoretical modeling may provide important constraints otherwise not attainable. 
Despite all the aforementioned uncertainties, the possible causal connections between slow-slip, tectonic tremor, and earthquakes provide a motivation for planning across agencies and state and national boundaries and should be a focus of ongoing discussions between the research community and emergency managers. The frequency and regular recurrence of episodic tremor and slow-slip also present an excellent opportunity for education and outreach (Lillie). Episodic tremor and slowslip is occurring approximately every 3 months somewhere in Cascadia. This provides educators with regular and somewhat predictable "teachable moments" and reminders that, even in the absence of damaging earthquakes, the Earth is a dynamic place.

\section{Working Group Summaries}

\section{Opportunities for Education and Outreach ${ }^{1}$}

Episodes of tectonic tremor and slow-slip provide tremendous opportunities for the public promotion of the novelty and excitement of scientific discovery, and they have the added benefit of being predictable in some places. The occurrence of tremor and slow-slip events present an opportunity to motivate preparations for crustal and mega-thrust earthquakes.

Capitalizing on the aforementioned opportunities requires that information about the phenomena and the hazard implications of these phenomena be clearly presented. In addition, in order to avoid panic, public presentation should have a positive message. Such messages might emphasize that study of tremor and slow-slip is about current scientific exploration with results that relate to important societal issues. Studies of slow-slip and tremor may be used to demonstrate how science works and how it depends on the collaboration of many people with varying interests and talents.

Effective communications may be best accomplished by cultivating relationships between scientists and the news media. To resonate with many people, the episodic tremor and slow-slip story needs to be placed "in context" to be useful and interesting. Consumers of information need tools to help them visualize what is being learned, such as analogies of processes in everyday experiences. The media and public need an easily accessed, single repository of links to

\footnotetext{
${ }^{1}$ This section is based on the discussion led by, and notes of, R. Lillie.
} 
authoritative and accurate information about tremor and slow-slip so that they may verify disseminated information and its accuracy.

The discovery and study of tremor and slow-slip also represent opportunities for engagement in the classroom and on the internet; we can capitalize on the real-time science offered by geodetic and seismic instrumentation that show these phenomena. Learning about these phenomena, as an example of the Earth's dynamism and of the scientific method and its applications, could be tied to state and provincial standards in K-12 school systems. Scientists engaged in tremor and slow-slip research should find opportunities to hold workshops for educators and the interpretive staff of museums and parks.

\section{Data and Instrumentation ${ }^{2}$}

The workshop discussion of data and instrumentation needs focused almost exclusively on Cascadia and on GPS, seismic, borehole-strainmeter, tiltmeter, offshore, and potential field measurements. While there is no doubt that the new instrumentation of the Plate Boundary Observatory (PBO) is providing useful data, the benefits and adequacy have yet to be quantified.

Differing viewpoints on the best strategy for deployment of additional GPS instrumentation ranged from characterizing the entire Cascadia zone to focusing on obtaining more detailed pictures of large recurring events in northern Cascadia. However, the consensus was that a high density of continuous GPS stations is needed to better constrain the location of slip and to determine if slowslip and tremor can occur separately, and that new installations should be targeted at specific sites where additional data are needed. Evidence to date suggests that additional permanent GPS instrumentation and sensitive strainmeters may be required to capture the smaller slow-slip events and to delineate more accurately the up-dip and down-dip limits of slip.

Concern was expressed about the departure of USArray from Cascadia, particularly in Oregon and northern California, where the remaining seismic stations will be too few for adequate monitoring of tremor. Additional gaps in seismic monitoring include the Puget Sound and the Olympic Mountains, which present logistical challenges. Some enthusiasm for the deployment of seismic arrays was expressed, with possible configurations including 20 broadband instruments in a

\footnotetext{
${ }^{2}$ E. Roeloffs led this discussion and provided notes for this summary.
} 
500-m square, sub-arrays of 3-4 instruments in a 100-m square, spaced on a grid, and a big array of about 1,000 instruments spaced 20-m apart over the strongest, most recurrent ETS source. A general consensus emerged that a spacing of $\sim 200 \mathrm{~m}$ is optimal for ensuring correlation of tremor between stations. The deployment of borehole seismometers offers lower noise, particularly at higher frequencies. The optimal depth of such installations remains unknown, but is being investigated in several places outside Cascadia (e.g., Costa Rica).

It was noted that another benefit of recording tremor with high fidelity was that it could be a valuable vertical source for imaging studies. The importance of looking for tremor outside Cascadia also was noted; for example, if tremor was discovered conclusively in a place like New Madrid, thinking about causative mechanisms would change. As demonstrated within Cascadia, the benefits of recording continuously in as many regions as possible was emphasized, but it was also noted that even paper records may be useful. In places where continuous high-rate data acquisition isn't feasible, preprocessing and down-sampling should be considered.

Borehole strainmeter discussion focused on the PBO network, largely in Cascadia. The 2005 and 2007 Cascadia ETS events were recorded on at least 2 borehole-strainmeters each, and the network has grown significantly since then. Thus, the potential of PBO borehole strainmeter data is still in the exploration phase. For example, it is still unclear if they will be useful for recording tremor; comparison of Japanese HiNet borehole, tiltmeter and dilatometer data seems an appropriate approach to assessing this. The utility of data from the pore pressure sensors that accompany the PBO strainmeters at each site needs to be explored. Some instrumental problems need to be addressed before considering expanding the network.

Three long-base tiltmeters now function stably in Cascadia. One tiltmeter recorded the 2007 ETS event, and more data are needed before making any decisions about the need for additional tiltmeters.

Offshore instrumentation would be valuable, but it presents significant challenges. To date, most deployments have been temporary, but lower-noise, cabled OBS deployments are being considered despite the tremendous cost, particularly in Japan. Current temporary deployments in Cascadia may be quieter than previous ones and should reveal whether tremor can be detected with temporary instrumentation (that is, as long as their durations are multiple years, spanning several ETS cycles). 
Other types of needed measurements mentioned include laboratory measurements of frictional properties of rocks under high temperature, pressure, and pore pressure conditions similar to those thought to prevail where slow-slip and tremor originate. Magnetic monitoring and resistivity monitoring have not been attempted, but might prove useful, and the Geological Survey of Canada is evaluating the potential of absolute-gravity measurements to detect fluid or fault movements. The utility of new rotational seismic sensors also may be worth investigating.

\section{User and Public Needs ${ }^{3}$}

The consensus in this session was clear that, in northern Cascadia, the formal earthquakeoccurrence probability gains during slow-slip events are too small to implement public advisories analogous to tsunami warnings. Nevertheless, ETS events may be useful to trigger reviews of emergency-response readiness and to initiate emergency-response exercises. These activities will improve preparedness for $\mathrm{a} \geq \mathrm{M} 6$ subduction-interface earthquake.

Processes for coordination among scientists and United States and Canadian emergency management agency personnel in regions likely to be affected need to be developed. Groups that might facilitate this coordination include the National Earthquake Prediction Evaluation Council, the Geological Survey of Canada, the Cascadia Regional Earthquake Working Group, and the Seismological Society of America.

Other activities that would benefit society might focus on updating scenarios and other information provided for emergency-response planning and exercises, and on providing electronic information-exchange forums (blogs). Some participants suggested that we need a set of protocols with alert/action levels pertaining to slow-slip, tremor and earthquake activity, although others felt that we did not yet know enough to know how to set them and what to do in response. In all instances, the need for common message, and possibly even a common distribution point was emphasized.

\footnotetext{
${ }^{3}$ The discussion of the topics summarized herein was led by a panel composed of M. Reichle, V. McConnell, and M. Bolton.
} 


\section{Research Coordination}

The consensus opinion in this session was that researchers would benefit from improved exchange of information across a wider range of disciplines, such as geodesy, seismology, geodynamic studies, petrology, geochemistry, lab studies on frictional properties, and theoretical and numerical modeling. In addition, this exchange of information should extend geographically across international borders.

One approach to improving information exchange would be to establish a single web portal for all things related to slow-slip and tremor. Earthscope has agreed to host such a Web site (http://www.earthscope.org/science/cascadia). Such a portal could link to both static and interactive informational sites, data repositories, and analysis tools. Informational Web sites for public information might include FaceBook and/or MySpace pages, which are widely used by graduate and younger students. Information exchange among researchers might be effectively accomplished using Wikis and blogs. University- or consortia-based Web sites might provide access to tremor and slow-slip event catalogs, processed GPS time series, near-realtime seismic and geodetic data, benchmarking examples for tremor detection and location methods, and analysis tools and software. The need for thorough documentation of all these data and software was emphasized. Announcements of workshops, new discoveries and publications could be posted to Web sites regularly, and links to publication downloads could be provided.

Continuous monitoring of various data-streams for episodes of slow-slip and tremor is now feasible on large scales and is important for documenting the range of conditions in which tremor, slow-slip and earthquakes do and do not occur. Global tremor monitoring by using the IRIS Quack tools is being implemented by Mike Brudinski, and regional monitoring for slow-slip events by using PBO GPS data is being implemented by John Langbein. More effort should be focused on making a wider range of processed data types publicly available (e.g., strainmeter data), noting that the processing steps applied should be well documented and easy to obtain.

Workshops are another effective means of information exchange, both for sharing results and for teaching. Participants noted a need for a workshop where researchers could learn how to process strain data. 


\section{Presentation Summaries}

\section{The Phenomenology: Observations of Aseismic Slip, Tremor, and Related (Temporally and Spatially) Earthquakes}

Long-Term and Short-Term Slow-Slip Events Inferred from GEONET GPS Data and the NIED Hi-Net Tiltmeter Data, Shinichi Miyazaki (Earthquake Research Institute, Japan), Paul Segall, Jeffery J. McGuire,Hitoshi Hirose, Shutaro Sekine, Kazushige Obara

GPS observations reveal "short-term" and "long-term" slow-slip events with spatial and temporal characteristics. The "long-term" events have durations of 4-5 years in Tokai and 8-12 months in Bungo, with depths of 25-40 km and 30-35 km, respectively. "Short-term" events correlate with tremor activity, have durations of 4-17 days in Tokai and 3-6 days in Bungo, depths are $40-45 \mathrm{~km}$ and $35-45 \mathrm{~km}$ respectively. The Bungo source region migrates in the strike direction with a velocity of about $10 \mathrm{~km} /$ day.

The Mechanics of Subduction-Zone Tremor and Transient Slip in Southwest Japan, David Shelly (University of California, Berkeley), Greg Beroza, Satoshi Ide, Sho Nakamula, Takahiko Uchide

Tremor is composed of a nearly continuous sequence of distinct "low frequency events" (LFEs). Precise locations show LFEs locate along a distinct dipping plane, interpreted as the plate interface. High-resolution tomography shows LFEs occur near a region of high $V p / V s$, suggestive of high fluid pressures. Slow-slip events do not evolve smoothly, but are composed of many subevents of a range of sizes generated directly by shear slip in the plate convergence direction. Precise tremor locations indicate transient-slip events do not evolve smoothly, but rather contain numerous smaller and shorter-duration pulses of slip. Most pulses migrate along dip, rather than along strike, possibly reflecting segmentation of the plate boundary. Slow events of various sizes occur together in the transition zone. 
Spatial-Temporal Patterns of ETS Tremors in Northern Cascadia: 10 Years of Observations from 1997 to 2007, Honn Kao (Geological Survey of Canada), Shao-Ju Shan, Garry Rogers, Herb Dragert, Kelin Wang, and Tony Lambert

A measurement scale for slow-slip events is proposed, classifying them by their spatial extent, duration, and possible migration directions. In Cascadia, tremors tend to occur in places with sparse local seismicity. They are most abundant near the ' $\mathrm{E}$ ' reflector, well above the inferred plate boundary, and thus, most consistent with a mechanism related to fluid migration. Jumping and halting are common, even in the largest episodes, and migrations can be from south to north or north to south, with speed varying from $\sim 5$ to $\sim 10 \mathrm{~km} /$ day, sometimes reaching peak speeds as high as $15 \mathrm{~km} /$ day. For each slow-slip event in SVI (as indicated by GPS data), an A- or B-class tremor episode is observed.

\section{GPS Observations of Cascadia ETS, Tim Melbourne (Central Washington University)}

Slow-slip events occur every few months, such that there have been 36 since 1997. Typically they have equivalent magnitudes of 6.3-6.8, or 2-3 $\mathrm{cm}$ of slip (lower GPS-detection limit). The slip may delineate a locked/transition zone. Inverted slip locations increasingly agree with tremor locations. The 2007 ETS episode was captured on 70+ GPS stations, and many more stations are planned.

Nonvolcanic Tremor on the San Andreas Fault: Why?, Bill Ellsworth (United States Geological Survey)

The tremor in the vicinity of the San Andreas fault occurs below the brittle-ductile transition, and although depth control is poor, it is probably shallower than in Japan and Cascadia (mostly) and distributed within a volume rather than on a plane. Focal depths are in the lower crust and upper mantle. Temperatures at the tremor depths are high $\left(500-600^{\circ} \mathrm{C}\right)$, comparable to those at tremor depths in Japan. Tremor activity occurs frequently. Episodes are typically short, lasting only a few minutes to a few hours, with sources that migrate rapidly $(\sim \mathrm{km} / \mathrm{min})$ during an episode. Preliminary results suggest that activity levels may be tidally correlated. Tremor sources, both ambient and triggered, spatially correlate with magnetic highs, interpreted by Hanna and others (1972) as a partially serpentinized ultramafic body in the mid-crust. 


\title{
The Underlying Physical Processes; Observational Constraints, Theoretical Models.
}

\author{
The Environment of Episodic Tremor and Slip: Temperature, Rock Composition, and \\ Water, Roy Hyndman (Geol. Survey of Canada)
}

Slow-slip events result from fluid pressure build-up and release on the subduction-thrust interface, downdip of seismic zone, perhaps through a fault-valve mechanism. Thermal and metamorphic models predict a peak in dehydration water release beneath the ETS zone, generating near-lithostatic pore pressures. This model predicts no slip events for cold subduction zones, because water dehydration occurs deeper beneath the arc/backarc, where little water is available. Rising fluid may generate tremor in forearc crust, but only in hot subduction zones. Serpentinite formation in forearc mantle absorbs rising water, so little gets to overlying forearc crust, providing a landward limit of ETS. In the lower forearc crust, silica deposition is expected and evident in tomography data, and it might be related to tremor. The latter suggestion is based on extensive field evidence of brittle, earthquake-like hydrofracture behaviour in exhumed deep quartz veins up to $700^{\circ} \mathrm{C}$.

Mechanical Models for Slow-Slip with Focus on Dilatant Strengthening Plus Speculation on Tremor and Triggered Earthquakes, Paul Segall (Stanford University), Allan Rubin, Jim Rice

A critical dimension exists for slip nucleation, defined as $h^{*} \sim G_{d} /[(\sigma-p)(b-a)]$. If slow-slip is due to rate-state friction near neutral stability, then in order to explain the large size of slip zones (of order $10 \mathrm{~km}$ ), either $d_{c}$ is large or the effective stress is small. Dehydration could generate high pore-pressures at $\sim 350^{\circ} \mathrm{C}$ in Cascadia. As the slip accelerates, the material changes from acting as if it is drained and frictional to undrained, which quenches the instability so that the slip velocity is limited. Dilatancy allows slip to nucleate a low speeds but limits fast slip. $\mathrm{E}=1-\mathrm{a} / \mathrm{b}$ divides fastslip and slow-slip domains, with slow-slip favored by low effective stress. Within the slow-slip domain, the dimensions of the transient-slip area are essentially unbounded. Local areas that drain rapidly cause short periods of high moment rate. If dilatancy quenches instability before thermal weakening effects are significant, slow-slip results. If dilatancy does not limit slip speeds 
sufficiently, thermal weakening becomes dominant and fast slip results.

In some cases slow-slip appears to trigger earthquakes, such as in Hawaii and Mexico.

\section{What Can Thermal-Petrologic Models and Field Studies of Subduction Zones Tell Us about Episodic Tremor and Slip? Simon Peacock (University of British Columbia)}

At ETS depths in warm subduction zones, $\mathrm{H}_{2} \mathrm{O}$ is liberated from the slab by metamorphicdehydration reactions and possibly by the collapse of porosity in the upper crust. The amount of $\mathrm{H}_{2} \mathrm{O}$ released is predicted to be small: $10^{-4} \mathrm{~m}^{3} /\left(\mathrm{m}^{2} \mathrm{yr}\right)=100$ milliliters of $\mathrm{H}_{2} \mathrm{O}$ per $\mathrm{m}^{2}$ column per

year. During subduction, the overriding lithosphere undergoes retrograde metamorphism ( $\mathrm{T}$ decreases) and variable amounts of $\mathrm{H}_{2} \mathrm{O}$ may be added due to infiltration of slab fluids. This metamorphism leads to pore pressures that are likely high ( lithostatic), at least where dehydration reactions are taking place. Absent ETS in NE Japan may be due to lack of fluid production (slabdehydration reactions) at shallow depth in the Kii channel (SW Japan) due to lack of hydrous minerals in incoming crust (tonalite), or to slab contortion increasing permeability. In general, prograde metamorphism occurs at convergent plate boundaries where rocks are buried, not at strike-slip boundaries. However, the San Andreas fault cuts through former subduction-zone forearc (chilled, variably hydrated rocks); post subduction heating (thermal relaxation) of previously hydrated forearc materials might generate $\mathrm{H}_{2} \mathrm{O}$ there (e.g., serpentinite dehydration).

Studies on the Physical Origin of Aseismic Deformation Transients in the Framework of Rate and State Friction, Yajing Liu (Princeton University), Jim Rice

Aseismic deformation transients can arise spontaneously when rate and state friction is applied to model subduction sequences with low effective stress near/downdip from stability transition. The recurrence interval of transients depends on the effective normal stress. Short-period ( $\sim 1 \mathrm{yr})$ transients can be produced with lab-like L (of order 10-100 mm) and near-lithostatic fluid pressure ( $\sim 1 \mathrm{MPa}$ ) near the end of the seismogenic zone, and further downdip into the stably slipping zone. The petrologic and thermal structures of subduction slabs, locations of nonvolcanic tremors, and widespread triggering of tremors hint that fluid pressure may be near-lithostatic in that region. Transient sequences can be triggered by stress perturbations from earthquakes in the descending slab, by pore pressure variations, or by along-strike variations in the seismic slip. Current models of 
the physical processes underlying aseismic transients, in the framework of rate and state friction, need to be constrained by lab (friction parameters) and field (geodetic) observations. Preliminary study on the moment-duration relation of transients suggests the width and level and spatial extent of high fluid-pressure zones are key parameters.

\section{Scaling and the Relation between Tremor and Slow-Slip, Heidi Houston (University of Washington)}

A scaling relation is inferred by using an automatic approach to define tremor events and tremor moment-rate (proportional to envelope). Spectra suggest tremor is band limited, so tremor

moment can be sensibly defined. From Cascadia data, duration scales as tremor moment ${ }^{\sim 0.85}$. This generally supports the scaling law under development for slow-slip processes in some aspects, reflecting the amplitude-limited nature of slow-slip. Total tremor moment is much less than the true moment associated with slow-slip in ETS. Most ETS slip is aseismic or outside 1-10 Hz (probably longer period). As tremor amplitude waxes and wanes over time-scales of minutes to hours, longer-period radiation (VLFs) does not always vary in tandem. Slow-slip is not simply the sum of tremor.

\section{Implications for earthquake hazards; what do users need/want to know and what do we need to do to deliver this?}

Seismic Hazard Implications of ETS-No Canary in the Gold Mine Yet. John Vidale (University of Washington)

Not much stress is redistributed in ETS, and the majority is too far from the megathrust to be significant, although it may load the locked zone near nucleation. ETS events last a week or so in duration, generating uneven 1-10 Hz radiation with time, limited spatial extent at any given time, and with likely slip versus tremor differences. Earthquakes are infrequent and ETS events are frequent. At best, an ETS episode in Pacific Northwest has 1/500 chance of causing "the big one." A global correlation between subduction tremor and earthquakes is likely to be most definitive measure of a causal relationship, although it has not yet been observed. Currently, the effect of ETS on earthquake probabilities is not yet sufficiently alarming to take mitigation action, and it is not 
clear it ever will be $\left(10^{-4} /\right.$ day compared to $10^{-5} /$ day, at best). Further study may reveal heretofore unseen patterns that provide clues to the stage in earthquake cycle and to earthquake nucleation. We should proceed full speed ahead.

\section{The California Earthquake Advisory Plan. Jim Goltz (California Office of Emergency Services)}

The State of California Office of Emergency Services (OES) issues Earthquake Advisories because 50 percent of California earthquakes are preceded by foreshocks; 5 percent of M5.0 earthquakes are followed by a larger earthquake within 3 days, and OES does not want to miss a precursory event no matter how ambiguous the evidence. A "prediction" requires a statement of magnitude, location, time frame, and probability, and may last from a few weeks to decades. An "advisory" is usually issued after an earthquake, is based on history and seismic potential, is reviewed before being issued by the California Earthquake Prediction Evaluation Council (CEPEC), and typically lasts 3-5 days. CEPEC consists of nine scientists from government, universities, or the private sector, is appointed by the OES Director, advises OES and the Governor on credibility of predictions and policy options, provides immunities, and convenes as needed. OES provides information to local governments, advising them to disseminate information to key personnel, ensure the readiness of systems essential to emergency operations, implement protective and mitigative actions, and provide guidance to the public on appropriate precautionary actions.

The Challenges of Communicating about Earthquake Hazards and Their Uncertainties, Ivan Wong, (URS Corporation)

To assess the hazard associated with Cascadia earthquakes, we need to know, how big (a full rupture seems likely, i.e. a M 9), how often (best estimates are 500, plus or minus 200 years), location of the eastern extent of the rupture, the mode of rupture and distribution of slip, ground motion attenuation (currently there are no strong-motion data from Cascadia, resulting in huge uncertainties). Based on the Japanese experience, ETS can help define the bottom of the megathrust rupture. We need to characterize the ETS zone along the whole of the Cascadia subduction-zone to define the rupture plane. This is not only important for ground shaking, but also for tsunami evaluation. Short-term forecasts have limited value generally, except for emergency preparedness 
and response. Long-term forecasts can be incorporated in time-dependent hazard estimates.

ETS and Regional Earthquakes: Looking for the Links Herb Dragert (Geological Survey of Canada) Garry Rogers, Kelin Wang, John Cassidy, and Stephan Mazzotti

Given that earthquakes and ETS are well documented for at least the northern Cascadia margin, we ask: "Are there spatial and temporal relationships between earthquakes and ETS?" We find good agreement with the deepest penetration of coseismic slip and the zone of occurrence of deep tremors, suggesting that tremors may demarcate the limit of subduction-thrust rupture. Calculations of the Coulomb stress for shallow-dipping thrust rupture due to a slip event on the deeper subduction interface indicate that the loading on the shallower locked portion of the interface is miniscule $(<0.1$ bars). However, if the stress level is close to critical, a discrete slip event could trigger a megathrust earthquake. No clear relationship between ETS and interplate earthquakes has yet emerged. Statistical "nearness" tests show that tremors locate in regions of minimal crustal seismicity and may correlate with shear-wave reflectors identified by previous structural studies. Additionally, the largest crustal earthquakes locate in a persistent tremor gap, suggestive of some as-yet unknown connection that leads to this anticorrelation.

\section{Program}

\section{Monday Evening, (5:00 - 9:30)}

Poster Setup, Room 260 (5:00-9:30)

Reception hosted by UNAVCO, Peninsula Lounge (6:00-7:00)

Dinner (7:00-8:30 start)

\section{Tuesday Morning Plenary (9:00-12:00)}

"The phenomenology; the observations of aseismic slip, non-volcanic tremor, related (temporally and spatially) earthquakes."

Shinichi Miyazaki, Earthquake Research Institute, Japan (9:00-9:30): Long-term and short-term 
slow-slip events inferred from GEONET GPS data and the NIED Hi-net tiltmeter data

David Shelly, University of California, Berkeley, (9:30-10:00): The mechanics of subduction zone tremor and transient slip in southwest Japan

Honn Kao, Geol. Survey of Canada, (10:00-10:30): Spatial-Temporal Patterns of ETS Tremors in

Northern Cascadia: 10 Years of Observations from 1997 to 2007

Break

Tim Melbourne, Central Washington University, (11:00-11:15): GPS observations of Cascadia ETS

Bill Ellsworth, USGS, (11:15-11:30): Nonvolcanic Tremor on the San Andreas Fault: Why?

Discussion (11:30-12:00)

Tuesday Lunch \& Posters (12:15-2:00)

Tuesday Afternoon Working Group Background Presentations (2:00-3:00)

E\&O Needs \& Opportunities Working Group Convener Presentation - 30 minutes

Convener: Robert Lillie, Oregon State University

Data and Instrumentation Working Group Convener Presentation - 30 minutes

Convener: Evelyn Roeloffs, USGS, Vancouver, WA

Tuesday Afternoon (Concurrent) Working Groups (3:30-5:00)

E\&O Needs \& Opportunities Working Groups

Convener: Robert Lillie, Oregon State University

Data and Instrumentation Working Group

Convener: Evelyn Roeloffs, USGS, Vancouver, WA

Tuesday Dinner (6-7:30)

Tuesday Evening E\&O Needs and Opportunities, Data and Instrumentation Working Group Reports (7:30-8:00)

Tuesday Evening (Concurrent) Working Group \& Posters (8:00 - 9:30)

Chapman Conference Working Group

Convener: Joan Gomberg, USGS, Seattle, WA

Posters

Wednesday Morning Plenary (9:00-12:00)

"The underlying physical processes; observational constraints, theoretical models."

Roy Hyndman, Geol. Survey of Canada, (9:00-9:30): The environment of Episodic Tremor and

Slip: Temperature, rock composition, and water

Paul Segall (presented by Jim Rice), Stanford University, (9:30-10:00): Mechanical models for slow-slip with focus on dilatant strengthening plus speculation on tremor and triggered earthquakes

Simon Peacock, University of British Columbia, (10:00-10:30): What can thermal-petrologic

models and field studies of subduction zones tell us about episodic tremor and slip?

Break 
Yajing Liu, Jim Rice, Princeton, Harvard Universities, (11:00-11:15): Studies on the physical origin of aseismic deformation transients in the framework of rate and state friction.

Heidi Houston, University of Washington, (11:15-11:30): The Scaling of the Tremor Source Discussion (11:30-12:00)

\section{Wednesday Lunch (12:15-1:30)}

\section{Wednesday Afternoon Plenary (1:30-3:00)}

"Implications for earthquake hazards; what do users need/want to know and what do we need to do to deliver this?"

John Vidale, University of Washington, (1:30-2:00): Seismic hazard implications of ETS - no canary in the gold mine yet

Jim Goltz (presented by Michael Reichle), Cal Tech, (2:00-2:30)

Ivan Wong, URS Corp, (2:30-2:45): The Challenges of Communicating About Earthquake Hazards and Their Uncertainties

Herb Dragert, Garry Rogers, Geol. Survey of Canada, (2:45-3:00): ETS and Regional

Earthquakes: Looking for the Links

\section{Wednesday Afternoon Working Group Panel (3:30-4:15)}

Panel on the User/Public Needs, particularly those concerned with earthquake hazards.

Panelists:

Michael Reichle, California Geological Survey

Vickie McConnell, Oregon Dept. of Geology and Mineral Industries

Maclaire Bolton, British Columbia Provincial Emergency Program

Wednesday PGC Field Trip 4:15-5:45 pm

Wednesday banquet 6:30-7:30 pm

Poster Summaries (7:30-8:15)

Posters (8:15-9:30)

Thursday Morning (Concurrent) Working Groups (8:00-9:30)

User/Public Needs Working Group

Convener: Selected Panel member

Research Coordination Working Group

Convener: Ken Creager, University of Washington, WA

Thursday Morning Chapman conference, User/Public Needs, Research Coordination Working Group Reports (9:30-10:00)

Thursday Morning Panel on Future Directions (10:30-12:00)

Regions outside Cascadia, Workshop summary and 'what next' presented by organizers 
Thursday Lunch (12:00-1:00)

Thursday afternoon (1:30-3:30)

Working group to prepare outline of Workshop Summary and EOS article.

\section{Participants}

$\begin{array}{lll}\text { Last } & \text { First } & \\ \text { Name } & \text { Name } & \text { Institution } \\ \text { Aguiar } & \text { Ana } & \text { Central Washington University } \\ \text { Beroza } & \text { Gregory } & \text { Stanford University } \\ \text { Bolton } & \text { Maiclaire } & \text { BC Provincial Emergency Program } \\ \text { Borsa } & \text { Adrian } & \text { UNAVCO } \\ \text { Bostock } & \text { Michael } & \text { University of British Columbia } \\ \text { Brodsky } & \text { Emily } & \text { University of California Santa Cruz } \\ \text { Brooks } & \text { Ben } & \text { University of Hawaii } \\ \text { Brudzinski } & \text { Michael } & \text { Miami University } \\ \text { Christensen } & \text { Douglas } & \text { University of Alaska Fairbanks } \\ \text { Creager } & \text { Kenneth } & \text { University of Washington } \\ \text { Davis } & \text { Earl } & \text { Geological Survey of Canada } \\ \text { Delahaye } & \text { Emily } & \text { Geological Survey of Canada } \\ \text { Dieterich } & \text { James } & \text { University of California Riverside } \\ \text { Dragert } & \text { Herb } & \text { Geological Survey of Canada } \\ \text { Ellsworth } & \text { William } & \text { U.S.Geological Survey } \\ \text { Goltz } & \text { Jim } & \text { California Office of Emergency Services } \\ \text { Gomberg } & \text { Joan } & \text { U.S.Geological Survey } \\ \text { Holtkamp } & \text { Stephen } & \text { Cornell University } \\ \text { Houston } & \text { Heidi } & \text { University of Washington } \\ \text { Hyndman } & \text { Roy } & \text { Geological Survey of Canada } \\ \text { Kao } & \text { Honn } & \text { Geological Survey of Canada } \\ \text { Langbein } & \text { John } & \text { U.S.Geological Survey } \\ \text { Langston } & \text { Charles } & \text { University of Memphis } \\ \text { Lienau } & \text { Michael } & \text { Global Net Productions } \\ \text { Lillie } & \text { Robert } & \text { Oregon State University } \\ \text { Liu } & \text { Yajing } & \text { Princeton University } \\ \text { Magliocca } & \text { Jaime } & \text { UNAVCO } \\ \text { McCaffrey } & \text { Robert } & \text { Inst. of Geological and Nuclear Sciences, New Zealand } \\ \text { McCausland } & \text { Wendy } & \text { U.S.Geological Survey } \\ \text { McConnell } & \text { Vicki } & \text { Oregon Dept. of Geology and Mineral Industries } \\ \text { Meertens } & \text { Chuck } & \text { UNAVCO } \\ \text { Melbourne } & \text { Timothy } & \text { Central Washington University } \\ \text { Miller } & \text { Megan } & \text { UNAVCO } \\ \text { Miyazaki } & \text { Shinichi } & \text { Earthquake Research Institute, Japan } \\ \text { Montgomery-Brown } & \text { Emily } & \text { Stanford University } \\ \text { Nadeau } & \text { Robert } & \text { University of California Berkeley } \\ & & \\ & & \end{array}$




$\begin{array}{lll}\text { Ohta } & \text { Kazuaki } & \text { University of Tokyo, Japan } \\ \text { Peacock } & \text { Simon } & \text { University of British Columbia } \\ \text { Peng } & \text { Zhigang } & \text { Georgia Institute of Technology } \\ \text { Psencik } & \text { Kimberly University of Miami } \\ \text { Reichle } & \text { Michael } & \text { California Geological Survey } \\ \text { Rice } & \text { Jim } & \text { Harvard University } \\ \text { Roeloffs } & \text { Evelyn } & \text { U.S.Geological Survey } \\ \text { Rogers } & \text { Garry } & \text { Geological Survey of Canada } \\ \text { Schwartz } & \text { Susan } & \text { University of California Santa Cruz } \\ \text { Segall } & \text { Paul } & \text { Stanford University } \\ \text { Shelly } & \text { David } & \text { University of California Berkeley } \\ \text { Trehu } & \text { Anne } & \text { Oregon State University } \\ \text { Vidale } & \text { John } & \text { University of Washington } \\ \text { Wang } & \text { Kelin } & \text { Geological Survey of Canada } \\ \text { Wech } & \text { Aaron } & \text { University of Washington } \\ \text { Wong } & \text { Ivan } & \text { URS Corporation }\end{array}$

\section{References}

Ide, S., Imanishi, K., Yoshida, Y., Beroza, G. C. and Shelly, D. R., 2008, Bridging the gap between seismically and geodetically detected slow earthquakes, Geophys. Res. Lett., 35, L10305, doi:10.1029/2008GL034014.

Mazzotti, S. and J. Adams, 2004, Variability of near-term probability for the next great earthquake on the Cascadia subduction zone, Bulletin of the Seismological Society of America, 94, 19541959.

Pollitz, F. F., and M. J. S. Johnston, 2006, Direct test of static stress versus dynamic stress triggering of aftershocks, Geophys. Res. Lett., 33, L15318, doi:10.1029/2006GL026764.

Yoshida, A., Hososno, K., Tsukakoshi, T., Kobayashi, A., Takayama, H., and Wiemer, S., 2006, Change in seismic activity in the Tokai region related to weakening and strengthening of the interplate coupling, Tectonophysics, 417, 17-31. 


\section{Appendix A: Abstracts from the Workshop on Aseismic Slip, Tremor, and Earthquakes}

Tremor Constraints on Moment Release During the 2007 ETS From Surface and Borehole Seismometers

Ana Cristina Aguiar, Timothy I. Melbourne, and Craig Scrivner pg. 1

The Plate Boundary Observatory: the Pacific Northwest Network

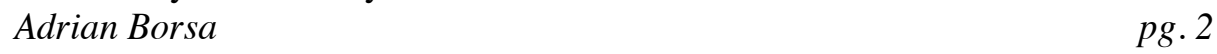

ETS in Cascadia - Structural Considerations

Pascal Audet and Michael Bostock pg.3

A Geological Fingerprint of Extremely Low Viscosity Fault Fluids During an Earthquake E.E. Brodsky, F. Meneghini, C.D. Rowe and J.C. Moore pg. 4

Field Deployments for Improved Resolution of Episodic Tremor and Slip Michael Brudzinski, Richard Allen, Alejandra Arciniega-Ceballos, Devin Boyarko, Enrique Cabral-Cano, Francisco Correa-Mora, Charles DeMets, Oscar Diaz-Molina, Hector Hinojosa-Prieto, Robert Porritt, and Stefany Sit pg. 6

Non-Volcanic Tremor and Slow-Slip Events in Alaska

Douglas Christensen, Chloe Peterson, and Steve McNutt pg.7

Cascadia Tremor Depths Constrained by S Minus P Times

Ken Creager, Mario LaRocca, Danilo Galluzzo, John Vidale, Steve

Malone, and Justin Sweet pg. 8

A Seismological Investigation of Slow Slip in the Hikurangi Subduction Zone, New Zealand

Emily Delahaye pg.9

Investigating Relationships of Episodic Tremor and Slip and Seismicity Along the Northern Cascadia Margin

H. Dragert, H. Kao, G.C. Rogers, K.Wang, J.F. Cassidy, and S. Mazzotti pg. 10

Origin of Nonvolcanic Tremor beneath the San Andreas Fault in Central California William L. Ellsworth

pg. 11

Emergency Response and Public Information Needs Associated with Possible Earthquake Precursory Information: A State Emergency Management Perspective James D. Goltz

pg. 12

Inferences from Triggered Nonvolcanic Tremor and Earthquakes Joan Gomberg, Paul Bodin, Kenneth C. Creager, Honn Kao, Zhigang Peng, Garry Rogers, Justin L. Rubinstein, John E. Vidale, and Aaron Wech pg. 13

Vertical Deformation Associated with Slow Slip Events in Cascadia: Methods of Detection and Model Inversion Stephen Holtkamp, Michael R. Brudzinski, Rowena Lohman, and Matt Pritchard

pg. 15

The Scaling of the Tremor Source

Heidi Houston

pg. 16 
The Environment of Episodic Tremor and Slip: Temperature, Rock Composition, and Water Roy Hyndman

pg. 17

Spatial-Temporal Patterns of ETS Tremors in Northern Cascadia: 10 Years of Observations From 1997 to 2007

Honn Kao, Shao-Ju Shan, Garry Rogers, Herb Dragert, Kelin Wang, and Tony Lambert

pg. 18

Utility Of Borehole Strainmeter Data To Measure Transient Strain From Cascadia Slow-Slip Event.

John Langbein

pg. 19

Possible Non-volcanic Tremor Discovered in the Reelfoot Fault Zone, Northern Tennessee Charles A. Langston, Robert A. Williams, M.Beatrice Magnani, and Duayne M. Rieger

pg. 20

Education and Outreach Needs and Opportunities

Robert J. Lillie

pg. 21

Modeling Moment-Duration Relation Of Aseismic Slip Events in Subduction Zones Yajing Liu

pg. 22

Inverting 3-Component GPS Time Series For Transient Sources and Inter-Event Site Velocities and Fault Coupling: Applications To Cascadia and Hikurangi (New Zealand) Margins Rob McCaffrey

pg. 23

Detecting Slow Slip Events along the Cascadia Subduction Zone Using Plate Boundary Observatory Borehole Strainmeters Wendy McCausland and Evelyn Roeloffs

pg. 24

Slow Slip and Tremor: Does This Physical Process Matter to DOGAMI? Vicki S. McConnell

pg. 25

36 and Counting Cascadia Episodic Tremor and Slip Events Observed On GPS, Seismic, and Strain/Tiltmeter Arrays

Timothy Melbourne

pg. 26

UNAVCO Support Activities for Episodic Tremor and Slip Investigations

M. Meghan Miller, S. Eriksson, M. E.Jackson, and C. Meertens

pg. 27

Slow Slip Events At Kilauea: Not Solely A Subduction Zone Phenomenon

E. Desmarais Montgomery-Brown, P. Segall, A. Miklius, M. Poland, and P. Cervelli

Evidence For Laterally Disctributed Tremor Activity Across the San Andreas

pg. 29

Fault Zone At Cholame

R. M. Nadeau and A. Guilhem

A New Hypocenter Determination Method Using the Summation Of Waveform

pg. 30 Cross-Correlation

Kazuaki Ohta and Satoshi Ide

pg. 31

What Can Thermal-Petrologic Models and Field Studies Of Subduction Zones Tell Us About Episodic Tremor and Slip?

Simon Peacock

pg. 32

Non-Volcanic Tremors Near Parkfield, CA Triggered By Teleseismic Earthquakes Zhigang Peng, John E. Vidale, Kenneth C. Creager, Justin L. Rubinstein, Joan Gomberg, and Paul Bodin

pg. 33

Slow Slip Event Under the Nicoya Peninsula, Costa Rica as Measured by a Continuous GPS and Seismic Network

Kimberly C. Psencik, Timothy H. Dixon, Susan Schwartz, Marino Protti, and Victor Gonzalez

pg. 34

Public Policy Implications of Episodic Tremor and Slip

Michael Reichle

pg. 35 
Studies on the Physical Origin of Aseismic Deformation Transients

Yajing Liu and James R. Rice

pg. 36

The Tokai Earthquake Warning Plan: An Example of Communicating Hazards Implications of Aseismic Slip Events to the Public

Evelyn Roeloffs

pg. 37

25 Years Of Episodic Tremor and Slip on Southern Vancouver Island - Going Back in Time Garry C. Rogers and Herb Dragert

pg. 38

Dilatancy Stabilization of Frictional Sliding as a Mechanism for Slow Slip Events P. Segall, A. Rubin, and J. R. Rice

pg. 39

A New Look at Episodic Slip Through Precise Tremor Locations in Southwest Japan:

"Fast" Sub-Events and Tidal Triggering

David R. Shelly, Gregory C. Beroza, and Satoshi Ide

pg. 41

Low Angle Thrust Earthquakes in the "Locked Zone" Beneath the Central

Cascadia Continental Margin

Anne M. Tréhu, Jochen Braunmiller, John L. Nabelek, and Mark Williams

pg. 42

Seismic Hazard Implications of ETS - No Canary in the Gold Mine Yet John Vidale

pg. 43

Spatial Characteristics and Thermal-petrological Conditions of Cascadia-type Slow Slip Events

Kelin Wang, Herb Dragert, Ikuko Wada, Honn Kao, and Jiangheng He

Washington Tremor Aaron Wech

pg. 44

pg. 45

How Strong Will the Ground Shaking Be? What we Don't Know About This Earthquake Hazard in the Cascadia Subduction Zone

Ivan G. Wong

pg. 46 
Tremor constraints on moment release during the 2007 ETS from surface and borehole seismometers

Ana Cristina Aguiar, Timothy I. Melbourne, Craig Scrivner

Department of Geological Sciences

Central Washington University

\section{Abstract}

The 2007 ETS event, which began around Jan 15 beneath the southwestern Puget Basin and ended around Feb 5 beneath southern Vancouver Island, was well-recorded on local surface seismic arrays, EarthScope borehole-seismometers, strainmeters and longbaseline tiltmeters, and continuous GPS of the PANGA and PBO networks. Seismic tremor, however, offers the highest resolution for studying moment release through time, since tremor bursts lasting less than 10-seconds are often visible across stations. To test the hypothesis that tremor and transient deformation are two manifestations of the same faulting process, and to quantify the relative contribution of moment release during times of strain-transients versus other times, we systematically analyze the tremor bursts during the time period of 2005-2007.2, which includes the 2007 ETS event.

We first consolidate daily seismic files from the Puget Basin of Washington State and SW British Columbia, where GPS density is highest. Seismic traces are included from the PNSN, the PBO borehole seismic network, and the EarthScope-funded CAFÉ experiment. We remove instrument gain, decimate the data to $10 \mathrm{sps}$, rectify it, compute its envelope using a Hilbert transform, and average the envelopes from regionally adjacent stations to provide a single metric indicative of tremor activity. This process is effective in quantifying small tremor bursts lacking GPS-inferred deformation and accurately identifies timing and duration of known events. We then compare tremor duration to equivalent moment slip inversions of corresponding GPS-derived deformation to obtain a model that relates hours of tremor to moment magnitude. To locate the tremor during the 2007 event, we use both picked waveform peaks and cross-correlated envelopes of band-pass filtered instruments. The location is determined by minimizing the L2-norm of the vector containing the differences between the measured and predicted stations offsets for a 3D grid of possible locations. Although the scatter is high, particularly in the depth, we find tremor during the 2007 event propagates in a northwesterly direction beneath the eastern Olympics Range over a three-week period. We find no instances of transient GPS deformation occurring in the absence of tremor, and a very linear relationship between tremor duration and GPS-estimated equivalent moment. However, the average amplitude of tremor, both during GPS-recognizable ETS and isolated bursts, varies little from the maximum velocity of $\sim 1 \mathrm{micron} / \mathrm{sec}$. 
The Plate Boundary Observatory: The Pacific Northwest Network

\section{Adrian Borsa}

The Plate Boundary Observatory (PBO), part of the NSF-funded EarthScope project, is designed to study the three-dimensional strain field across the active boundary zone between the Pacific and North American plates in the western United States. To meet this goal, UNAVCO is in the final stages of installing 880 continuous GPS stations, 103 borehole strainmeters, 5 laser strainmeters, and 28 tiltmeters from the U.S.-Mexico border to Alaska. Although the PBO network will not be complete until October 2008, it is already the largest integrated geodetic network in the United States and the second largest in the world.

The Pacific Northwest, with its large population living above an active convergent plate boundary, is a region of great interest to UNAVCO community scientists. As of January 2008, there were 97 continuous GPS stations in the region, with three-quarters of the stations west of the Cascades and a local concentration at Mount St. Helens. In addition, the Pacific Northwest hosts the largest number of borehole sites within PBO, with all 31 installed borehole strainmeters collocated with borehole seismometers. Of particular interest to the monitoring of episodic tremor and slip under Vancouver Island are PBO's installations on the Olympic Peninsula and the Puget Sound (with a few on the Island itself). These complement the Geological Survey of Canada's instruments on Vancouver by extending spatial coverage to the south and east.

By combining seismic, strainmeter and GPS data in the Pacific Northwest, the integrated PBO network is ideal for capturing transients that may be associated with episodic tremor and slip events. The presence of strainmeters in the PBO network, with their ability to robustly detect deformation on the order of $1 \mathrm{ppb}$ over a period of hours to days, fills an observational gap between seismic and GPS measurements where noise would otherwise be an issue. The spectral bandwidth of the combined PBO datasets is broad enough to capture high-frequency ETS tremor and any significant temporallycorrelated slip, while placing these events within the context of long-term plate motion and regional deformation.

PBO's data archiving and processing framework is designed to provide rapid access to low-level data and quick turnaround of higher-level products. For GPS, daily RINEX files are typically available within several hours of midnight UTC, and PBO's GPS Analysis Centers at Central Washington University and the New Mexico Institute of Mining and Technology produce daily "rapid" station positions with a nominal latency of 24 hours. Raw strainmeter data flow hourly to the Borehole Strainmeter Analysis Center in Socorro, New Mexico and the Laser Strainmeter Analysis Center at the University of California, San Diego and are made available within 24 hours. These analysis groups transform the raw strainmeter observations into cleaned individual strain gauge components. Seismic data flow via the Antelope software suite to the IRIS Data Management Center for archiving and distribution. Near-real time data are available via the IRIS Buffer of Uniform Data (BUD) webpage prior to archiving. 


\title{
ETS IN CASCADIA - STRUCTURAL CONSIDERATIONS
}

\author{
Pascal Audet \& Michael Bostock \\ Department of Earth \& Ocean Sciences \\ The University of British Columbia
}

Studies of episodic tremor in Cascadia and Japan point to an origin that likely involves, either directly or indirectly, fluid dynamics in the general vicinity of the plate boundary, downdip of the locked zone. In developing an understanding of the ETS phenomenon it is, accordingly, important to relate the spatial occurrence of tremor to principal structural elements within the subduction complex. In northern Cascadia, where ETS has been extensively documented, there exists considerable uncertainty in the actual location of the plate interface. Estimates of plate depth from tomographic studies have been based on the assumption that the oceanic Moho correspond to a somewhat arbitrary iso-velocity contour (usually near $7.8 \mathrm{~km} / \mathrm{s}$ ). In contrast, previous studies of scattered teleseismic body waves at several locations along the margin have revealed that structure at scale lengths of 1 to $10 \mathrm{~km}$ is dominated by an east dipping, $10 \mathrm{~km}$ thick, low-velocity zone (LVZ) that corresponds to the so-called E-layer of high reflectivity first observed on Lithoprobe profiles in the mid 1980's. Interpretation of this structure as the subducting oceanic crust places it as much as $10 \mathrm{~km}$ above estimates derived from tomographic velocity models.

In this work we have assembled a large teleseismic body wave data set comprising stations from northern California to northern Vancouver Island. We demonstrate that the LVZ is well developed along the entire convergent margin from the coast eastward to the forearc basins (Georgia Strait, Puget Sound, Willamette Valley). Its diminishing signature further landward and to greater depths is consistent in a petrologic context with an interpretation as subducting oceanic crust. Reconciliation with tomographic velocity models is achieved through identification of high $\mathrm{Vp} / \mathrm{Vs}$ ratios for the oceanic crustal interval at depths above $40 \mathrm{~km}$ that imply high associated pore fluid pressures and an impermeable plate boundary. Oceanic mantle velocities are also significantly reduced, presumably the result of water liberated through deserpentinization. We will present margin-wide contour maps of slab topology, oceanic crustal $\mathrm{Vp} / \mathrm{Vs}$ ratios and velocity contrasts that should prove useful in constraining the nature of ETS. 


\title{
A Geological Fingerprint of Extremely Low Viscosity Fault Fluids During an Earthquake
}

\author{
E.E. Brodsky, F. Meneghini, C. D. Rowe* and J.C. Moore \\ Dept. of Earth \& Planetary Science, University of California, Santa Cruz \\ *Present address: University of Cape Town, South Africa
}

Physical models of earthquakes, creep and tremor require knowledge of the stress on the fault during slip, but there are few constraints on this quantity on real faults. The problem is particularly acute for subduction zones where the relationship between creep and seismic slip is likely related to the stress state. Here we use the geological record of an exceptional outcrop to calculate the slip rate and stress on an ancient megathrust fault in a new way. We discovered a structure in a fluidized fault rock on a preserved megathrust that is interpretable as a gravitational (Rayleigh-Taylor) instability (Figure 1). The wavelength to thickness ratio of the intrusion is much shorter than can be explained by a low Reynolds number flow. The short wavelengths between buoyant intrusions are best explained by moderately inertial flow with fluid velocities of order of $10 \mathrm{~cm} / \mathrm{s}$. These slip velocities are typical of an earthquake or its immediate afterslip and thus require a coseismic origin. The Reynolds number of the buoyant flow requires a very low viscosity ( $\leq 1 \mathrm{~Pa} \mathrm{~s}$ ) and thus implies local dynamic weakening to extraordinarily low stress $(<10 \mathrm{~Pa})$ during an earthquake on the megathrust.

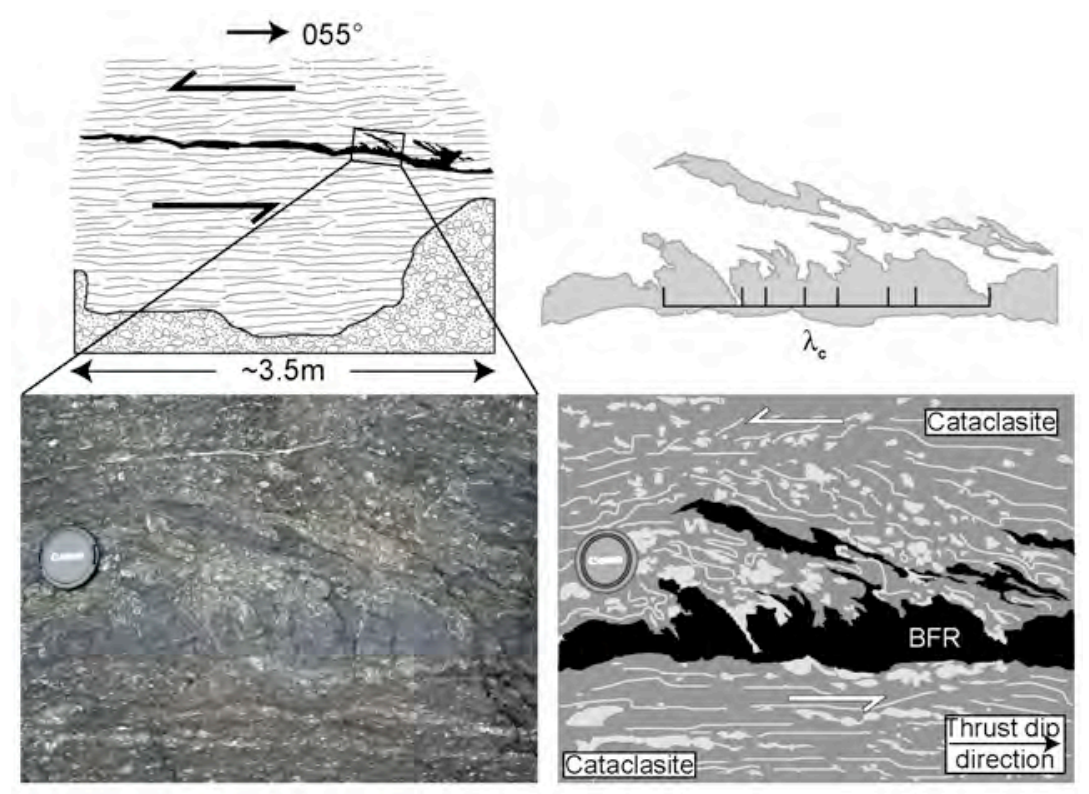

Photograph and explanatory sketch of the outcrop of black, ultr-fine-grained

fault rock in Kodiak Island, AK. Lens cap diameter is $6 \mathrm{~cm}$ for scale. Upper right

inset illustrates the wavelengths between intrusions as measured on the outcrop.

The wavelengths are comparable to the thickness of the layer. 
From 1998-2007 the mobile south flank of Kilauea volcano, Hawaii has been the site of at least 7 slow slip events (SSE) recorded principally with continuous GPS data from the network operated jointly by the USGS-Hawaii Volcano Observatory, Stanford University, and the University of Hawaii. The Kilauea SSEs are an important example of the SSE phenomena, occurring in a very different tectonic setting from SSEs in subduction zones. Although the precise depth and mechanism of the Kilauea SSEs is still debated, they certainly occur more shallowly than $\sim 10 \mathrm{~km}$ in oceanic crust. Additionally it is possible that these aseismic slip transients locate largely offshore, updip of the zone where major south flank earthquakes nucleate, unlike the downdip SSEs at subduction zones.

Here, we demonstrate by using a surface displacement event correlation filter, that the Kilaeua events can be clearly divided into two spatially distinct families. Prior to July, 2007, the "Western" family comprised four events that exhibited a high degree of periodicity (774 +/- 7 days) whereas the "Eastern" family comprised three events with no apparent periodicity. The data are coincident either with SSEs occurring on spatially distinct and neighboring fault planes or occurring on separate slip patches of the same fault plane, such as the regional decollement below Kilauea's south flank. The spatial association of the displacement fields for the two families with shallow slump structures within the south flank interpreted from submarine seismic reflection surveys suggests a common structural control, and raises the possibility of a longer term kinematic segmentation.

Of particular interest, the Western family events appear to trigger microseismicity, which our waveform cross correlation and high precision relocation analysis demonstrates occurred on distinct fault zones that form streaks aligned with the SSE GPS surface displacements (Wolfe et al., 2007). Due to the unknown effects of velocity heterogeneity and nonideal station coverage, our relocation analyses cannot distinguish whether some of these fault zones occur within the volcanic crust at shallow depths or whether all occur on the decollement.

Additionally we show that the June $17^{\text {th }}$ dike intrusion at Kilauea's east rift zone apparently triggered an SSE with characteristics very similar to previous Western family events. Inclusion of this event in the overall time series yields SSE repeat times of 798 +/- 50 days, which still maintains these events as more regularly occurring than other well established slow slip locales such as Cascadia or Guerrero, Mexico. We suggest that constant stressing rate due to relatively constant opening of Kilauea's rift zones since 1998 could explain the regular behavior of the Western family, though this explanation is still not satisfactory for the neighboring Eastern family. Moreover, the correlation of the Western family events with triggered microseismicity allows us to test how long these events have been occurring with their current periodicity by examining the Kilauea earthquake catalog. We conclude that there is no evidence of this periodicity prior to January 1997, suggesting that the periodicity, itself, may be a transient phenomenon. 


\title{
Field Deployments for Improved Resolution of Episodic Tremor and Slip
}

\author{
Michael Brudzinski ${ }^{1}$, Richard Allen ${ }^{2}$, Alejandra Arciniega-Ceballos ${ }^{3}$, Devin Boyarko ${ }^{l}$, Enrique Cabral-Cano ${ }^{3}$, \\ Francisco Correa-Mora ${ }^{4}$, Charles DeMets ${ }^{4}$, Oscar Diaz-Molina ${ }^{3}$, Hector Hinojosa-Prieto ${ }^{l}$, Robert Porritt ${ }^{2}$, Stefany Sit $^{5}$ \\ ${ }^{1}$ Miami University, ${ }^{2}$ U. of California-Berkeley, ${ }^{3} \mathrm{UNAM},{ }^{4} \mathrm{U}$. of Wisconsin-Madison, ${ }^{5}$ Lawrence University
}

The recent discovery of episodic tremor and slip (ETS) has focused our attention on the behavior of the subducting plate interface. Although the link between ETS and megathrust earthquakes is as of yet unclear, the proximity of the source zones for each process suggests that stress transfer and triggering is a possibility. Seeking to better understand the processes that govern ETS and its potential links to earthquakes has led researchers to squeeze a great deal of information out of existing seismic and geodetic recordings. However, our understanding of the large scale processes can be biased by local networks that provide good resolution in some areas and limited coverage in others. Several recent field deployments have been designed to help improve our ability to resolve details of the ETS process over broader regions. Two such experiments are a joint seismic and GPS network along the Oaxaca segment of the Middle American trench (OXNET) and an EarthScope Flexible Array deployment across Oregon and Washington in the Cascadia subduction zone (FACES). We will present up-to-date characterizations of ETS utilizing these experiments and compare them with previous measurements to better characterize long-term patterns over broader regions of the subduction zones. We will also describe variations in magnitude and frequency of ETS events between the two subduction zones to help investigate what controls the physical process.

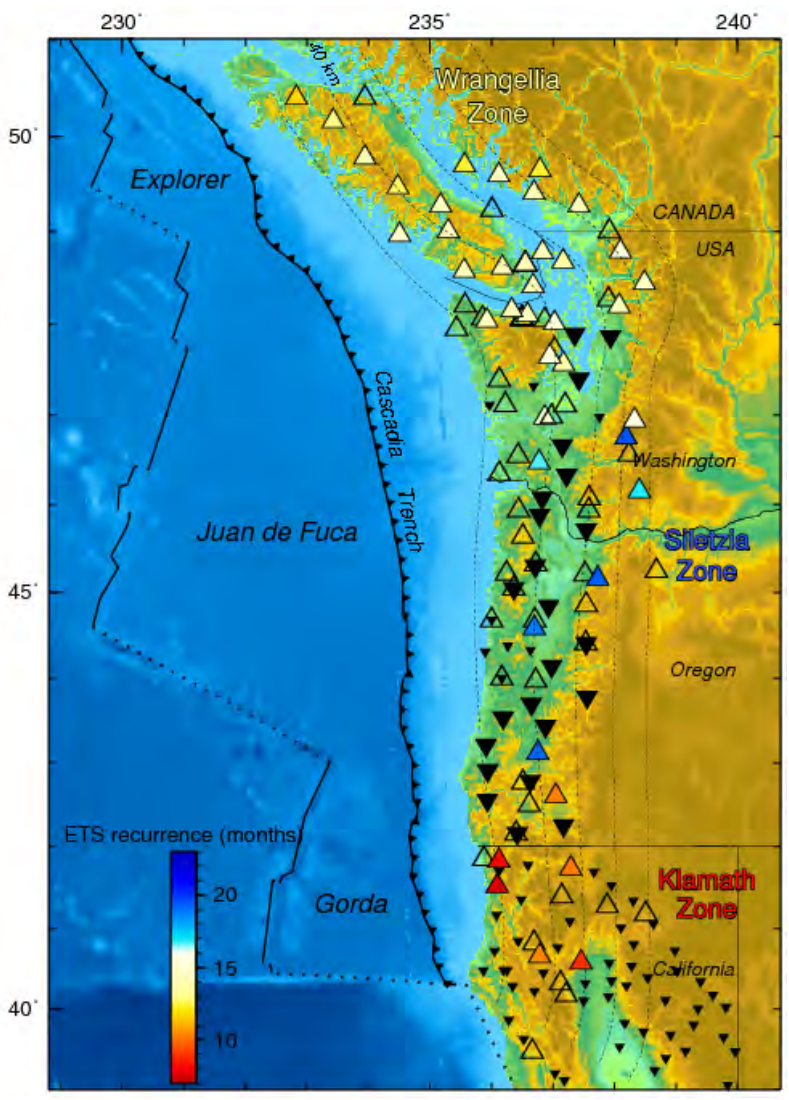

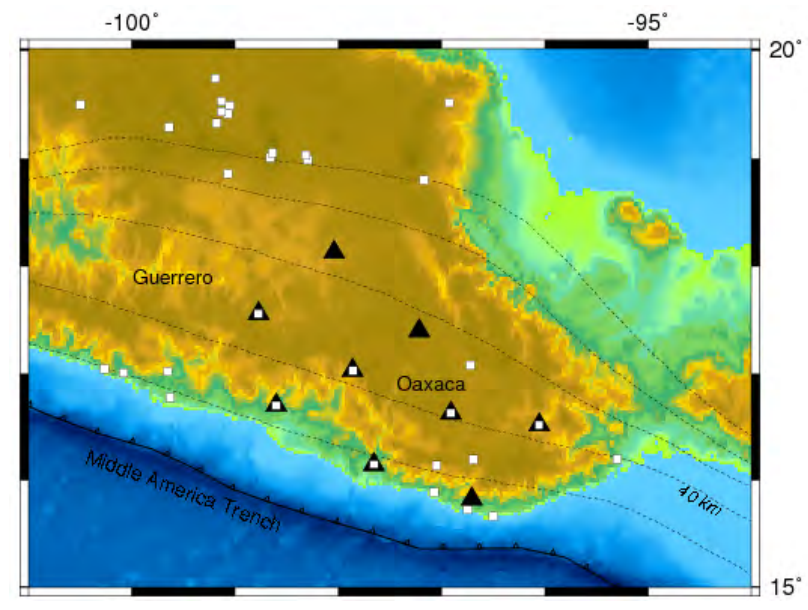

Maps show station configurations in Cascadia (left) and Mexico (right) above the subducting plate (dashed lines show depth contours). Large black triangles are recently deployed seismometers situated to improve resolution of ETS, and smaller triangles are collaborating experiments. Other triangles are permanent stations where non-volcanic tremor has been observed, colored for recurrence interval if at least 3 events have occurred. White squares are permanent GPS monuments in Mexico where slow slip events can be observed. PBO stations in Cascadia are not shown but have significantly improved the coverage of permanent GPS monuments. 
Non-Volcanic Tremor and Slow-Slip Events in Alaska

Douglas Christensen (Geophysical Institute, University of Alaska Fairbanks, AK 997757320, ph. 907-474-7426, fax. 907-474-5618, email doug@giseis.alaska.edu);

Chloe Peterson (Geophysical Institute, University of Alaska Fairbanks, AK 99775-7320, ph. 907-474-7187, fax.907-474-5618, email chloe@giseis.alaska.edu);

Steve McNutt (Geophysical Institute, University of Alaska Fairbanks, AK 99775-7320, ph. 907-474-7131, email steve@giseis.alaska.edu)

Alaska is a non-volcanic tremor and slow-slip event target-rich environment. Alaska and the Aleutian arc are expansive with over $2500 \mathrm{~km}$ of subduction zone. One aspect of its large size is that there are a variety of segments with different seismic histories. For example, the Adak region had $M \sim 8$ earthquakes in both 1986 and 1996; the Shumagin region has been identified as a seismic gap (but may be a creeping section of the subduction zone); the eastern end of the 1957 M-9.1 rupture zone has a slip deficit; and the 1964 M-9.2 region is still undergoing post-seismic deformation. The plate convergence rate is high (about $8 \mathrm{~cm} / \mathrm{yr}$ ) so significant motions may occur on short time scales. With $\mathrm{M} \sim 7$ earthquakes occurring on average about every two years and a $M \sim 8$ earthquake occurring about every 13 years, the opportunity to observe the relationship between non-volcanic tremor, slow-slip events and large damaging earthquakes is quite high.

In south-central Alaska we have documented non-volcanic tremor occurring simultaneously with a large slow-slip event that occurred in the region between 1998-2000. The slow-slip event and non-volcanic tremor occurred in the transition zone directly down-dip of the main asperity of the 1964 earthquake. Because of the shallow dip of the subducting Pacific plate in this region, the transition zone is extremely wide (more than $100 \mathrm{~km}$ ). We have tabulated the observed non-volcanic tremor events in terms of durations, locations (when possible), and maximum amplitudes for three months of each year between 1999 and 2001. The majority of the non-volcanic tremor signals observed after the onset of the slow-slip event in March 1998 are bursts lasting between 10 and 15 minutes with frequencies ranging from 1-10 Hz. Similar signals lasting up to a day are also observed, but less frequently. By the summer of 2001 the quantity of non-volcanic tremor decreases dramatically from the previous summers. Episodes rarely last up to 10 minutes and maximum amplitudes are lower than those for previous years. The decrease in non-volcanic tremor activity in the summer following the slow-slip event is the first evidence that the relationship between slow-slip events and non-volcanic tremor seen in Cascadia and southwest Japan may also exist in Alaska.

Non-volcanic tremor occurs regularly in the Aleutian arc. Over the last three years we have noted more than 32 instances of non-volcanic tremor in the arc from five distinct locations. While we do not have direct evidence (from GPS) of associated slow-slip events, we do have some indirect evidence of associated strain events which could be caused by creep in the subduction zone. As an example, we recorded a strong non-volcanic tremor event in the Rat Islands in August 2006. This event occurred close in time to a sequence of several M-6 earthquakes that also occurred in the Rat Islands region in July -August 2006. The near simultaneous occurrence of the non-volcanic tremor and M-6 earthquakes might suggest that a slow-slip event occurred nearby and triggered the various activity observed. With the expansion of continuous GPS networks into the Aleutians (through PBO and other sources) we will soon be able to substantiate these relationships. 


\title{
Cascadia Tremor Depths Constrained by S Minus P Times
}

\author{
Ken Creager ${ }^{1}$, Mario LaRocca ${ }^{2}$, Danilo Galluzzo ${ }^{2}$, John Vidale ${ }^{1}$, Steve \\ Malone $^{1}$, Justin Sweet ${ }^{1}$ \\ ${ }^{1}$ Department of Earth and Space Sciences, University of Washington, Seattle, \\ WA 98195-1310; kcc@ess.washington.edu \\ ${ }^{2}$ Osservatorio Vesuviano, Instituto Nazionale di Geofisica e Vulcanologia, \\ Naples, Italy
}

A key to understanding Episodic Tremor and Slip (ETS) is obtaining accurate tremor depths. In Shikoku, Japan this has been done using S minus P times observed by stacking many hundreds of low-frequency events (LFEs) that are postulated to compose the tremor. In Japan, the tremor sources occur at (or at least very near) the plate interface. In Cascadia, however, LFEs have not yet been detected, and tremor locations scatter over tens of $\mathrm{km}$. It has not been clear whether this represents uncertainty or true variability. We have developed a method for determining S minus P times that works best using arrays recording tremor that is traveling nearly vertically. For observations across the three arrays deployed to observe the July, 2004 Cascadia ETS, the S minus P times range from about 4 to $7 \mathrm{~s}$. By adding these $\mathrm{S}$ minus $\mathrm{P}$ time constraints to our method of estimating tremor locations using cross correlation of seismogram envelope functions, we greatly reduce both the uncertainty and scatter in source depth. Our preliminary analysis indicates that, similar to Japan, the Cascadia tremor sources are coming from locations at, or at least very near, the plate interface. In addition, polarization analysis of tremor seismograms indicates that the tremor focal mechanism is consistent with slip on the plate boundary in the direction of relative plate motion. Together this suggests that tremor and geodetically observed slip are both manifestations of the same process corresponding to the two plates slipping past each other along the plate boundary. 
A Seismological Investigation of Slow Slip in the Hikurangi Subduction Zone, New Zealand by Emily Delahaye

This is the first study to systematically examine continuous broadband seismic data during slow slip events in New Zealand. A total of 20 weeks of continuous broadband seismic data was reviewed during the times of three slow slip events: two in the shallow region of the Hikurangi subduction zone near Gisborne (in 2004 and 2006) and one deeper, 18 month-long event beneath the Manawatu region (early 2004 to mid-2005).

Using the same methods that have been used in northern Cascadia by the Geological Survey of Canada (GSC), seismic tremor similar to that seen elsewhere was not detected during any of these slow slip events. This observation does not appear to be the result of network limitations: as five additional seismographs were deployed in the latter stages of the 2006 Gisborne event to augment the permanent network, and still seismic tremor was not detected. However, local earthquakes that had not been detected during routine analysis were detected and located during this study.

The analysis revealed a pronounced increase in microseismicity during the 2004 Gisborne event that is spatially restricted to a region of the subducting plate downdip from the slow slip patch inferred from GPS observations and temporally restricted to the period of slow slip. This increased rate of local seismicity is only seen in the small magnitude earthquakes. The increased rate of seismicity is not evident in the routine analysis records and was only detected by a methodical review of continuous seismic data. The 2004 slow slip event triggered microseismicity with magnitudes of $\mathrm{M}_{\mathrm{L}} \sim 1-2$, similar to the "co-shocks" reported by Segal et al. (2006) in an intraplate setting.

A similar increase in microseismicity was not observed during the 2006 Gisborne event or the 2004-2005 Manawatu events. The analysis of the 2004-2005 Manawatu data is preliminary but these results indicate that seismic tremor or increased microseismicity did not occur during this slow slip event.

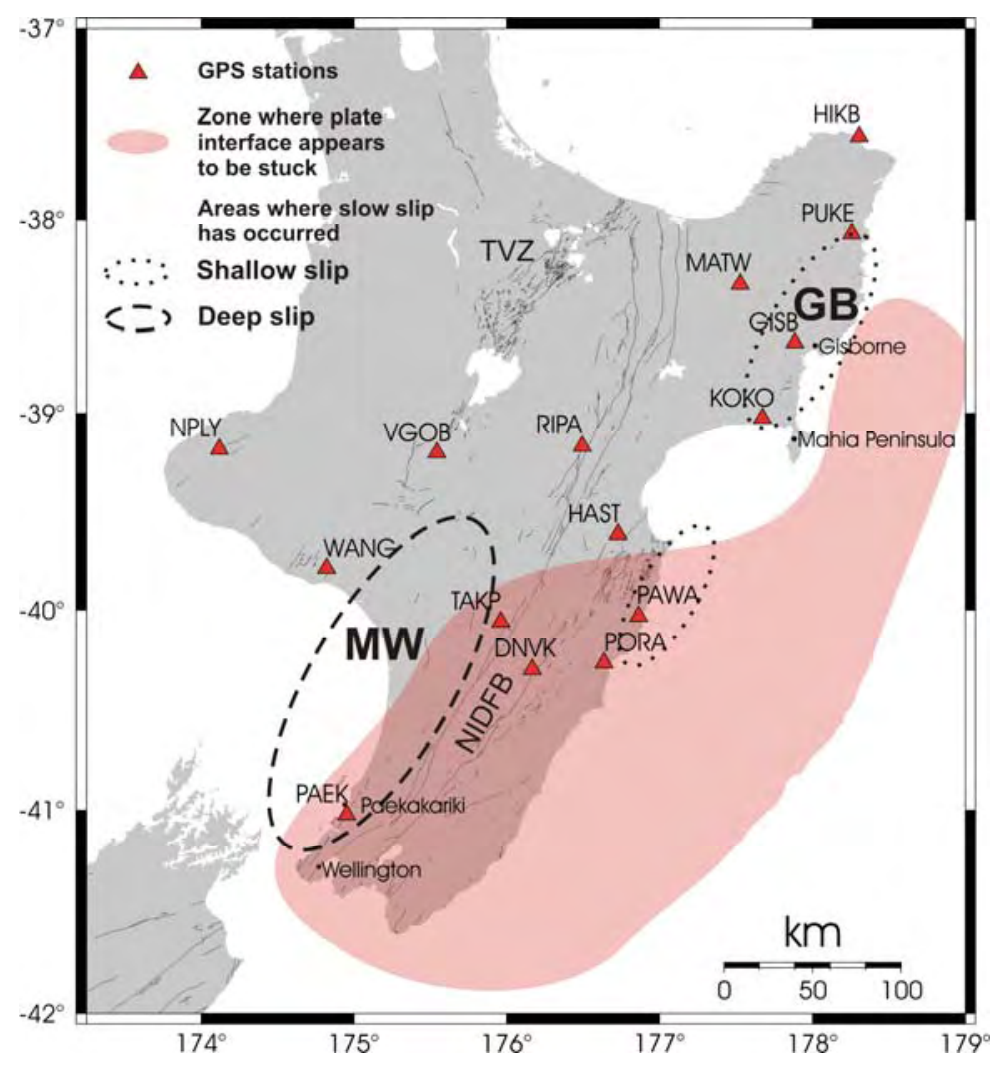

Figure 1. Distribution of slow slip events in North Island, New Zealand. Areas of observed slow slip events are indicated by the ellipses. GPS stations where slow slip has been observed. GB Gisborne, MW - Manawatu and Paekakariki, TVZ - Taupo Volcanic Zone, NIDFB North Island Dextral Fault Belt. 


\title{
Investigating Relationships of Episodic Tremor and Slip and Seismicity Along the Northern Cascadia Margin
}

\author{
H. Dragert, H. Kao, G.C. Rogers, K.Wang, J.F. Cassidy, and S. Mazzotti \\ Geological Survey of Canada, Pacific Geoscience Centre, Sidney, B.C. V8L 4B2 Canada
}

Episodes of prolonged occurrences of non-volcanic tremor and of slow slip have now been documented for the southern Vancouver Island region for the past 25 years and 14 years respectively. Based on these combined seismic and GPS observations, we currently define Episodic Tremor and Slip (ETS) empirically as repeated, transient ground motions at a plate margin, roughly opposite to longer-term elastic deformation motion, accompanied by distinct, emergent seismic signals in the 0.5 to $5 \mathrm{~Hz}$ band. Although all the processes involved in ETS are not fully understood, these observations to date suggest spatial and possibly temporal relationships between ETS and the three types of regional earthquake activity that characterize Cascadia seismic hazard. Spatially, ETS and regional seismicity tend to be mutually exclusive. Although the last Cascadia subduction thrust earthquake pre-dates written historical records, instrumental observations of non-volcanic tremor in the Nankai subduction zone of southern Japan (Obara, 2002) suggest that the ETS zone may mark the landward limit for megathrust rupture (Dragert et al., 2004). Furthermore, the northern Cascadia ETS zone appears to be confined to a region overlying the descending Juan de Fuca plate where fewer in-slab earthquakes occur. Detailed observations of more recent tremor episodes have not only established an extended depth distribution for tremor sources but also suggest tremors occur in regions where fewer crustal earthquakes are found (Kao et al., 2006). Epicentres of the large ( $M>6$ ) crustal earthquakes that occurred on central Vancouver Is. in 1918 and 1946 fall outside of observed tremor concentrations, suggesting crustal stress relationships between large earthquakes and tremor.

Temporal relationships are more conjectural. If ETS episodes are the direct result of slip on the deeper plate interface, it is conceivable that a slip event could develop into a trigger for rupture on the locked portion of the thrust fault lying directly up-dip of the slip region. Commensurately, the cumulative weekly conditional probability for a megathrust event is increased at the time of an ETS event (Mazzotti and Adams, 2004). How significant such an increase in probability may be is not clear since ETS episodes occur with different repeat intervals along the full extent of the Cascadia margin (Brudzinski and Allen, 2006) and triggering of the megathrust earthquake could occur anywhere along the margin. Any ubiquity of ETS activity over time would require anomalous changes in the character of a particular ETS episode in order to make it useful as a precursor of a megathrust earthquake. A search for changes of rates of in-slab earthquakes coincident with ETS events has produced ambiguous results so far, showing marginal changes in seismicity rates for some of the ETS events but not for others. Coulomb stress from a slip on the deeper subducting plate interface would tend to retard the occurrence of a normal in-slab rupture directly down-dip of the slip but promote normal in-slab rupture directly up-dip of the slip. No convincing temporal correlation has yet been established between ETS occurrence and low-magnitude crustal seismicity. Interestingly, the July 2004 M6.4 earthquake that occurred $40 \mathrm{~km}$ offshore from central Vancouver Is. coincides with an "out-of-sequence" ETS event in northern Vancouver Is., again suggesting stress interactions between ETS and large crustal earthquakes.

Brudzinski, M. R., and R. M. Allen, (2007), Geology 35 (10) 907-910, doi: 10.1130/G23740A.1.

Dragert, H., K. Wang, and G. Rogers, (2004), Geodetic and seismic signatures of episodic tremor and slip in the northern Cascadia subduction zone, Earth Planets Space, 56, 1143-1150.

Kao, H., S.-J. Shan, H. Dragert, G. Rogers, J.F. Cassidy, K. Wang, T. James, and K. Ramachandran (2006), Spatial-temporal patterns of seismic tremors in northern Cascadia, J.Geophys.Res.,111, B03309, doi:10.1029/2005JB003727.

Mazzotti, S.,and J. Adams (2004), Variability of near-term probability for the next great earthquake on the Cascadia subduction zone, Bull. Seismol. Soc. Am., 94, 1954-1959.

Obara, K., (2002), Non-volcanic deep tremor associated with subduction in southwest Japan, Science, 386296, 1679-1681. 


\title{
Origin of Nonvolcanic Tremor beneath the San Andreas Fault in Central California
}

\author{
William L. Ellsworth \\ U.S. Geological Survey, Menlo Park, CA
}

The principal source region of nonvolcanic tremor in California lies deep beneath the San Andreas Fault in the Palo Prieto Pass region, central California. Nadeau and Dolenc [2004] determined the source region extends for approximately $25 \mathrm{~km}$ along the fault with its northwestward terminus near the southern end of Cholame Valley. Although the depth of the tremor is not well-resolved at present, hypocenters they determined by the envelope correlation method of Obara [2002] locate beneath the seismogenic zone $(\leq 15$ $\mathrm{km}$ ) at depths between 20 and $40 \mathrm{~km}$. The tremor source is spatially correlated with the northernmost extent of the locked southern section of the San Andreas Fault, and with the northern terminus of rupture in the great 1857 earthquake. However, it is unclear if these correlations are meaningful or coincidental.

There are several aspects of the geology of the Palo Prieto Pass region that may be significant to the localization of tremor in this area. The largest magnetic amomaly along the San Andreas Fault coincides with the tremor source. Gravity and magnetic modeling by Hanna et al. [1972] indicate that it represents an east-side mid- to lower-crustal ultramafic body that has not undergone substantial serpentinization. Deep seismic reflection data collected across the fault a Cholame reveal lower crustal reflectors immediately to the west, possibly representing subducted sedimentary material in the lower crust (Trehu and Wheeler, 1987), and a deeply penetrating low velocity zone within the fault. By analogy with the proposed role of metamorphic fluids in the generation of nonvolcanic tremor in subduction zones (Kao, et al., 2005, Shelly et al, 2006), the ingredients may be present here, but with the direction of the metamorphic reactions reversed.

\section{References}

Hanna, W. F., S. H. Burch, and T. W. Dibblee, 1972, Gravity, magnetics and geology of the San Andreas Fault area near Cholame, California, U.S. Geological Survey Professional Paper 646-C.

Kao, Honn, Shao-Ju Shan, Herb Dragert, Garry Rogers, John F. Cassidy, and Kumar Ramachandran, 2005, A wide depth distribution of seismic tremors along the northern Cascadia margin, Nature, v. 436, p. 841-844.

Nadeau, Robert M., and David Dolenc, 2005, Nonvolcanic tremors deep beneath the San Andres Fault, Science, v. 307, p. 389.

Obara, Kazushige, 2002, Nonvolcanic deep tremor associated with subduction in southwest Japan, Science, v. 296, p. 1679-1681.

Shelly, David R., Gregory C. Beroza, Satoshi Ide, and Sho Nakamula, 2006, Lowfrequency earthquakes in Shikoku, Japan and their relationship to episodic tremor and slip, Nature, v. 442, p. 188-191.

Trehu, Anne M., and Walter H. Wheeler IV, 1987, Possible evidence for subducted sedimentary materials beneath central California, Geology, v. 15, p. 254-258. 


\title{
Abstract \\ Emergency Response and Public Information Needs Associated with Possible Earthquake Precursory Information: A State Emergency Management Perspective
}

\author{
By \\ James D. Goltz Ph.D. \\ Branch Chief, Earthquake and Tsunami Program \\ California Governor's Office of Emergency Services \\ Pasadena, CA
}

Historically, the California Governor's Office of Emergency Services has responded to a number of non-damaging though potentially precursory seismic events by issuing "earthquake advisories" to local government and the public. These advisories have been addressed to those Operational Areas (county governments) located within a geographical area that could be impacted should a damaging earthquake follow an anomalous event or set of events. Typically, the seismic activity that results in an earthquake advisory is an earthquake of $\mathrm{M} \geq 5$ in an area, or associated with a fault, known to have a high probability of generating damaging earthquakes. In addition, earthquake advisories have been considered for earthquake swarms in areas from which large events may nucleate. Accelerated creep events or aseismic slip may represent an additional category of seismic activity that could prompt an earthquake advisory.

In 1990, California OES developed the California Earthquake Advisory Plan which provides a set of procedures to be followed in evaluating potentially precursory seismic events, notifying local governments and the public in areas that may be impacted by a damaging follow-on earthquake, and recommending appropriate actions to be taken by emergency management and the public in the region affected. Upon the occurrence of an event that could be considered precursory to a larger damaging event, the California Earthquake Prediction Evaluation Council is convened to review the event and advise OES regarding the likelihood that the event is a foreshock and the extent to which the probability of a damaging earthquake has increased. If an earthquake advisory is deemed appropriate, California OES will prepare a message to local jurisdictions in the region that may be affected and communicate that message through secure emergency management communications channels, then issue a media advisory intended to notify the public.

The recommendations by California OES to local governments vary according to the evaluated threat but as minimum precautions, OES recommends that local emergency managers disseminate information to key personnel, ensure the readiness of systems essential to emergency operations, implement protective and mitigative actions and provide guidance to the public on appropriate precautionary actions. 


\title{
Inferences from Triggered Nonvolcanic Tremor and Earthquakes
}

\author{
Joan Gomberg, Paul Bodin, Kenneth C. Creager, Honn Kao, Zhigang Peng, Garry \\ Rogers, Justin L. Rubinstein, John E. Vidale, Aaron Wech
}

We study triggered tremor and earthquakes, emphasizing the former, in which triggering deformations come from seismic waves. The common signatures of triggered tremor and ETS or ambient tremor suggest they share common underlying mechanics. We focus on the Cascadia subduction zone and transform boundary of California, to learn what local environmental (e.g. fault properties, ambient slip velocities, temperatures, etc.) and loading conditions facilitate both phenomena. In both regions we examine seismic data to identify tremor and seismicity rate increases triggered by posited triggering seismic waves. Herein we summarize our findings and ongoing investigations.

The conditions necessary for triggering tremor cannot be unique to subduction zones. Waves from the Denali earthquake triggered tremor at seven sites in California and at a single site on Vancouver Island. Sumatra earthquake waves also triggered tremor in both regions, in central California in the vicinity of Denali-triggered tremor sources near Parkfield. A preliminary search for triggering waves from Sumatra and other earthquakes near the Denali-triggered tremor source close to the San Jacinto fault in southern California thus far shows neither triggered tremor nor earthquakes.

Triggered tremor may occur often in the near field of frequent, moderate and small earthquakes, but cannot be distinguished from the signals of the triggering waves.

Aseismic slip facilitates, but doesn't guarantee, tremor triggering and does not correlate with triggered earthquake activity. Seismic and GPS data analyses for 30 posited triggering teleseismic wavetrains impacting Vancouver Island show aseismic slip concurrent with the two smaller deformations that triggered tremor, while other equal or larger waves arriving during periods of no detectable slip did not. However, several non-triggering earthquakes occurred during periods of aseismic slip. We are examining strainmeter data recorded near Parkfield around times when triggering waves passed through; in the few cases examined to date we find no obvious signs of concurrent slow slip.

If sufficiently large, seismic waves may trigger tremor and earthquakes even in the absence of detectable aseismic slip. The peak Denali earthquake surface wave velocities exceeded those of any other posited triggering earthquake examined by more than double, except in the near-field of moderate earthquakes that triggered vigorous aftershock sequences and where tremor cannot be distinguished. Denali waves triggered tremor most clearly and at the greatest number of sites, as well as the being the only unambiguous case for which earthquakes were triggered on Vancouver Island.

If tremor requires transitional frictional properties, other properties also must be important; e.g., perhaps the pressures or temperatures at shallow depths do not allow tremor generation. This follows from the lack of correlation between the locations of the seven tremor sources triggered by the Denali surface waves in California and where faults creep, are locked, or transitional, and assuming frictional properties control ambient slip behavior. We are investigating this further by looking for tremor in association with observed shallow slip events near San Juan Bautista, California.

High heat production, presumed high pore pressures, and fluids appear to promote triggering of earthquakes, but not tremor. The observation that Denali waves triggered earthquakes but no tremor in the geothermal areas of California supports this inference. 
Triggering tremor and earthquakes appear to require different environmental conditions. On Vancouver Island only the extraordinarily large waves of the Denali earthquake triggered both tremor and earthquakes, although in different locations. 


\section{Vertical Deformation Associated with Slow Slip Events in Cascadia: Methods of Detection and Model Inversion}

Stephen Holtkamp (1)(2), Michael R. Brudzinski (2), Rowena Lohman (1), Matt Pritchard (1)

(1) Cornell University, Earth and Atmospheric Science, Ithaca, NY

(2) Miami University, Geology Department, Oxford, OH

Best fit hyperbolic tangent solutions for Cascadia Episodic Tremor and Slip (ETS) events for vertical components of GPS stations in the PANGA data set are examined and a number are shown to display measurable transient offsets. Timing of ETS events is taken as the best hyperbolic tangent fit from a grid search over time in the longitudinal time series, as the longitudinal time series is a good proxy for trench perpendicular motion. Large uncertainties in vertical time series make identification of vertical transient motion independent of horizontal components difficult. Displacements are calculated for each event observation in the data set, but only solutions with an F-test greater than 99 are believed to accurately represent transient motions.

Examination of the PANGA data set from 1997 to early 2007 yields 40 observations of slow slip events showing transient vertical motion. These events show uplift near the trench and subsidence farther away from the trench with an inflection point of no substantial vertical motion at about $40 \mathrm{~km}$ above the plate interface, consistent with thrust-type faulting events on the plate interface with a down-dip extent of $\sim 40 \mathrm{k}$. Examination of the densely sampled Northern Washington/Southern Vancouver Island yields 28 event observations and shows a peak in the uplift at $\sim 25$ to $30 \mathrm{~km}$ above the plate interface and a peak in the subsidence at $\sim 50$ to $60 \mathrm{~km}$ above the interface.

Preliminary modeling of slip on the interface during several recent, well-observed ETS events incorporating vertical offsets will be discussed. Well constrained vertical deformation may help confine the down-dip extent of the slow slip source region, as Green's functions associated with vertical deformation are more sensitive to the downdip extent of slip. Slip models generated are then used to predict surface deformation over the entire area affected by each event. These forward models are used to produce synthetic InSAR interferograms by projecting the predicted surface deformation in the line of sight (LOS) of various satellites commonly used for InSAR studies. Preliminary models show that LOS deformation on the order of $1 \mathrm{~cm}$ can be expected from ETS events in northern Washington/southern Vancouver Island. Discussion will include beginning a search for observing deformation associated with Cascadia ETS events within the InSAR data set. 
The Scaling of the Tremor Source

Heidi Houston, University of Washington

The scaling of the tremor source quantifies the striking differences between tremor and regular earthquakes and offers clues on the underlying physics of this lately-discovered phenomenon. Recently, a compilation of various different types of slow slip events by Ide et al. (2007) suggested that durations of such events are linearly proportional to their seismic moments.

Here I conduct a systematic study of source scaling of non-volcanic tremor using a consistent data stream for the 2005 Cascadia ETS. Day-long horizontal seismograms from the small-scale PA array above the Cascadia subduction zone are integrated, corrected for gain, and filtered from 1 to $8 \mathrm{~Hz}$ to highlight the tremor. Then envelopes of the horizontal records are stacked and lightly smoothed (low-passed below several trial frequencies of 0.03 to $0.002 \mathrm{~Hz}$ ). Tremor events are defined as intervals during which the envelope is greater than a threshold level. Durations of tremor events thus defined range from $\sim 100 \mathrm{~s}$ to several hours. The envelopes of the tremor events are treated as time functions (moment-rates). A band-limited "tremor moment" is associated to a tremor event assuming the tremor signal consists of direct far-field S-waves emanating from the plate boundary below the array. I find that event duration is proportional to $\mathrm{M}_{0}{ }^{0.85}$. This result does not depend on the absolute estimation of moment and appears robust - over a range of thresholds and smoothing periods, the exponent varies from 0.80 to 0.88 , being commonly between 0.82 and 0.86 . This allows for modest growth of the amplitude of tremor events with duration, which is clearly seen in the envelopes. This scaling contrasts markedly with that of regular earthquakes, which follow duration proportional to $\mathrm{M}_{0}{ }^{0.33}$ over many orders of magnitude, and for which amplitudes grow strongly with increasing moment. Such earthquake scaling occurs due to the rough proportionality of fault displacement, length, and width, and the imposition of a roughly constant value of rupture velocity by the dynamic stress propagation associated with earthquakes. One or more of these factors must be missing from tremor generation, and constraints on the spatial parameters will be useful in interpreting the tremor scaling relation.

The total seismic moment associated with tremor appears to be much less than the true moment associated with slow slip in ETS. With the simple assumption of direct far-field $\mathrm{S}$ waves and ignoring reverberations at the station, the total tremor moment for a representative vigorous day of the 2005 ETS corresponds to that of a M5.3 earthquake. Preliminary calculations using small local earthquakes to provide empirical calibration suggests that reverberations increase amplitudes by at least an order of magnitude. This does not affect the slope of the moment-duration scaling relation, but does imply that the moment associated with tremor is at most a few percent of the moment associated with slow slip in ETS. Most of the slip in an ETS period occurs silently, without generating seismic signals in the bandwidth in which tremor is typically detected. This suggests slow slip is not simply the sum of tremor events. 


\title{
The Environment of Episodic Tremor and Slip: Temperature, Rock Composition, and Water
}

\author{
Roy Hyndman \\ Pacific Geoscience Centre, Geological Survey of Canada
}

In this study we examined the special conditions associated with episodic slip and tremor (ETS): temperature and rock composition where ETS occurs, and the probable role of water driven upward from the dehydrating subducting plate. Detailed numerical thermal models constrained by heat flow and other temperature indicators are now available for many subduction zones. For hot subduction zones like Cascadia and SW Japan the downdip limit of great earthquake rupture is at about 350C with a transition to stable sliding at about 450C. ETS slow slip occurs downdip from this limit extending until just landward of where the thrust meets the aseismic forearc mantle, i.e, $450-550 \mathrm{C}$, at a depth range of $30-50 \mathrm{~km}$. For these temperatures, laboratory data indicate velocity strengthening (stable sliding) for quartzofelspathic rocks, so a special mechanism is required for slip events. Increasing pore pressure on the thrust from rising fluids, that is released episodically is one possible mechanism.

The subducting oceanic crust and entrained sediments carry large amounts of water (e.g., 5-10\% avg. porosity) that are initially incorporated in low temperature hydrated minerals. With downward increasing P-T there is progressive dehydration and water production from various metamorphic minerals. The reactions of the basalt-eclogite transformation are especially important for water expulsion. For Cascadia and SW Japan this transformation occurs mainly in the depth range of the ETS slip, i.e., $\sim 500 \mathrm{C}$, and overlying tremor zone in the forearc crust (although the depth range is still debated). Upward fluid production peaks in this region.

Landward of the ETS zone, the upward moving water hydrates the forearc mantle to serpentinite (antigorite) which laboratory data shows to be aseismic stable sliding. For Cascadia $\sim 30 \%$ serpentinite is evident in seismic tomography data (high Poisson's Ratio). Little rising water is inferred to get through to the overlying forearc crust from this point landward. The landward termination of ETS tremor in the forearc crust at this point gives one indication that upward expelled water plays a role in ETS tremor. For cold subduction zones, most of the upward fluid expulsion is further landward beneath the forearc mantle where it is consumed in serpentinization. Fluid-related tremor is then not expected.

That substantial water is rising in the Cascadia ETS region is indicated by tomography evidence for silica concentrations in the lower forearc crust in this region (very low Poisson's Ratio). The fluids rising from the subducted slab are concluded to be silica saturated and the silica solubility decreases rapidly with upward decreasing temperature and pressure, so silica is precipitated in the lower forearc crust in the region of ETS tremor. The inferred amount of silica (quartz) approximately equals that estimated to be removed from the rising fluid in the $40 \mathrm{~m}$.y. most recent phase of subduction. This quartz may represent $30 \%$ of the lower crust and is a substantial volume addition. Two possible sources for tremor in the lower to mid-forearc crust associated with this fluid are: (1) local discrete events of incremental rising percolating fluid, i.e., "mobile hydrofractures", (2) local deformation events associated with the added volume of silica deposition from the rising fluids.

The structure of exhumed deep quartz veins has been well studied (because of gold association), and a number of authors have described evidence for past earthquake rupture processes (for example the "fault valve" model of earthquakes; Sibson and others). Most outcrop sections studied represent lower temperatures, but some studies have shown evidence for "episodic hydraulic fracturing and the formation of breccias at fast strain rates" for temperature of 500-700C. Do these described processes represent the ETS tremor sources? 


\title{
Spatial-Temporal Patterns of ETS Tremors in Northern Cascadia: 10 Years of Observations From 1997 to 2007
}

\author{
Honn Kao, Shao-Ju Shan, Garry Rogers, Herb Dragert, Kelin Wang, and Tony Lambert \\ Geological Survey of Canada, Pacific Geoscience Centre, Sidney, BC V8L 4B2, Canada
}

We systematically examine the continuous seismic records of the northern Cascadia subduction zone during the past 10 years (1997-2007). Hourly waveforms are processed by the Tremor Activity Monitoring System (TAMS) to identify the time and region(s) of a possible ETS occurrence. When a daily TAMS index exceeds a preset threshold, waveforms at stations showing coherent tremor patterns are analyzed by the Source-Scanning Algorithm to determine the locations of tremors. In total, $>6300$ solutions are obtained and shown below in both map view and cross sections.

Most ETS tremors in southern and middle Vancouver Island (VI), where the Juan de Fuca plate subducts beneath the North America (NA), are observed in the band bounded by the 30 and $50-\mathrm{km}$ contours of the plate interface. This band is shifted seaward in the north where the convergence between NA and the younger Explorer plate is much slower. Occurrence of ETS tremors appears to be particularly less in the epicentral regions of large crustal earthquakes (crosses in the figure). This observation, combining with an earlier conclusion that most ETS tremors occurred in places with sparse background seismicity, can provide important clues to explain where and why large (and potentially hazardous) crustal earthquakes take place.

The spatial and temporal distribution of ETS tremors seems to follow the prediction of "Gap Theory" with a significantly shorter filling cycle (c.f. the gap theory for major interplate earthquakes). Except the epicentral regions of large crustal earthquakes where tremors always try to avoid, the incoming episode is more likely to fill one of the gaps left by previous episodes. The recurrence interval of major ETS episode in southern VI is well defined at $14+/-2$ months, but it is less regular toward the north. For tremor-active days, a correlation is found between the numbers of tremors and tidal signals, suggesting that the tidal stress can be a factor in the seismogenic process of ETS tremors.

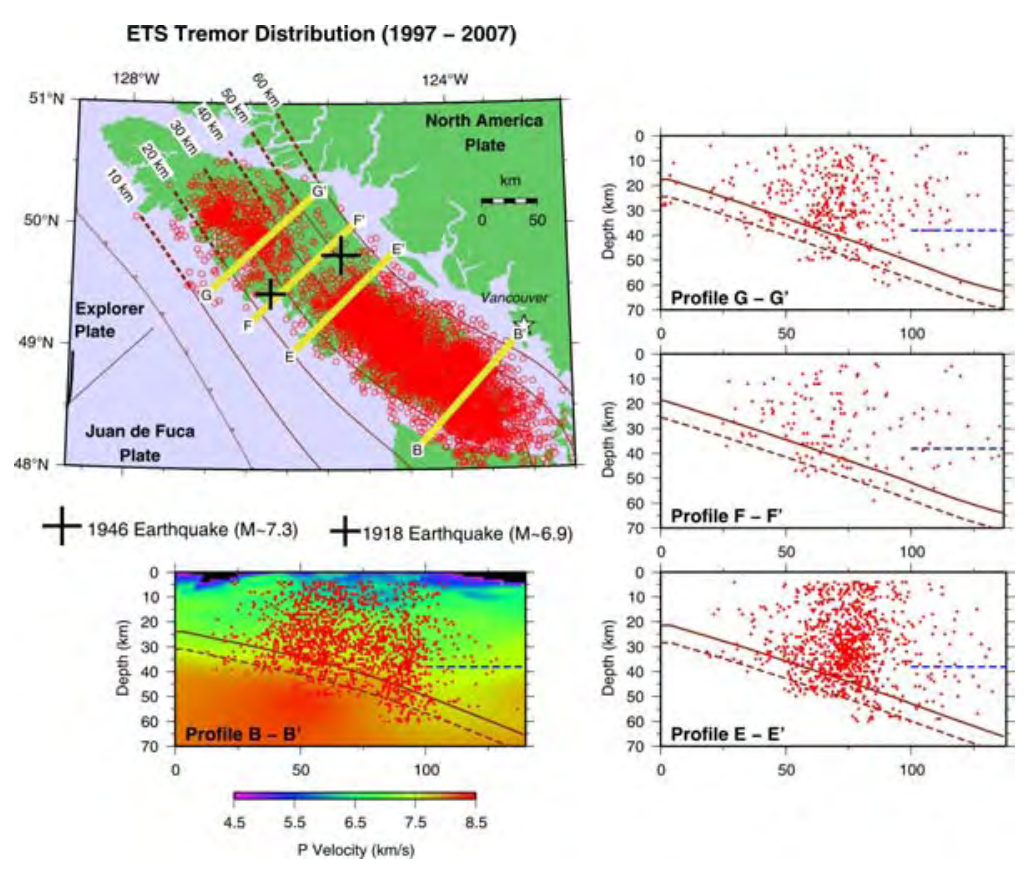




\section{Utility of borehole strainmeter data to measure transient strain from Cascadia slow-slip event.}

John Langbein, USGS, Menlo Park, CA 94025 langbein@usgs.gov

Approximately 25, four-component borehole strainmeters have been installed by the Plate Boundary Observatory to provide high precision and high temporal resolution measurements of transient strain from slow-slip events that occur on the interface of the Cascadia Subduction Zone. Combination of the four components should provide a redundant estimate of changes in the tensor quantities of strain. To date, the data from the GPS network in the Pacific Northwest indicate that these slow-slip events on the northern portion of the subduction zone occur roughly every 14 months with a duration of about 2 weeks. Modeling of GPS data by others (D. Schmidt, personal communication, 2008) suggests that the peak strain change is of the order of 100 nanostrain (ns).

The borehole strainmeter data should complement the GPS data since the strain data are recorded at 20 -second intervals and can provide resolution down to less than $0.5 \mathrm{~ns}$. However, these data are compromised in at least two ways: 1 ) The strain recorded in the instrument is not the strain in the rock that surrounds the instrument; and 2) the timeseries of strain changes have a large ambient drift that is characteristic of a randomwalk (or worse). Both of these elements affect the accuracy and the precision of the strain data.

To match the strain recorded by the instrument to that in the rock, the strain data are typically compared with a known signal, the Earth Tide. Several assumptions can be made when performing the tidal calibration, but for nearly all of the strainmeters installed by PBO, the simplifying assumption of isotropic coupling to the rock does not provide satisfactory agreement between the predictions of the theoretical Earth Tide and the observations. In many PBO instruments, though, relaxation of the isotropic coupling assumption does provide satisfactory agreement between the theoretical Earth Tide and the strain data. The tensor quantities of the Earth Tide can range between 1 to 15 ns. Typically, one can estimate a calibration matrix such that strain data matches theoretical tide within 2 ns. However, since some of the tensor quantities of strain exhibit a small Earth Tide, this indicates that the strainmeter can not be completely calibrated using the Earth Tide. In addition, for the components that can be calibrated, there is a question of whether the calibration is good over the entire range of strain to 2 ns level or to $13 \%$ level ( 2 ns compared to $15 \mathrm{~ns}$ ). This becomes critical in determining the accuracy of a recorded strain transient from a slow-slip event.

The drift of the strain data can be seen both in the time and frequency domain. Although the short-term repeatability or precision of these strainmeters is $<0.5 \mathrm{~ns}$ for periods of less than a few hours, the longer term wander or drift shows a much larger amplitude that ranges between 10 to more than 50 ns over a 10-day period. This variation in drift appears to be seasonal in some instruments. The largest contributor is transients from large rainfall events. Thus, assessment of the background noise needs to be done carefully since variations in the drift can be the same magnitude as signal from a slowslip event.

The poster will present examples of processing of raw strainmeter data to convert into tensor strain and the estimates of uncertainties for observed strain changes. This scheme can be used for routine monitoring to detect onset of deformation that might be associated with a Cascadia slow-slip event. 


\section{Possible Non-volcanic Tremor Discovered in the Reelfoot Fault Zone, Northern Tennessee}

Charles A. Langston, Robert A. Williams, M.Beatrice Magnani, and Duayne M. Rieger Center for Earthquake Research and Information, University of Memphis, and U.S. Geological Survey (R.W.), Denver, CO.

A swarm of $\sim 80$ microearthquakes was fortuitously detected in 20,14 second-duration long-offset vibroseis shotgathers collected for a seismic reflection experiment near Mooring, TN, directly over the Reelfoot fault zone on the afternoon of 16 November 2006. These natural events show up in the shotgathers as near-vertically incident $P$ waves with a dominant frequency of $10-15 \mathrm{~Hz}$. The reflection line was $715 \mathrm{~m}$ in length consisting of 144 channels with a sensor spacing of $5 \mathrm{~m}, 8 \mathrm{~Hz}$ vertical geophones, and recording using a Geometrics 24bit Geode seismograph. Small variations in event moveout across the linear array indicate that the seismicity was not confined to the same hypocenter and probably occurred at depths of approximately $10 \mathrm{~km}$. The largest events in the series are estimated to have local magnitudes of $\sim-1$ if at $10 \mathrm{~km}$ distance from the array. This is about 2.5 magnitude units lower than the threshold for local events detected and located by the CERI cooperative network in the area. The seismicity rate was $\sim 1000$ events per hour based on the total time duration of the shotgathers. The expected number of earthquakes of ML greater than or equal to -1 for the entire central United States is only 1 per hour. This detection of microseismic swarms in the Reelfoot fault zone indicates active physical processes that may be similar to non-volcanic tremor seen in the Cascadia and San Andreas fault zones and merits long-term monitoring to understand its source.

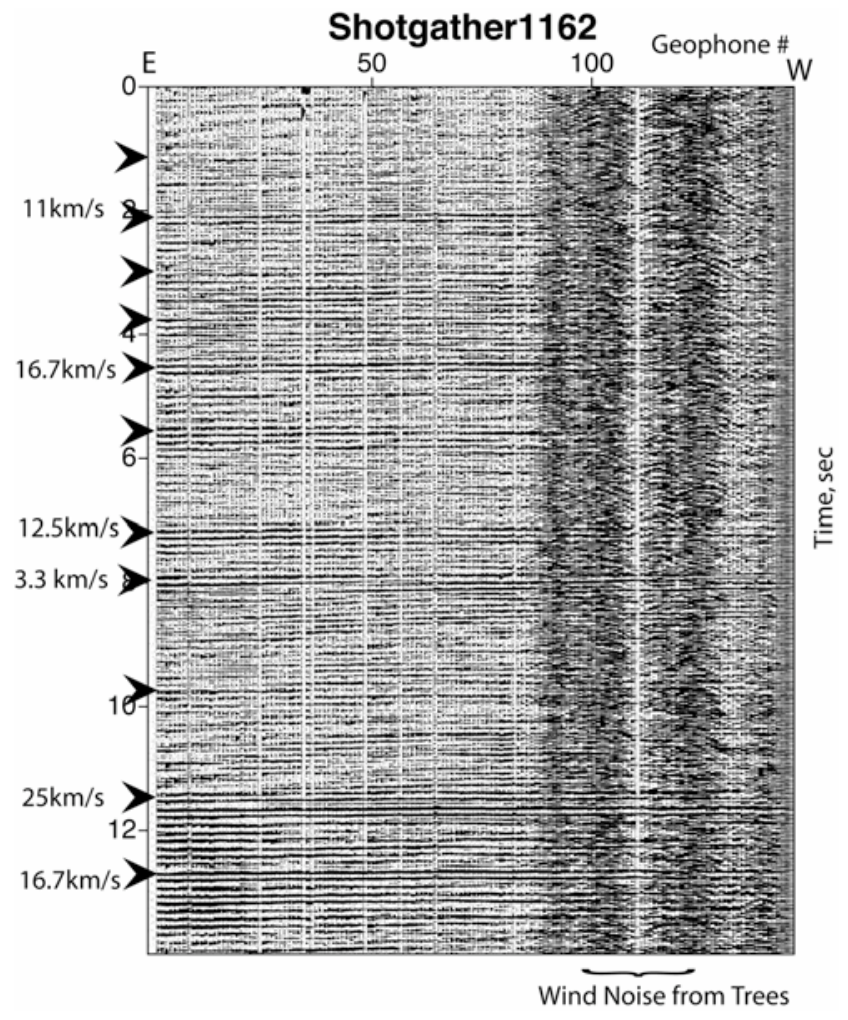

Figure 1 - Example of a filtered shotgather showing high-velocity events. Based on the similarity of event waveforms with nearby recordings of larger magnitude earthquakes, these high velocity arrivals are interpreted to be $\mathrm{P}$ and $\mathrm{Sp}$ converted phases from ML -2 to -1 earthquakes situated west of the array. The variation in phase velocity implies several different hypocentral locations. 
Education and Outreach Needs and Opportunities

\author{
Robert J. Lillie \\ EarthScope Education and Outreach Manager \\ Professor of Geology, Oregon State University
}

EarthScope is a National Science Foundation (NSF) program that applies the latest science and technology to explore the structure and evolution of the North American continent and to understand the physical processes that cause earthquakes and volcanic eruptions. The EarthScope National Office (ESNO) is working with the Incorporated Research Institutions for Seismology (IRIS), UNAVCO, Inc., and other partners to expand the program's education and outreach. The ESNO efforts will complement ongoing E/O aimed at formal educators in the K-16 school system by targeting interpretive professionals who engage the public in informal education settings such as parks and museums.

One of the fundamental aspects of EarthScope is the integration of many types of observations to study the structure and evolution of the continent. Two challenges facing the EarthScope community include providing the public with access to timely EarthScope science and presenting complex data and related principles in language and formats accessible to varied audiences. Park rangers and museum educators are in a unique position to engage the public on the relevance of Earth processes by incorporating EarthScope discoveries as they are being made. A series of three-day workshops will combine presentations by EarthScope scientists with interpretive methods to convey stories of geological hazards and the development of the dynamic landscape of the western United States. The initial workshop, to be held April 7-10, 2008, at the Mt. Rainier National Park Education Center, will focus on results of EarthScope's USArray and PBO observations from the Cascadia Subduction Zone. The workshop will show how incorporating EarthScope data and scientific results into interpretive programs and exhibits can enhance the "sense of place" represented by the dynamic landscape of the Pacific Northwest. Presentations and activities will focus on engaging visitors on not only how and why science is important, but also that it is understandable and meaningful. Earthquakes, volcanoes, and tsunamis reveal the power of Earth's forces that form the spectacular landscape of the Pacific Northwest. Interpretive professionals can draw on connections that park and museum visitors have to the landscape to relate how and why seismic and geodetic measurements are so important. Participants will learn how to use EarthScope data and science results, and will develop and present actual programs and exhibits during the workshop.

The EarthScope National Office is working with partners in many other ways to engage students, teachers, and the general public on how deformation of the North American continent affects their lives. The 2008 EarthScope Speaker Series presents scientific results of EarthScope research to faculty and students in geology/geophysics departments at colleges and universities. Increased awareness of EarthScope and its achievements by scientists is a first step toward broader outreach. The series will be expanded in future years to include presentations to more general audiences in public forums. ESNO is also working with programs such as the Science and Math Investigative Learning Experiences (SMILE) program at Oregon State University. SMILE focuses on school districts throughout the state that have large minority and underrepresented student populations. We are focusing on the informal education component of SMILE that works with teachers and students in after-school science clubs. During discussions at the "Aseismic Slip, Non-Volcanic Tremor, and Earthquakes" Workshop we will examine these examples and others from workshop participants to discuss needs and opportunities for ETS education and outreach. 
Modeling moment-duration relation of aseismic slip events in subduction zones

\section{Yajing Liu, Princeton University}

Observations of the "slow earthquake" phenomena, including aseismic slow slip events, afterslips, and low-frequency earthquakes at different tectonic settings, suggest a linear relation between their moments and characteristic durations [Ide et al., 2007]. Following Liu and Rice [2007], we study the moment duration relation by applying rate and state friction to model short-period aseismic transients, which occur spontaneously in the times between great subduction earthquakes when pore pressure is near lithostatic around the stability transitional depth. Specif cally, we assume a constantly low effective normal stress $\bar{\sigma}(=\sigma-p)$ within a zone extending $W$ up-dip and downdip, respectively, from the stability transition, and much higher $\bar{\sigma}$ beyond. By varying $W$ and $\bar{\sigma}$ independently and keeping $W / h^{*}$ in the range where occurrence of spontaneous transients is allowed, we can produce abundant aseismic transients with moments and durations spanning several orders of magnitude.

There are three major features noticed from the collection of moment $(M)$ and duration $(T)$ of the modeled transients. First, all events lie within a well def ned band that follows the linear trend of $M \propto T$. Second, events of a f xed width of low $\bar{\sigma}$ follow a more strictly def ned linear trend, even with moderate variations in $W / h^{*}$. For the same $W / h^{*}$, moment and duration increase linearly with $\bar{\sigma}$. Third, as the region of low $\bar{\sigma}$ decreases in size, the linear trend $M \propto T$ migrates toward regimes of smaller moment and shorter duration. Temperature prof les of friction parameter $a-b$ of granite under wet [Blanpied et al., 1998] and dry [Lockner et al., 1986] conditions are applied and both consistently show the three features. If the existence of near-lithostatic pore pressure around the stability transition is the origin of multiple episodes of slow slip events observed worldwide, our simulation shows that the level of pore pressure and the spatial extent of the high pore pressure zone contribute to the linear relation between events moment and duration. Moment and duration here are determined when the moment rate exceeds the steady-state rate within the low $\bar{\sigma}$ zone, where aseismic slip takes place. An alternate criterion of choosing moment and duration when the maximum slip rate exceeds the steady-state rate results in a similar linear relation. The alongstrike width of fault involved in transient slips are not included in this current 2D model; we used a nominal $W_{\text {strike }}=100 \mathrm{~km}$ in the moment calculation. The modeled linear band would only shift slightly in the vicinity of the empirical $M /[\mathrm{N}-\mathrm{m}]=10^{12-13} \mathrm{~T} /[\mathrm{s}]$ given the variance in the observed $W_{\text {strike. }}$ 


\title{
Inverting 3-component GPS time series for transient sources and inter-event site velocities and fault coupling: Applications to Cascadia and Hikurangi (New Zealand) margins
}

\author{
Rob McCaffrey \\ GNS Science, Lower Hutt, New Zealand \\ (with collaboration from John Beavan (New Zealand) and Bob King (Cascadia); thanks to Marcello \\ Santian and Andrew Miner for Cascadia data)
}

Geodetic time series contain information about the processes of transient events, strain accumulation on the plate boundary in the time between events, and rotations of the crustal blocks on which the sites sit. Estimating site velocities by linear fits to such data typically averages over the signals. I am inverting the displacement time series (continuous and campaign) to separate out the time-dependent transient (slow-slip and earthquakes) and constantvelocity motions. The linear velocities are then used to estimate block angular velocities and locking on the faults in the time between transients. Eventually this will be done in a single step - the time series will be used to solve directly for the parameters of a physical model that includes the transients, fault coupling and block rotations (hopefully, by the time of the meeting). The slip distribution on the fault of each slow-slip event is represented by Gaussian functions in the along-strike and down-dip dimensions and time ( 7 free parameters each).

Cascadia. I invert the continuous GPS (cGPS) time series (1996 through 2007) of 52 sites for the parameters of 15 slow-slip events and one earthquake (Nisqually) and the 3 velocity components of each site. In addition I use campaign time series from 70 survey GPS (sGPS) sites with more than 5 occupations from 1993-2004

(McCaffrey et al., Geophys. J. Int., 2007). (It is not yet clear whether or not the sGPS adds constraints on the transient sources but at the very least this approach automates correction of sGPS velocities for the transients). Inverting the new velocities for fault locking suggests that locking extends farther landward below the Olympic Peninsula but does not reach the depths of the slow slip events (see figures). Below central Oregon the slow-slip events are poorly constrained due to a paucity of sites

Hikurangi. I invert only the cGPS time series (2002.5 through 2007) as there are no sGPS data spanning this time period. Eight slow-slip events were detected to date. Unlike Cascadia most of these are shallow, between 10 and $20 \mathrm{~km}$ depth where the subduction fault is only $100-150^{\circ} \mathrm{C}$. Using the corrected velocities and the block model of L. Wallace et al. (J. Geophys. Res., 2004), the new inter-event locking distribution shows a much clearer relationship of the transition zone to the slow slip events. The slow-slip appears to follow the geodetically estimated transition zone very well, even as it deepens significantly beneath the southern part of the island. The results suggest that the slow-slip events release strain associated with the very bottom of the transition zone.

Figures. Maps show locking distributions inferred from site velocities (blue arrows) corrected for any transient motions. Red curves are slip contours for SSE ( $50 \mathrm{~mm}$ for NZ, $25 \mathrm{~mm}$ for Cascadia). Time series are red for observed, dark blue for calculated and light blue for residuals. Linear trends representing the inter-event velocity have been removed from each time series.
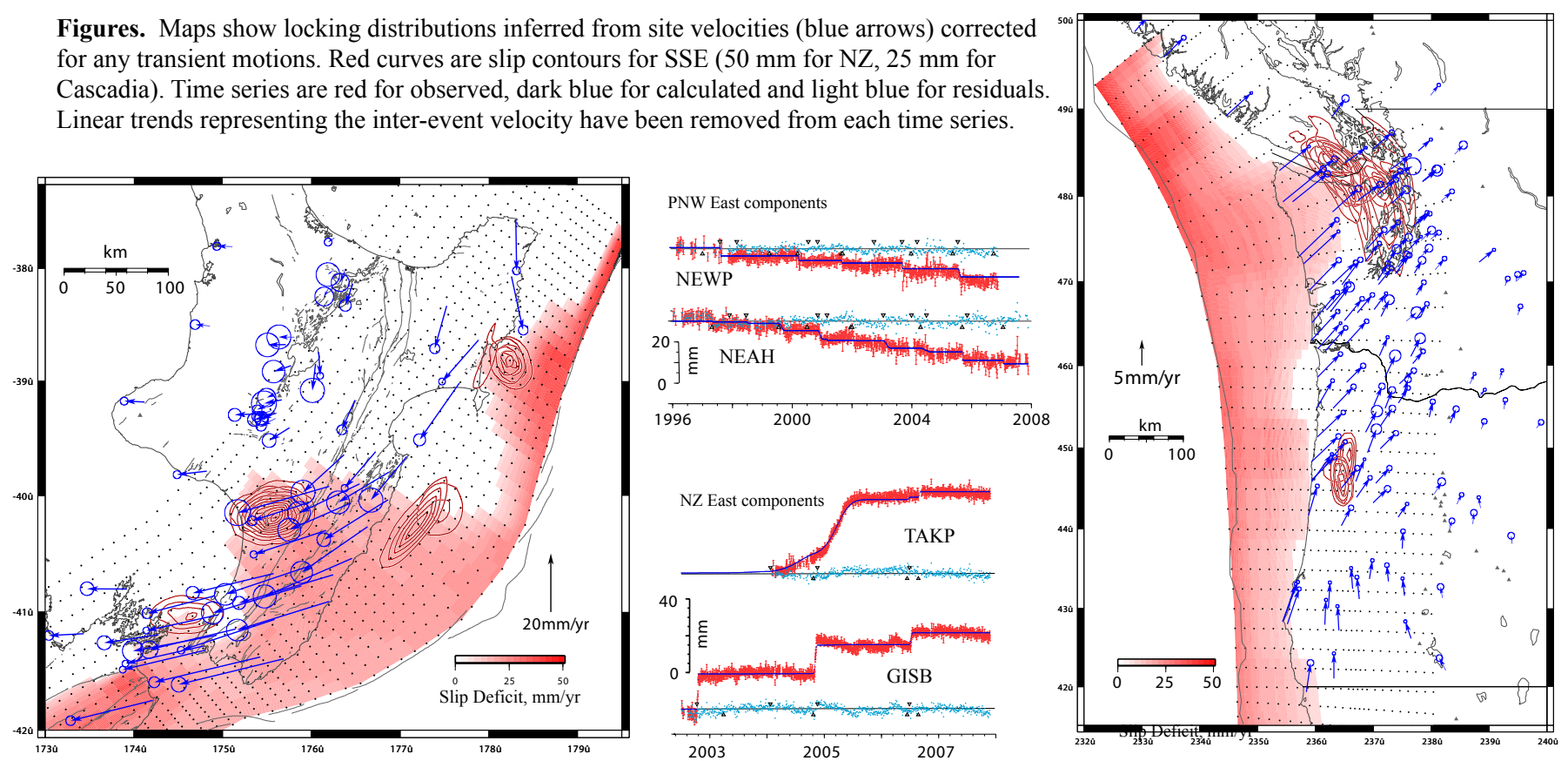
Detecting Slow Slip Events along the Cascadia Subduction Zone Using Plate Boundary Observatory Borehole Strainmeters

Wendy McCausland and Evelyn Roeloffs, U.S. Geological Survey, Vancouver, WA

Slow slip events (SSEs) and subduction tremor have been documented all along the Cascadia subduction zone from Northern Vancouver Island through Northern California. However these phenomena are harder to detect in less instrumented regions (from N. California through Oregon), because their detection relies upon similar observations at several stations. We developed a technique to scan the recently installed Plate Boundary Observatory (PBO) borehole strainmeter data for strain transients, a technique that is most helpful in areas with sparser geodetic and seismic coverage.

The frequency band of SSEs in Cascadia (days to weeks) overlaps with the frequency band of the atmospheric pressure response. This makes the SSE transients difficult to detect in the raw data, even at stations where the transients are most obvious (e.g. B004 and B018). However, the strain induced by SSEs is different than the strain induced by atmospheric pressure changes. The atmospheric pressure response is primarily an areal strain and therefore should be uniform across the individual gauges, i.e. each channel should have the same amplitude and phase. The SSEs produce large shear strains, and therefore will not have the same amplitude and phase on the individual gauges.

Our scanning technique takes advantage of these different responses, whereby the strainmeter gauge data are band passed between 4 and 16 days, and time periods when the gauge data are neither tracking the atmospheric pressure nor one another are investigated as possible tectonic strain events. Next the gauge data are combined into the horizontal strain tensor components. On a given instrument, the areal strain component can be computed using two different gauge combinations, and these two calculations must be equal for a real strain signal. We can distinguish between tectonic strain events and other nontectonic strain variations by characterizing the response of each instrument to strain events like rainfall loading and local pumping. We successfully tested the technique on strainmeters in northern Washington during two previously identified SSEs in September 2005 and January-February 2007.

This poster will show data for several possible tectonic strain events in southern Oregon and Vancouver Island. One example is from the Grant's Pass, OR, strainmeters (B035 and B036), where we detected a tectonic strain transient on both strainmeters during July and early August 2007. This transient has similar amplitude to, but longer duration than those that regularly occur in the $\mathrm{N}$. Washington - S. Vancouver Island region. Further corroborating this observation, during the same time period there is significant tremor activity located near Grants Pass, OR, and GPS data (from the PANGA website:

http://www.geodesy.cwu.edu/) from stations DDSN PTSG and YBHB reveal decreased rates of eastward displacement, similar to previous SSEs in this region. 
Panel on User/Public Needs - Wednesday Afternoon Working Group Panel

By Panelist Vicki S. McConnell, Oregon State Geologist

\section{Slow Slip and Tremor: Does This Physical Process Matter to DOGAMI?}

Most state geologic surveys are responsible for characterizing geologic hazards and in many cases working to develop mitigation actions to reduce the risk of those hazards to the public. The Oregon Department of Geology and Mineral Industries (DOGAMI) performs that function for the state of Oregon. We have a second objective of almost equal importance; to educate the public about geological hazards and risk. We have built into all our geological hazard mitigation programs an outreach and education module to develop informative material and conduct activities for outreach and education. Our primary goals are technical transfer of mitigation and risk reduction tools, promoting basic understanding of geological hazards, and maintaining a library, both real and virtual, of relevant geoscientific information.

So from a practical point of view, basic research into the slow slip and tremor phenomena will primarily remain an academic exercise until their impact on earthquakes or other tectonic processes, if any, are determined. Only then will agencies and organizations tasked with protecting the public be willing to consider integrating the affect of slow slip and tremor into characterization of earthquakes and seismic activity or revising mitigation tactics to include it. To that end of course one of the driving questions regarding slow slip and tremor is "Does the process increase or decrease earthquake hazards?"

In the British Isles studies have shown that $<0.5 \%$ of the general public can read (understand) a geologic map and only 5\% can locate themselves on a grid reference. I do not expect the ratio is much different for North America. Explaining any science can result in misunderstandings and over reactions that can have serious repercussions. However; if we as science organizations do not share our information we will never overcome the barriers to an informed society. While we may not be ready to adjust our overall approach to mitigation of earthquake hazards in response to the affects of slow slip and tremor we recognize an opportunity to include the public in the learning process. We should all develop a program of sharing with the public expected slow slip activity, how the science is maturing, what are the implications - both good and bad, and how are we as a scientific community responding to new information. 
$\underline{36 \text { and counting Cascadia Episodic Tremor and Slip events observed on GPS, seismic, and }}$ strain/tiltmeter arrays

Melbourne, Timothy (CWU),

Several rapidly expanding GPS networks along the greater Cascadia forearc have enabled identification of 36 isolated Episodic Tremor and Slip (ETS) events since 1997, including two in 2007. ETS events are observed throughout the forearc, from northern California to southwestern British Columbia, with station density generally increasing towards the north. Events located in well-instrumented regions can be tracked as they migrate laterally north-south along the plate boundary, but increasing station density has resolved many smaller transients that could not previously be confidently identified. At the specific latitude of the northern Washington State and southwestern British Columbia, the 14-month average recurrence interval still holds true, 5 events after first recognition. Elsewhere, this periodicity is not observed. Along central Vancouver Island, a host of smaller events distinct from the 14-month recurrence occur with an aperiodic fashion. Sporadic smaller events also appear throughout the subduction zone to the south, including within the region known for the 14-month periodicity. In southern Washington State, some of the largest transient displacements are observed, but lack any obvious periodicity in their recurrence. Along central Oregon, an 18-month recurrence is evident, while in northern California (Yreka) the 11-month periodicity previously documented still holds true.

We invert estimated GPS offsets for the largest 14 events using non-negative thrust faulting along a plate interface divided into roughly 500 subfaults. Those events have equivalent moment magnitudes ranging from 6.3 (smallest resolvable with GPS) to 6.8 , and typically $2-3 \mathrm{~cm}$ of slip. The largest spatial extent of the events resolved to date is just under $500 \mathrm{~km}$ along strike, and maximum duration is seven weeks, which lies in marked contrast to other subduction zones. Averaged over many ETS events, the upper limit of transient slip in the vicinity of Seattle, WA lies just west of the heavily urbanized Puget Sound region, suggesting that the lower limit of megathrust seismic rupture may extend much closer to this area than previously thought.

During the time window of 2005-2007.2, a systematic quantification of seismic tremor observed both during and outside of ETS events has demonstrated a very linear relationship between tremor duration and inverted GPS equivalent moment. Moreover, no GPS transients during this time period are observed in the absence of tremor. This suggests that the GPSmeasured transient deformation may be the integrated near-field offsets resulting from many small, discrete seismic slip events (meaning aseismic, transient creep is not needed to explain the GPS signal). This hypothesis is supported from inferences about tremor source characteristics drawn from borehole seismic spectral features and tremor locations determined from surface arrays: the observed quantity, timing and location of tremor largely explains the ETS signal as observed on surface and borehole strain- and tiltmeter arrays. Together, these data suggest that Cascadia, and presumably other subduction zone ETS events, are comprised largely of a form of microseismic clustering unique to subduction zones and may in fact have little aseismic creep associated with them. 
UNAVCO Support Activities for Episodic Tremor and Slip Investigations

Miller, M Meghan, Eriksson, S., Jackson, M.E., and Meertens, C.

UNAVCO, 6350 Nautilus Dr. Boulder CO, 80301

Cascadia's enigmatic Episodic Tremor and Slip (ETS) and similar events now identified in other subduction zones and tectonic regimes around the world are revealed through integrated geophysical observations. UNAVCO provides support for ETS research and education through integrated equipment support, instrument installation, data and product services, and community education and outreach.

In subduction zones, the physical processes and properties that give rise to ETS events are not yet well understood. The Plate Boundary Observatory (PBO) showcases the power of integrated geophysical observations in characterizing these events, and will add to understanding both the physics and the societal impacts of damaging earthquakes. Under the auspices of EarthScope's PBO, UNAVCO has led deployment of instruments with periods of 100's Hz to decades that characterize the secular deformation, episodic displacement and associated tremor as well as the background seismicity and accompanying small strain changes associated with ETS events. These data sets will augment those explored by secondary teachers and scientists during the workshop "Using EarthScope Data in Secondary Classrooms: A Pilot Workshop to Engage Scientists and Teachers in Cascadia Curriculum Development", co-sponsored by UNAVCO, with IRIS, Earthscope, and Teachers on the Leading Edge (ToTLE), in Portland in 2006.

UNAVCO has also supported university-based research at a number of global subduction zones (including Oaxaca, Nicoya Peninsula, Alaska, and New Zealand) with deployments of broadband instrumentation (campaign and permanent GPS, strainmeters, seismometers, tiltmeters), and providing data retrieval, quality control, data services and products to a broad community of researchers, educators and the general public.

PBO is also poised to characterize similar slip events on the San Andreas fault across the frequency spectrum, with long baseline strain meters added to the suite of instruments that UNAVCO supports. Researchers recently showed evidence unusual signals from the San Andreas Fault south of Cholame suggesting tremor signals similar to those seen in Cascadia. The tremor appears to be at much greater depth $(35 \mathrm{~km})$ than the earthquake seismicity along this part of the fault and the cause remains enigmatic. Initial searches for associated deformation did not show any short-term dilatation associated at the times of the tremor indicating that if there is an aseismic transient, it is too weak or protracted to be detected with currently deployed instrumentation. To address this UNAVCO is managing the installation of two long-baseline laser strain meter components and installing a number of deep borehole strainmeters and seismometers near Cholame. The sensitivity of the planned instrumentation is anticipated to be capable of resolving the physical processes responsible for the tremor.

\section{References}

Brudzinski, M R, Arciniega-Ceballos, A, DeMets, C, and Diaz-Molina, O, (2007) Preliminary Evidence for Non-Volcanic Tremor in the Oaxaca Region, Mexico, Eos Trans. AGU, 2007 Joint Assembly, Acapulco Mexico.

Dragert, H., Wang, K., and James, T., 2001, A silent slip event on the deeper Cascadia subduction interface: Science, 292, 1525-1528.

Freymueller, J T and Ohta, Y (2007) Slow slip events at the Alaska Subduction Zone, Eos Trans. AGU, 2007 Joint Assembly, Acapulco Mexico.

Johnston, M. J. S., R. D. Borcherdt, A. Linde, and M. T. Gladwin (2006). Continuous borehole strain and pore pressure in the near field of the 28 September 2004 M 6.0 Parkfield, California, earthquake:
Implications for nucleation, fault response, earthquake prediction, and tremor,Bull. Seismol. Soc. Amer.,96,S56-S72.

Johnson, D.J., Creager, K., Wech, A., Bennett, R., Thompson, S., Blume, F., and Feldl, N (2005), Stalking the September 2005 Cascadia episodic tremor and slip event: results from a dense GPS deployment, Eos Trans. AGU, 86(52), Fall Meet. Suppl., Abstract G51B-0831.

Kostoglodov, V, Larson, K M, Santiago, J A , and Franco, S I (2007) A History of Slow Slip Events in the Mexican Subduction Zone, Eos Trans. AGU, 2007 Joint Assembly, Acapulco Mexico.

Melbourne, T, Santillan, M, Szeliga, W and Miller, M (2007) GPS constraints on 35+ slow slip events 
within the Cascadia subduction zone, 1997-

February, 2007, Eos Trans. AGU, 2007 Joint Assembly, Acapulco Mexico.

Miller, M., Melbourne, T., Johnson, D., and Sumner, W., 2002, Periodic slow earthquakes from the Cascadia subduction zone: Science, 295, 2423

Nadeau, R. M. and D. Dolenc, Nonvolcanic tremors deep beneath the San Andreas Fault, Science, 307(5708), 389, 2005.
Rogers $\mathrm{G}$ and Dragert H, 2003, Episodic tremor and slip on the Cascadia subduction zone: the chatter of silent slip, Science, V. 300, p. 1942-43.

Yoshioka, S., T. Mikumo, V. Kostoglodov, K.M. Larson, A.R. Lowry, and S.K. Singh, Interplate coupling and a recent aseismic slow slip event in the Guerrero seismic gap of the Mexican subduction zone, as deduced from GPS data inversion using a Bayesian information criterion, Phys. Earth Planet. Int., 146,513-530, 2004

Map of the San Andreas Fault (brown) in the Cholame area (intersection of the fault with Highway 46). Black and purple arrows are long-term motions relative to GPS site P539; purple is from PBO, black from SCEC Crustal Motion Map. Green dots are PBO borehole strainmeters, smaller ones those installed by the USGS. Dotted line shows area of deep seismic tremor found by Nadeau and Dolenc (2005). Yellow star is the epicenter of the 2004 Parkfield earthquake; the 1966 epicenter is to the NW of the area shown here. Seismicity is from 1970 to just before the 2004 event. Map (D. Agnew, per. comm. 2008).

\section{Cholame: Crustal Motion, Seismicity}

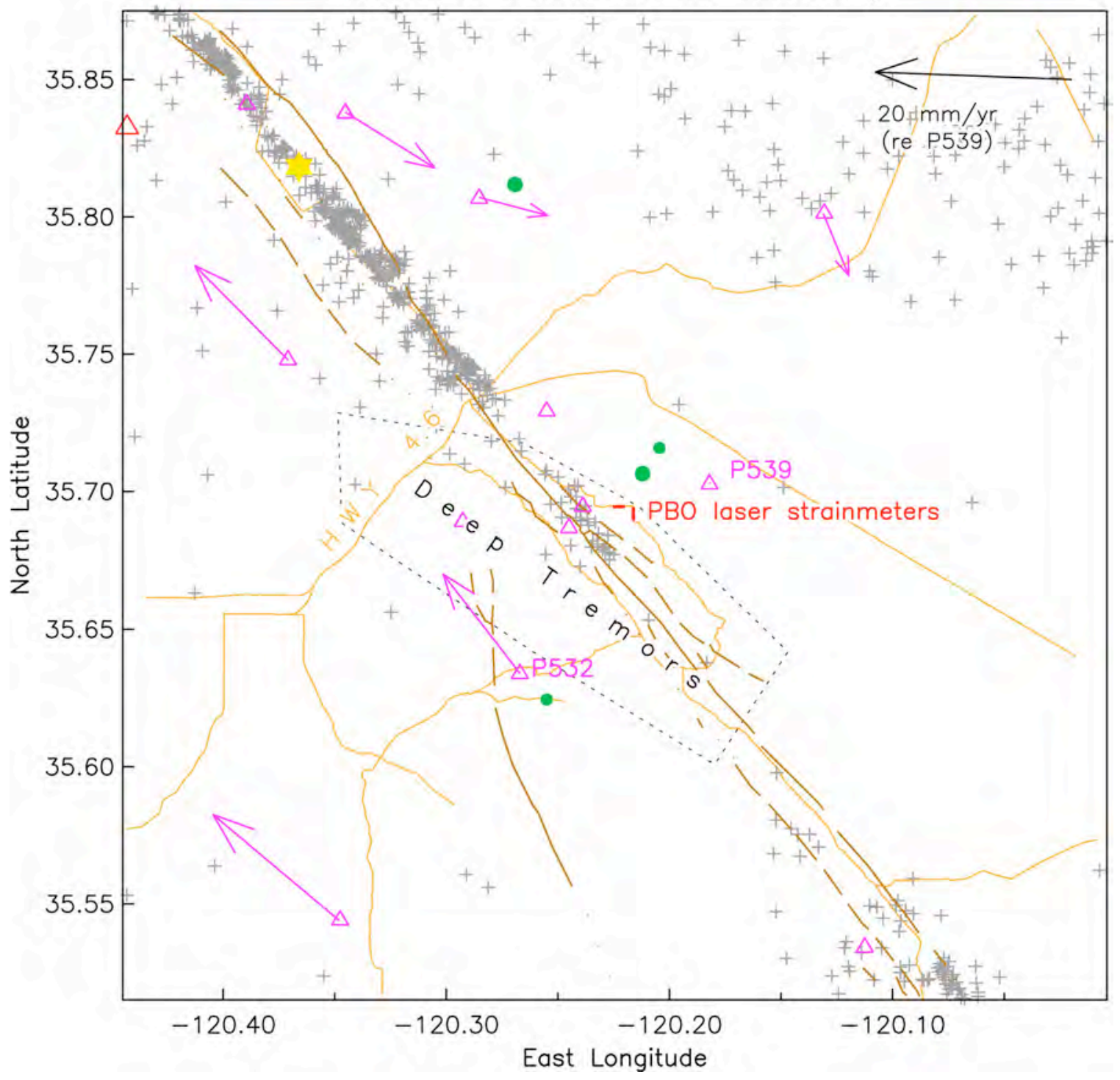




\title{
Slow slip events at Kilauea: not solely a subduction zone phenomenon
}

\author{
E. Desmarais Montgomery-Brown, P. Segall, A. Miklius, M. Poland, and P. Cervelli
}

Kilauea volcano's south flank decollement structure has hosted at least six slow earthquakes since 1998. The decollement shares some similarities with subduction zones, which are often thought of as the type locale of slow slip events, however there are important differences. Kilauea's decollement is shallowly dipping and is assumed to contain a transition zone between the stably sliding flank and the locked zone that ruptures in large earthquakes, like subduction zones, but is much shallower, $<10 \mathrm{~km}$, and therefore at a much lower pressure.

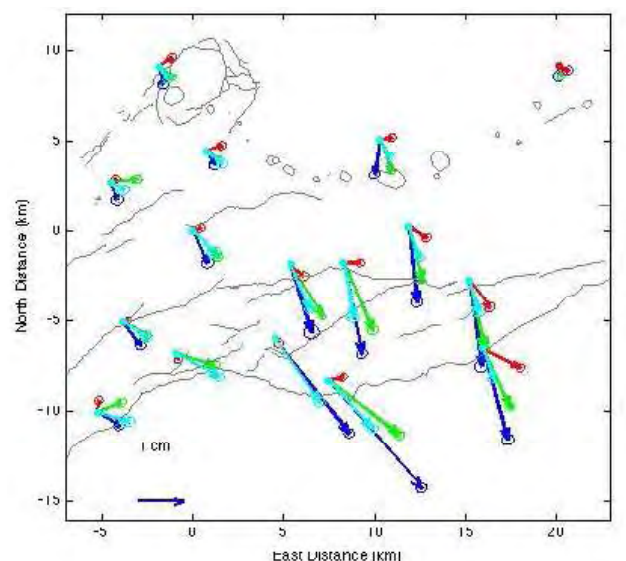

Figure 1. Displacements from four Kilauea slow slip events.
Slow events on Kilauea have tended to occur faster than most subduction zone events, accumulating $\sim 0.2 \mathrm{~m}$ of slip in only about 2 days. Kilauea events also have not coincided with recorded non-volcanic tremor, although it is unclear whether tremor is not occurring, or if it has simply not been observed given the existing network.

Spatial displacement patterns for all of Kilauea's slow slip events are similar, with maximum displacements of $\sim 2 \mathrm{~cm}$ at the south central coastal sites, indicating a repeating source. Some events do appear to have larger displacements in the eastern part of the network (e.g. July 2003, red vectors in Fig. 1), though, suggesting that some events may not follow the trend. It has been postulated that some subset of the Kilauea slow earthquakes may be periodic (Brooks et al., 2006, EPSL), but including all known events quickly leads to a breakdown in the periodicity. Sorting of events based on spatial displacement pattern increases the fit to a periodic model of one subset of events, but does not fit all events.

Inversion of slow slip displacements for fault parameters, assuming a homogeneous elastic half-space, favor shallow fault depths $(<5 \mathrm{~km})$. The occurrence of triggered microseismicity accompanying the slow-slip events, that must occur in zones of increased Coulomb stress change, however, suggests a deeper fault source between $6.5-8.5 \mathrm{~km}$ (Segall et al., 2006, Nature). This is consistent with optimizations for fault parameters including the effects of topography and a layered elastic structure. Distributed slip models of the largest events favor slip south of the surface trace of the Hilina Pali normal faults, and extending a few kilometers offshore. 
EVIDENCE FOR LATERALLY DISTRIBUTED TREMOR ACTIVITY ACROSS THE SAN ANDREAS FAULT ZONE AT CHOLAME CA.

Nadeau, R.M. and A. GUILHEM, U.C., Berkeley Seismological Laboratory

Understanding the relationship of nonvolcanic tremor (NVT) activity to the fault zones on which they occur is crucial for a clearer picture of the conditions and mechanisms responsible for their generation. Comparisons between the spatial and temporal behavior of ambient NVTs on convergent and transform plate boundaries may also provide additional constraints on the NVT generation problem.

Obtaining a clear picture of the spatial relationship of NVTs with the core of fault zones (in particular inclined/subducting faults) has been difficult due to depth control limitations and to demanding computational requirements (Kao et al., 2005). Computational demands also make assessment of the longer-term evolution of NVT activity at high resolution difficult (Shelly et al., 2006).

Vertically oriented NVT bearing fault zones (e.g., the San Andreas Fault, SAF) may provide a better opportunity for understanding the fault-lateral (i.e., across-fault) and temporal behavior of NVT activity about the fault core, since since depth control issues are less critical in with this fault orientation and less computationally expensive location techniques can be applied.

In this presentation we report on the spatial and temporal relationships of several hundred NVT episodes detected along the SAF near Cholame and the Monarch Peak areas of California during 2006 and 2007 (inclusive). Data from 5 different seismic networks (NC,BP,TA,BK,CI, 74 stations) are used in the analysis, and locations of the NVTs are determined using a highly automated envelope cross-correlation approach similar to Obara, 2002, with particular attention paid to the identification and exclusion of inconsistent station-pair alignments. Uncertainties in the relative positions of the NVTs are estimated using a bootstrap approach (Shearer, 1997) and yield estimates of (+/- 3.5, 3.0, and $5.0 \mathrm{~km}$ in the across- and along-fault directions and in depth, resp.)

Preliminary results indicate that the Cholame NVTs occurring during the 20062007 period continue to occur at subseismogenic depths (generally between 15 and $30 \mathrm{~km})$, that they are distributed over an $15 \mathrm{~km}$ wide zone in the fault-normal direction, and that they are concentrated in at least 3 and possibly as many as 5 subregions and with significant differences in the evolutionary pattern of NVT activity among subregions. Also apparent from the bootstrap analysis are clear indications that the non-uniform station coverage in the Cholame area places significant limits on the resolvability of the spatial distribution of the NVTs in this region. 


\section{A new hypocenter determination method using the summation of waveform cross-correlation}

Kazuaki Ohta and Satoshi Ide (Dept. Earth \& Planet. Physics, Univ. of Tokyo)

Deep low frequency tremor is a swarm activity of low-frequency earthquakes (LFEs) at least in the western Shikoku, Japan [Shelly et al., 2007]. LFEs are considered as shear slip on the plate interface because their focal mechanism has a low-angle thrust fault plane [Ide et al., 2007] and because precisely determined hypocenters are located on the plate interface [Shelly et al., 2006]. However, it is not obvious whether LFEs in other regions have the same characteristics. For example, in the Tokai region and the Kii Peninsula the hypocentral depths of LFEs determined by Japan Meteorological Agency are widely distributed from 20 to $50 \mathrm{~km}$. Precise hypocenters of LFEs are essential for discussion on regional diversity of low frequency tremor.

The low signal-to-noise $(\mathrm{S} / \mathrm{N})$ ratio of $\mathrm{LFE}$ records can be a source of larger estimated error in the hypocenter determination. Although waveform cross-correlation is a useful tool for precise hypocenter determination, it is not reliable in the case of the low $\mathrm{S} / \mathrm{N}$ ratio because the value of cross-correlation is generally small. However, Shelly et al. [2007] showed that the summation of waveform cross-correlation for many stations can enhance event detectability. Similarly, using the summation of waveform cross-correlation, we develop a new hypocenter determination method that is less sensitive to noises. We apply this method to LFEs in the western Shikoku, the Tokai region and the Kii Peninsula.

The data are 3-component velocity records from the NIED Hi-net, bandpass filtered between $2-8 \mathrm{~Hz}$. We first determine the relative hypocenter location between a pair of LFEs in a event list. Assuming a layered structure, we calculate theoretical differential travel times of body waves relative to the arrival times from the one event, After shifting the records of the other event using these differential travel times, we calculate the summation of the waveform cross-correlation coefficient between two events for all stations. The relative location is determined to maximize this summation by a grid search. For some pairs the maximum takes a statistically significant value that is not explained by a Gaussian distribution. Then we invert the relative locations to determine the hypocenter distribution using least square which is weighted according to a value of sums of waveform cross-correlation. 


\section{What can thermal-petrologic models and field studies of subduction zones tell us about episodic tremor and slip?}

Simon Peacock, Dept. of Earth and Ocean Sciences, University of British Columbia

Episodic tremor and slip (ETS) detected in the Cascadia and Nankai subduction zones occurs at depths that can not be directly observed. The results of thermalpetrologic modeling, together with studies of exposed subduction-zone metamorphic rocks, can provide insight into the conditions under which ETS occurs.

The Nankai and Cascadia subduction zones are relatively warm compared to most subduction zones due to the young (warm) incoming lithosphere and modest convergence rates. Temperature-dependent dehydration reactions in the subducting plate are predicted to occur at relatively shallow depths. In the Nankai subduction zone, low-frequency earthquakes occur on the plate interface at depths of 30-35 km and are temporally linked to non-volcanic tremor, [Shelly et al., 2006, Nature]. Thermal models predict plateinterface temperatures of $\sim 400{ }^{\circ} \mathrm{C}$ at these depths, with temperatures in the subducting oceanic crust increasing to $\sim 500{ }^{\circ} \mathrm{C}$. Slightly warmer thermal conditions are predicted for the Cascadia subduction zone, but here tremor appears to occur over a broad depth range extending from the warm subducting plate upward well into the forearc crust [Kao et al., 2005, Nature] where temperatures are lower.

Many features of subduction zones are directly linked to the subduction of $\mathrm{H}_{2} \mathrm{O}$. Indeed, subduction on Earth likely only occurs because $\mathrm{H}_{2} \mathrm{O}$ and hydrous minerals weaken the plate interface. Water is subducted both as pore $\mathrm{H}_{2} \mathrm{O}$ in sediment and crustal porosity and as chemically bound $\mathrm{H}_{2} \mathrm{O}$ in hydrous minerals in sediments, oceanic crust, and oceanic mantle. During subduction, $\mathrm{H}_{2} \mathrm{O}$ is expelled from the subducting plate as porosity collapses and hydrous minerals breakdown via metamorphic dehydration reactions. In the Nankai and Cascadia subduction zones, at depths of 30-35 km, the subducting mafic crust passes through the greenschist to blueschist and greenschist to amphibolite metamorphic facies transitions, where mineral dehydration reactions are complex. In contrast, the overlying forearc crust is stationary and therefore is not expected to undergo metamorphic dehydration reactions. As several authors have proposed, the fluids released by dehydration reactions in the subducting plate could play a role in the triggering or enabling ETS.

Subduction zones, in general, and subduction-zone forearcs in particular, are complex lithologically and structurally (and petrologically and hydrogeologically and ...). One of the challenges to understanding subduction-zone ETS is the wide range in possible rock types in which ETS may be occurring. Can ETS occur in any rock type under appropriate conditions (e.g., brittle-ductile transition $+/-\mathrm{H}_{2} \mathrm{O}$-fluid)? Or might ETS only occur in specific materials such as weak serpentinite? Field studies of ancient subduction zones, such as the Franciscan Complex, demonstrate that the rock types and structures at subduction-zone ETS depths can be exceedingly complex and include melange zones, broken formations, sedimentary diapirs, and metamorphic (hydrothermal) vein systems. 


\title{
Abstract for "Aseismic Slip, Non-Volcanic Tremor, and Earthquakes" Workshop Dunsmuir Lodge, Sidney, British Columbia - Feb. 25-28, 2008
}

\author{
Non-volcanic tremors near Parkfield, CA triggered by teleseismic earthquakes \\ Zhigang Peng (GT), John E. Vidale (UW), Kenneth C. Creager (UW), Justin L. Rubinstein (UW), \\ Joan Gomberg (USGS), Paul Bodin (UW)
}

Non-volcanic tremor (NVT) is a weak, long-duration seismic signal with no clear body wave arrivals. It has been observed along the circum-Pacific subduction zones [Obara, 2002; Rogers and Dragert, 2003; Kao et al., 2005; Schwartz and Rokosky, 2007] and the San Andreas fault (SAF) system in California [Nadeau and Dolenc, 2005]. NVT is often associated with episodic slow-slip events [Rogers and Dragert, 2003], and can be triggered by surface waves of teleseismic events [Miyazawa and Mori, 2005; 2006; Miyazawa and Brodsky, 2008; Rubinstein et al., 2007; Gomberg et al., 2008]. However, the underlying mechanisms of triggered tremor generation remain unclear. Some studies propose that fluid flow due to changes in dilatational stresses associated with the Rayleigh waves is responsible for triggering tremors [Miyazawa and Mori, 2005; 2006], while others suggest that perturbation of Coulomb failure stresses on the fault interface instantaneously trigger NVT [Miyazawa and Brodsky, 2008; Rubinstein et al., 2007].

Here we show clear evidence of NVT around the Parkfield section of the SAF triggered by 2002 Mw7.8 Denali earthquake. We identify tremors as bursts of non-impulsive extend-duration seismic signals in the frequency range of $2-8 \mathrm{~Hz}$ that are coherent among many stations and are modulated by the surface waves. The tremor emanates from at least two source regions deep within the SAF. The first source region is $\sim 50 \mathrm{~km} \mathrm{NW}$ of the SAFOD in the creeping section of the SAF, and the second region is $\sim 45 \mathrm{~km}$ SE of the SAFOD near Cholame, close to the location where the ambient NVT has been found previously [Nadeau and Dolenc, 2005]. NVT is excited when the Love waves promote right-lateral shear motion along the SAF strike, indicating a simple frictional response to the driving stress. The NVT originates at $10-25 \mathrm{~km}$ depth around the lower edge of the seismogenic zone, suggesting a complex transition from locking to steady deformation at greater depths.

In addition, we conduct a systematic survey of NVT at Parkfield during and immediately after the arrival of seismic waves generated by 56 teleseismic events with $\mathrm{M} \geq 7.5$ since 1996 . We qualitatively judge the clarity of tremor observations and find 10 earthquakes triggered clear tremors around Parkfield. Many tremors are initiated and modulated by the Love waves. However, in several cases tremors continue after the passage of the surface waves, and the tremor amplitude does not appear to be solely controlled by the surface wave amplitude. These observations indicate a mixture of driven, instantaneous, perhaps Coulomb-friction response with an added component of self-sustaining activity more suggestive of fluid flow. The tremortriggering threshold at Parkfield is about $2.5 \mathrm{KPa}$, smaller than the $30 \mathrm{KPa}$ threshold for regular earthquakes [Gomberg and Johnson, 2005]. The relatively low-triggering threshold suggests that the effective stress at the tremor source region is very low, most likely due to near-lithostatic fluid pressure [Liu and Rice, 2007]. This is compatible with recent observations of tidal modulations of tremors [Shelly et al., 2007; Rubinstein et al., 2008], indicating that tremors are more sensitive to transient stress perturbations than regular earthquakes. Since tremors appear to occur near the transition from the locked to the freely creeping portion of an active fault, which is a universal feature for many crustal faults [Scholz, 1998], we hypothesize that tremors and the associated slow-slip events may exist at a wide range of active tectonic environments. 


\title{
Slow Slip Event Under the Nicoya Peninsula, Costa Rica as Measured by a Continuous GPS and Seismic Network
}

\author{
Kimberly C. Psencik ${ }^{1}$, Timothy H. Dixon ${ }^{1}$, Susan Schwartz ${ }^{2}$, Marino Protti ${ }^{3}$, Victor Gonzalez ${ }^{3}$ \\ ${ }^{1}$ University of Miami/RSMAS 4600 Rickenbacker Causeway, Miami FL 33132 \\ ${ }^{2}$ University of California Santa Cruz \\ ${ }^{3}$ OVSICORI, Costa Rica
}

The close proximity of the Nicoya Peninsula land mass to the Cocos-Caribbean subduction zone plate boundary makes it a prime location to use GPS to study such plate boundary processes as locking zone dynamics and episodic tremor and slip. Nicoya Peninsula currently has an operating network of 12 continuous GPS (CGPS) and 10 seismic stations designed to identify and characterize the pattern of episodic tremor and slip (ETS) events along the seismogenic zone under Costa Rica's Pacific Margin. The CGPS stations have varying degrees of equipment and communication. Of the 12 sites, four are equipped with SIM cards and modems for direct download capabilities, one of which is connected to a router for direct internet access. This site, LMNL, located in Limonal, is being monitored on the PBO network by UNAVCO with all of the quality and systems checks that this implies. All sites with NetRS receivers are currently partitioned to record both $5 \mathrm{~Hz}$ and 30 second position data. The advantage to recording at a $5 \mathrm{~Hz}$ interval is that the receivers may be used to record long period dynamic events during large earthquakes along the Cocos-Caribbean plate boundary. The occurrence of slow slip events has been previously postulated in this region based on correlated fluid flow and seismic tremor events recorded near the margin wedge in 2000 and from sparse GPS observations in 2003. Paucity of data prevented details of these events from being resolved. In May 2007 a slow slip event was recorded on our densified GPS network and accompanied by seismic tremor. We will present the preliminary GPS time series and correlated seismic tremor for both likely slow slip events in September 2003 and May 2007. Once the displacement patterns have been characterized, we intend to model both the transient motion on the fault plane as well as the locking pattern before and after the events in an effort to determine if the occurrence of an ETS event has any impact on the nature and distribution of the locking pattern. Future plans include installation of two more sites, one in the interior of the peninsula to further optimize the network for the recording and characterization of ETS and another on the stable Caribbean plate to use as a baseline reference station. 


\section{Public Policy Implications of Episodic Tremor and Slip Michael Reichle California Geological Survey}

On October 30,2007, a magnitude 5.6 earthquake occurred along the Calaveras fault in California, near that fault's junction with the Hayward fault. Both faults are known active faults, capable of producing large, damaging earthquakes. The Hayward fault produces Magnitude 6 to 7 earthquakes every 150 years or so, the last being in 1868 .

On the evening of the earthquake, the California Earthquake Prediction Evaluation Council (CEPEC) met to discuss the possible implications of the earthquake. There was concern that the event on the Calaveras fault could trigger a larger earthquake on the Hayward fault. In its advisory statement to the Governor's Office of Emergency Services (OES), CEPEC noted that the earthquakes "significantly increased the probability above the normal level for a damaging earthquake along the Calaveras and/or Hayward faults within the next several days. However, the overall likelihood of such an event is still low." CEPEC recommended no specific actions to OES except that residents review their earthquake preparedness and family communication plans. Generally, events such as these, widely felt but inflicting little damage, can be used as reminders that people who live in California should be prepared for a damaging earthquake to occur anytime.

The situation for Episodic Tremor and Slip (ETS) is both similar and different. It is similar in that during an ETS episode, the probability gain for a large earthquake is large, perhaps a factor of 10 or so (Geological Survey of Canada), but the probability itself is still low, at least for a major megathrust event. But the situations are also different. There is currently (at least as of the May 18 meeting of the National Earthquake Prediction Evaluation Council) no evidence worldwide that it is more likely for an earthquake to occur during an ETS episode than during an inter-episode time. ETS has been occurring regularly for at least the past 25 years, and probably much longer, along the Cascadia subduction zone but has not been associated with an increase in seismic activity. This makes formulation of a reasonable public policy response difficult. Additionally, the ETS episodes are not noticed by the general public. Therefore, they do not offer the same opportunity for public education that magnitude 4 and 5 earthquakes do.

As research worldwide on Episodic Slip and Tremor continues and matures, models can be developed that better quantify the hazard during the episodes. These will naturally lead to the development of appropriate public policy responses. 


\title{
Studies on the Physical Origin of Aseismic Deformation Transients
}

\author{
Yajing Liu (Princeton) and James R. Rice (Harvard)
}

Rate and state friction, when applied to a model of a shallow subduction fault, loaded by a steady plate slip rate far down-dip along the thrust interface, can naturally produce aseismic transients for certain effective normal stress $(\bar{\sigma} \equiv \sigma-p)$ variations with depth. Velocity-weakening to strengthening stability transitional properties are suggested to be an ingredient allowing transients near the downdip end of the seismogenic zone [Liu and Rice, JGR, 2005, 2007]. When fluid pore pressure is near-lithostatic around that transition, the system exhibits sustained short-period (several months to a few years as observed) aseismic oscillations, with laboratory friction parameters and their temperature (hence depth) variations [Liu and Rice, 2007]. Evidence that such fluid pressure conditions may actually be present is independently provided by the occurrence of nonvolcanic tremors as apparent responses to extremely small $(<0.01 \mathrm{MPa})$ stress changes, and by petrological constraints on the expected regions of metamorphic dehydration in shallow-dipping subduction zones where short-period transients have been detected. Dimensional analysis and numerical studies show that the transient fault response depends primarily on a parameter $W / h^{*}$, where $W$ is the distance over which the high pore pressure zone extends up-dip from the stability transition, and $h^{*}$ is the stable patch size for steady sliding. Scaling relation between the recurrence interval of transients and the effective normal stress has been derived from extensive simulations in which most of the up-dip seismogenic zone is effectively locked, and suggests a northern Cascadia typical interval of 14 months at $\bar{\sigma} \sim 2$ to $3 \mathrm{MPa}$. When the seismogenic zone is allowed to slip at a much higher $\bar{\sigma}$, the model can simulate megathrust earthquake cycles filled with spontaneous short-period aseismic transients with slip rates and recurrence intervals similar to those observed events. At conditions that spontaneous occurrence is not favored, transient sequences can also be triggered by a modest interseismic stress perturbation on the thrust fault, due to nearby earthquakes or pore pressure fluctuations during episodes of metamorphic fluid release. The spatial-temporal correlation between slow slip events and seismicity [Liu, Rice and Larson, EPSL 2007] in Guerrero, Mexico, may be an example of such interaction. We also found cases in which transients can spontaneously occur during some earthquake cycles, but not in others, in an unlocked seismogenic zone model, suggesting that initial conditions may sometimes also be important in the cause of transients. Related to that, we have identified cases in which small perturbations during otherwise transient-free interseismic intervals can trigger sequential transients.

In previous models with Cascadia-like geometry and geothermal profile, the down-dip extent of the aseismically slipping zone and the resulting surface deformation associated with the spontaneous transients are generally smaller than that observed during episodes of slow slip events in northern Cascadia. We have thus studied several models that possibly favor deeper friction, such as inclusion of dilatancy, which becomes an effective stabilizing factor at high fluid pressure, friction parameters with smaller $a-b$ at high temperatures based on dry granite and gabbro gouges, and inclusion of a second state variable in the friction law. Preliminary results show that application of the dry granite type of rheology (with one state variable) does give a better fit to the geodetic measurements during the Guerrero, Mexico, transients [Liu, DeDontney and Rice, EOS 2007]. 
The Tokai Earthquake Warning Plan: An Example of Communicating Hazards Implications of Aseismic Slip Events to the Public

Evelyn Roeloffs

The Plate Boundary Observatory, part of the National Science Foundation-funded Earthscope Initiative, has instrumented the Pacific Northwest with extensive networks of continuous GPS stations and borehole strainmeters, capable of detecting and characterizing slow slip events related to Cascadia subduction. There is the publicly expressed scientific viewpoint that, during slow slip events, the probability of a dangerous Cascadia megathrust earthquake may be elevated. Taken together, these two realities challenge the seismological community to define the hazards implications of the slow slip events, and impose a responsibility upon the U.S. Geological Survey (USGS) to monitor the geodetic data.

For some ideas about how to meet these two challenges, we can look to the Prediction Scheme for the Tokai Earthquake in Japan, which has been in place for over 25 years. The Tokai segment of the Nankai-Suruga trough is now unruptured since a M8.4 event in 1854, and is considered a dangerous seismic gap. Evidence of anomalous deformation prior to nearby earthquakes in 1944 and 1946 has motivated the government of Japan to intensively monitor aseismic deformation, with the goal of issuing a warning prior to the next great Tokai earthquake (EERI Committee on the Anticipated Tokai Earthquake, 1984). The Tokai scheme has some features that could be adapted for Cascadia.

To translate the geodetic information into a form that can be utilized for a public warning, simplified schemes have been developed to flag anomalies in the geodetic data that are consistent with the occurrence of preseismic slip in the anticipated Tokai rupture zone. Anomalous data can prompt an earthquake Report, Advisory, or Warning. If the data are ambiguous, which is the usual situation, the Coordinating Committee for Earthquake Prediction is convened rapidly. This Committee evaluates the data and decides on the appropriate level of concern, which is then passed to the government for pre-arranged action. Pre-agreed criteria on what type of deformation warrants Advisories or Warnings are a key feature of the Tokai scheme. For Cascadia, where aseismic slip events are ubiquitous, unusually large or rapid amounts of slip, or slip that impinges on the seismogenic zone, might be considered more significant.

Although the Tokai scheme employs automated anomaly detection schemes, these do not substitute for review and evaluation of the data by scientists. As in Cascadia, the geodetic instrumentation and data analysis for the Tokai Prediction Scheme are operated by a number of universities and government agencies. Biannually, at least one representative of each institution submits a report (posted online at http://cais.gsi.go.jp/KAIHOU/index.html) and attends a data review in Tokyo. Meetings of this type could be held for Cascadia, and would facilitate collaborative interpretation of the large amount of data that is now being acquired. 
25 YEARS OF EPISODIC TREMOR AND SLIP ON SOUTHERN VANCOUVER ISLAND GOING BACK IN TIME

GARRY C. ROGERS and HERB DRAGERT. Geological Survey of Canada, Pacific Geoscience Centre, P.O. Box 6000. Sidney, BC V8L 4B2 Canada

Examination of continuous digital seismic data and continuous GPS data since 1996 for southern Vancouver Island has revealed repeated episodes of deep plate slip and seismic tremors, called Episodic Tremor and Slip (ETS). For all tremor events exceeding a week in duration there is a one to one correlation with GPS observed slip events. However, about one third of the tremor occurs in short lived tremor events of less than a week which have no detectable GPS signature. For the southern Vancouver Island region the ETS episodes last anywhere from a week to a month and have a regular recurrence interval of about 14 months. Prior to mid 1996 there is no continuous digital seismic data but a continuous seismic record is archived on a number of one day paper helicorder records. There are some continuous GPS observations before 1996 and slip events have been identified in 1994 and 1995. By noting the character of ETS tremor on helicorder records these signatures can be used as a proxy for ETS events, making it possible to go back in time to identify earlier events. They appear as recognizable bands of noise across the helicorder record lasting from minutes to hours. While the ETS tremor signal signature can be recognized on individual seismic stations, it can sometimes be masked or confused with cultural noise or wind noise. However, if there are other stations within about $100 \mathrm{~km}$, the simultaneous recording makes it possible to unambiguously identify ETS tremor episodes and to identify the direction of propagation along strike. By exhaustively examining pre-1996 helicorder seismograms for ETS events it has been possible to back to 1982 when the seismic network on southern Vancouver Island was expanded to approximately the present network geometry. Thus the record of ETS occurrences has been extended from 10 years to 25 years on southern Vancouver Island. The average repeat time for ETS events over 25 years is also about 14 months. 


\section{Dilatancy Stabilization of Frictional Sliding as a Mechanism for Slow Slip Events}

P. Segall (Stanford), A. Rubin (Princeton), J. R. Rice (Harvard)

Slow slip events and associated non-volcanic tremor have been discovered in a number of tectonic settings, yet the processes giving rise to these phenomena are as yet not understood. One proposal is that friction changes from rate weakening behavior at low slip speeds to rate-strengthening at higher slip speeds, as has been observed in halite. This mechanism does not appear to be supported by lab data on silicates, however there is a prominent lack of data for mafic rocks under appropriate pressure and temperature conditions.

Transient slip in subduction zones appears to occur between the locked megathrust and the steadily creeping fault below, suggesting that slow slip occurs in regions near frictionally neutral stability. However, the width of the transiently slipping zone $W$ must be large enough to allow non-steady slip ( $W>h^{*}$, where $h^{*}$ is the critical nucleation dimension) but not so large that the rupture becomes dynamic. The size range for which transient, quasi-static slip occurs is small, particularly for the slip-law form of rate-state friction, which is favored by velocity stepping experiments. At sufficiently low effective normal stresses (high pore pressures), $h^{*}$ could be large enough to explain geodetic observations.

A further possibility is that rate-state friction nucleates slip under drained conditions but that as slip accelerates deformation becomes effectively undrained, and dilatancy induced pore-pressure reductions quench the instability. We have studied this process assuming 2D elasticity, rate-state friction and a highly simplified dilatancy law [Segall-Rice, 1995, JGR]. Porepressure fluctuations are governed either by simplified, isothermal membrane diffusion: $d p / d t=\left(p^{\infty}-p\right) / t_{f}+(1 / \beta) d \phi / d t$, where $p$ and $p^{\infty}$ are fault and remote pore-pressure, $t_{f}$ a characteristic diffusion time, $\beta$ pore and fluid compressibility and $\phi$ fault zone porosity, or by one-dimensional (fault normal) diffusion into the surrounding medium computed by finite difference.

For the membrane diffusion model, dimensional analysis shows that dilatant strengthening scales with $E \equiv f_{0} \epsilon / \beta b\left(\sigma-p^{\infty}\right)$, where $f_{0}$ is nominal friction and $b$ the rate-state parameter. Linearized stability analysis [SegallRice, 1995, JGR] suggests that $E=1-a / b$ defines a boundary between slow and fast slip. Indeed, numerical simulations with $E<1-a / b$ accelerate to radiation damping limits for sufficiently large $W / h^{*}$, whereas for $E>1-a / b$ the maximum slip-speed is well below inertial for a very wide range of $W / h^{*}$. 
This suggests that stable slip is favored by low effective stress, consistent with some seismic observations. It may be that what ultimately controls whether slip is fast or slow depends on whether dilatancy limits maximum slip-speeds to values below where thermal pressurization rapidly degrades fault strength.

The physical mechanism for tremor is far from clear, however spatial variations in permeability, due for example to fractures intersecting the principal slip surface, could play an important role. 2D simulations show that slow slip accelerates in regions that drain faster than the surrounding fault. Seismic radiation will result if slip rates become fast enough for thermal pressurization to become significant.

An important societal rationale for studying slow slip is that stress transfer to the locked mega-thrust could trigger a damaging earthquake. We note in this regard that slow slip events on Kilauea volcano, the Boso Peninsula Japan, and the north island of New Zealand are associated with microseismicity. Further study of these localities could lead to a better understanding of triggered earthquakes and what controls their ultimate size. 


\section{A new look at episodic slip through precise tremor locations in southwest Japan: "fast" sub-events and tidal triggering}

David R. Shelly (UC-Berkeley), Gregory C. Beroza (Stanford University), and Satoshi Ide (University of Tokyo)

Transient slow slip events are increasingly being recognized as important components of strain release on faults and may substantially impact the earthquake cycle. Surface-based geodetic instruments provide estimates of the overall slip distribution in larger transients but are unable to capture the detailed evolution of such slip, either in time or space. Accompanying some of these slip transients is a relatively weak, extended duration seismic signal, known as nonvolcanic tremor, which has recently been shown to be generated by a sequence of shear failures occurring as part of the slip event. By precisely locating the tremor, we can track some features of slip evolution with unprecedented resolution. Here, we analyze two weeklong episodes of tremor and slow slip in western Shikoku, Japan. We find that these slip transients do not evolve in a smooth and steady fashion but contain numerous sub-events of smaller size and shorter duration. In addition to along-strike migration rates of $\sim 10 \mathrm{~km} /$ day observed previously, much faster migration also occurs, usually in the slab dip direction, at rates of $25-150 \mathrm{~km} /$ hour over distances of up to $20 \mathrm{~km}$. We observe such migration episodes in both the up-dip and down-dip directions. These episodes may be most common on certain portions of the plate boundary that generate strong tremor in intermittent bursts. The surrounding regions of the fault may slip more continuously, driving these stronger patches to repeated failures. Tremor activity has a strong tidal periodicity, possibly reflecting the modulation of slow slip velocity by tidal stresses. This suggests that the expected high confining pressures may be mitigated by high pore fluid pressures in the tremor source region, making the very small tidal stress perturbations relatively more important. 


\title{
Low angle thrust earthquakes in the "locked zone" beneath the central Cascadia continental margin
}

\author{
Anne M. Tréhu, Jochen Braunmiller, John L. Nabelek, Mark Williams \\ College of Oceanic and Atmospheric Science, Oregon State University, Corvallis OR 97331 \\ trehu@coas.oregonstate.edu, 541-737-2655
}

In the summer of 2004, two clusters of "repeating" earthquakes occurred beneath the continental shelf of the central Cascadia subduction zone near $44.5 \mathrm{~N}, 124.5 \mathrm{~W}$ where the subduction megathrust is thought to be locked or transitional (Fig. 1A). The largest event in each cluster had moment magnitude $\mathrm{M}=4.8$-4.9. Seismicity has continued since with small $(\mathrm{M}<3)$ earthquakes occurring in each cluster on August 23-25, 2007 (Fig 2). Moment tensor analysis for the main shock in each cluster indicates thrusting on a $6-15^{\circ}$ eastward dipping fault plane (Fig. 3). These earthquakes are occurring on a transect along which crustal structure is well known from active source seismic experiments, and raytracing through this crustal model to match observed relative arrival times of secondary phases places the mainshocks within $1 \mathrm{~km}$ of the plate boundary (Fig 1B). This segment of the forearc also displays several anomalous characteristics including: a subducted ridge on the downgoing plate; a "bright spot" on the plate boundary at a depth of $\sim 15-20 \mathrm{~km}$; a transition in plate coupling indicated by inversion of GPS data; geologic indications of active folding in the upper plate; and anomalous deformation in the adjacent oceanic plate. We have recently deployed the Central Oregon Locked Zone Array (COLZA), which comprises 15 ocean bottom seismometers (3 broadband, 12 short period) and 4 (soon to be 6) EarthScope USArray Flexible Array stations (Fig. 2). A primary objective of COLZA is to better define the spatial and temporal patterns of seismic activity in the nominal "locked zone," the neighboring Juan de Fuca plate, and the adjacent down-dip region, where episodic tremor and slip is occurring.

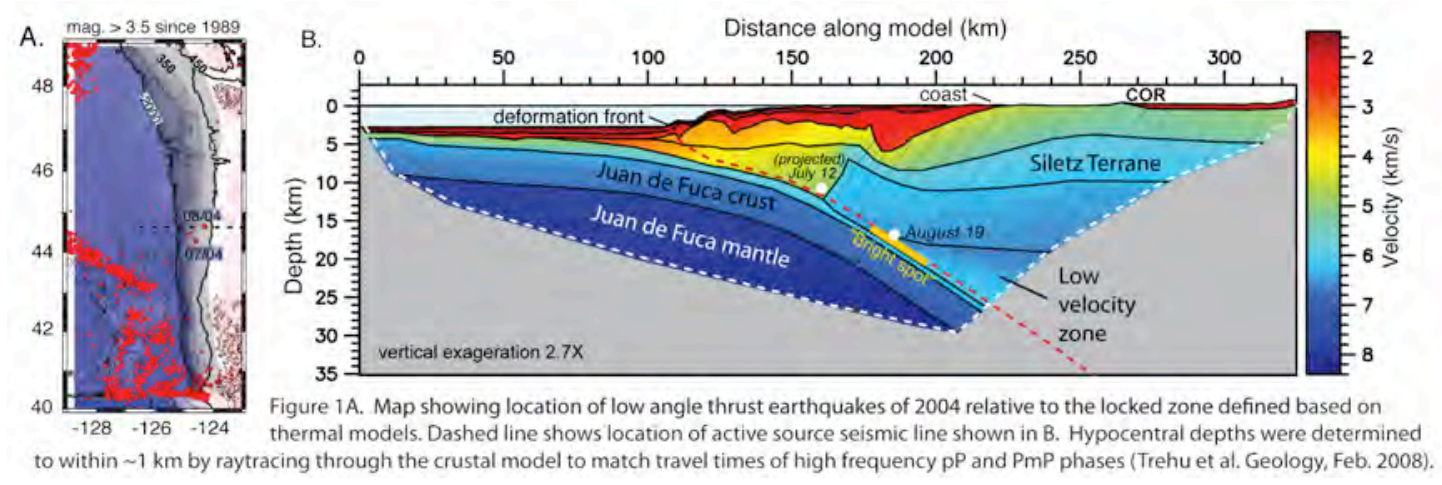

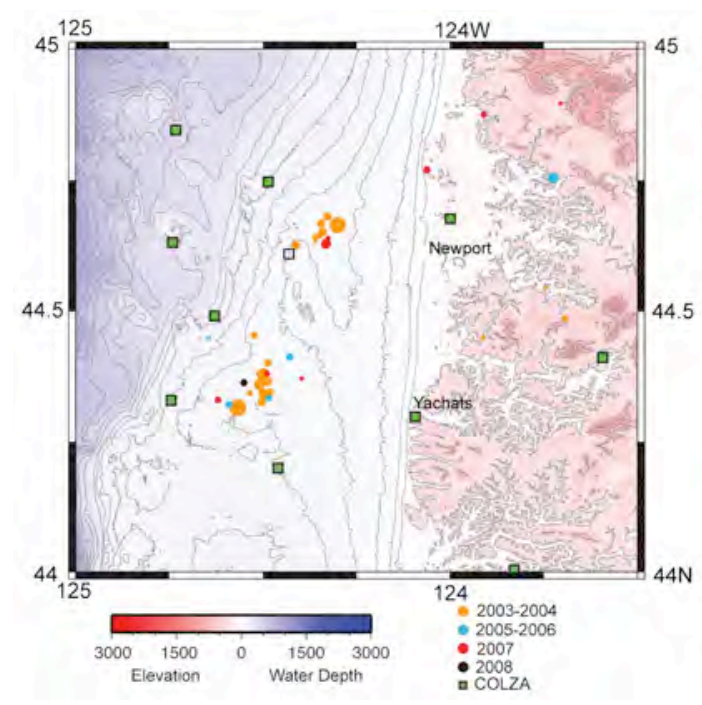

Fig. 2. Seismicity from 01/01/2003 to $25 / 01 / 2008$ from the ANSS catalog. Circles are proportional to magnitude. Seismicity continues in the two patches defined by the events of summer 2004. Continued observation should reveal whether seismicity on one patch triggers seismicity on the other, as suggested in 2004 and 2007, and whether there is any consistent temporal correlation between microearthquake activity offshore and ETS episodes onshore. Note that additional COLZA stations are located to the east and west of this figure. OBSs were deployed in September 2007 and will be recoved in July 2008. They will be redeployed in July and Sept. 2008 and recoved in 2009. FA stations will operate until Sept. 2009.
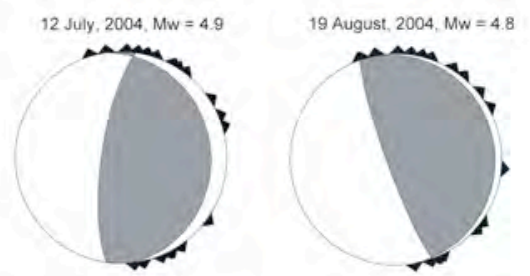

Fig. 3. Moment tensor solutions for the 2004 mainshocks (from Trehu et al., Geology, Feb. 2008). 


\section{Seismic hazard implications of ETS - no canary in the gold mine yet John Vidale, $U W$}

The mechanism of ETS episodes remains inscrutable, but the tectonic implications are becoming clear. Slip is accumulating unsteadily on megathrust faults in the region downdip of their locked zones, and perhaps the volume above the megathrust is also deforming. Similar but less frequent tremor is seen beneath some strike-slip faults.

ETS deformation is bound to encourage earthquakes in the shallower locked portion of the faults, but the salient question is by how much. This question does not yet have a final answer, but I will guess here it is not by much. I'll use the Cascadia megathrust as an example because it runs directly beneath my backyard.

The limit on current probability gain is that ETS is active under Seattle 4\% or $1 / 25$ th of the time. Since we expect to have M9 earthquakes every 500 years or so, the danger of an M9 only rises from $1 / 25,000$ to at most 1/1000 during the weeks with tremor, which is not enough to justify extra hazard mitigation steps during tremor.

The probability gain is probably even less. A great Cascadia earthquake is expected to rupture across several megathrust segments with distinct tremor cycles, and we do not know in which segment such an earthquake would nucleate (Brudzinski). Thus, tremor just downdip of the Cascadia locked zone is active more than $4 \%$ of the time, reducing the probability gain.

Another factor working against tremor triggering quakes is the low stresses inferred for ETS deformation in combination with the possibility that subduction earthquakes might not start adjacent to regions slipping in ETS. It is more likely that earthquakes trigger tremor than the converse. Also, empirically, we have not seen a clear coincidence of earthquakes with ETS episodes, with the caveat that very large earthquakes in wellinstrumented areas are scarce (Schwartz).

ETS can inform hazard mitigation, however. Tremor might provide a legible marker for the down-dip limit of the locked portion of megathrusts - such an interpretation for Cascadia brings the rupture zones of the dreaded M9 1700AD-repeat event alarmingly close to Puget Sound with Tacoma and Seattle (Wong). This interpretation is now being checked against geodetic data (Melbourne).

Also, spatiotemporal patterns that are heretofore unsuspected might emerge to show which tremor signals sensational increases in large earthquake probabilities - maybe tremor is louder or migrates closer to locked asperities later in the seismic cycle, maybe downdip slow slip even starts the process of great earthquakes, as has been suggested for the 1960 Chile earthquake. Maybe fluids are involved in tremor, migrate far enough up the megathrust fault plane to directly loosen locked zones, and do so in a distinctive way.

For these reasons, ETS requires intense scrutiny so we can unravel the mechanics of ETS and the connection between the locked, ETSing, and steadily deforming regions, but the timing of ETS is not yet known to meaningfully modulate earthquake risk. 
Spatial Characteristics and Thermal-petrological Conditions of Cascadia-type Slow Slip Events

\author{
Kelin Wang $^{1,2}$, Herb Dragert ${ }^{1,2}$, Ikuko Wada ${ }^{2}$, Honn Kao ${ }^{1,2}$, and Jiangheng $\mathrm{He}^{1}$ \\ ${ }^{1}$ Pacific Geoscience Centre, Geological Survey of Canada, Sidney, British Columbia \\ ${ }^{2}$ School of Earth and Ocean Sciences, University of Victoria, Victoria, British Columbia
}

Slow slip events (SSE) and/or nonvolcanic seismic tremor are abundantly reported for various tectonic environments, but ETS events - episodic occurrence of both SSE and tremor in the same place, have been confidently observed only at the Cascadia and Nankai subduction zones. The SSE in ETS events are different from other types of SSE for their characteristic week-scale duration and centimetre-scale slip. Their accompanying tremor may also be different from those in other tectonic settings, at least in their frequency content. Here we study the spatial characteristics of the SSE at northern Cascadia in order to understand their thermal and petrological conditions.

We determined the spatial extent of the slip patches from GPS observations and, wherever available, borehole strain-metre data, using dislocation modeling, assuming a bell-shaped downdip distribution of slip proposed by Wang and He (2008). Competing structural models for northern Cascadia, depending on the interpretation of a band of seismic reflectors (the "E layer"), place the plate interface at different depths. We found that a shallower interface requires the slip magnitude to be smaller. However, regardless of the structural model, the slip patches extend to at least $40 \mathrm{~km}$ depth, downdip of the intersection of the plate interface with the continental Moho. Slip patches in different slip events have variable along-strike dimensions ranging from $>300 \mathrm{~km}$ to $<90 \mathrm{~km}$, but the maximum slip always occurs in the $\sim 30-40 \mathrm{~km}$ depth range. The strikenormal span of the slip patches is very consistent with the locations of their accompanying tremor. Limited borehole strain time series for the 2005 ETS event indicate that the along-strike propagating slip patch had a sharp propagating front, supporting the notion that the slip occurred along a thin slip zone or a single decollement.

Undoubtedly, the slow slip at Cascadia occurs around the tip of the mantle wedge where the temperature is higher than $450^{\circ}$ (Wada et al., 2008). Friction models show that episodic slip occurs at a frictional stability transition, e.g., the downdip limit of the megathrust seismogenic zone (Liu and Rice, 2007). But the northern Cascadia SSE are significantly deeper than the thermally defined stability transition $\left(\sim 350^{\circ}\right)$ and the geodetically constrained seismogenic zone. The Nankai seismogenic zone extends to a greater depth, but the Nankai ETS also occur around the mantle wedge tip. We propose that the Cascadia-type (including Nankai) SSE are related to the full serpentinization of the tip of the mantle wedge and the availability of free $\mathrm{H}_{2} \mathrm{O}$ released from the young and warm slab that dehydrates at shallow depths. The buoyant antigorite serpentine formed in the wedge tip may intrude updip along the plate interface owing to its extremely low strength at this depth (Hilariet et al., 2007). Antigorite exhibits velocity-dependent stability transition behaviour (Reinen et al., 1994). The highly nonlinear flow rheology and complex frictional behaviour of antigorite and the very high pore fluid pressure may be responsible for the Cascadia-type SSE. The association with the shallow dehydration of warm slabs also explains the rarity of ETS in cold-slab subduction zones and other tectonic settings.

Hilariet, N. et al. (2007), Science, 318, 1910-1913.

Liu, Y., and J.R. Rice (2007), J. Geophys. Res., 112, B09404, doi:10.1029/2007JB004930.

Reinen, L.A., J.D. Weeks, and T.E. Tullis (1994), Pure Appl. Geophys., 143, 317-356.

Wada, I., K. Wang, J. He, and R.D. Hyndman (2008), J. Geophys. Res., in press.

Wang, K., and J. He (2008), Bull. Seismol. Soc. Am., in press. 


\section{Washington Tremor \\ Aaron Wech \\ University of Washington}

We employ a cross correlation method to locate deep non-volcanic tremor in western Washington and summarize the spatio-temporal tremor migration patterns during the July 2004, September 2005, and January 2007 ETS events. All three sequences were located within the same geographic area, roughly between the surface projection of the 30 and $45 \mathrm{~km}$ depth contours of the plate interface.

Small-aperture seismic array data from the Olympic Peninsula region of the Cascadia subduction zone during the September 2005 episodic tremor and slip (ETS) event reveal uncharacteristic stability in the linearity and polarization direction of particle motion as tremors passed beneath the array. In the tremor frequency band $(1-6 \mathrm{~Hz})$, the measured ground motion became highly linear and dominantly horizontal, stabilizing to an azimuth of $57+/-8$ degrees. This coincides with $\mathrm{S}$-wave polarization predicted by fault slip on the plate boundary in the direction of relative plate motion, suggesting that tremor is the direct result of fault slip along the plate boundary or a series of vertically stratified faults accommodating the slow slip over a range of depths.

Current research is utilizing CAFE, TA, and borehole data to search for very low frequency earthquakes during the January 2007 ETS event. 


\title{
HOW STRONG WILL THE GROUND SHAKING BE? WHAT WE DON'T KNOW ABOUT THIS EARTHQUAKE HAZARD IN THE CASCADIA SUBDUCTION ZONE
}

\author{
Ivan G. Wong \\ Seismic Hazards Group \\ URS Corporation \\ 1333 Broadway, Suite 800 \\ Oakland, CA 94612
}

In the past two decades since we started worrying about large megathrust earthquakes on the Cascadia subduction zone (CSZ), only a somewhat modest level of effort has been put forth to estimate the level of ground motions that might shake the Pacific Northwest. However, a major handicap faced by researchers is the lack of strong motion data from CSZ megathrust earthquakes which has forced us to resort to numerical modeling and looking at data from other regions worldwide. Unfortunately, a major opportunity was lost with the occurrence of the 2004 M 9.3 Great Sumatra earthquake because of the lack of strong motion instrumentation in the epicentral region. This event may bear some strong resemblance to a future CSZ event.

The difficulty in both numerical modeling and transporting data from other regions is obviously the lack of region-specificity. Earthquake ground shaking will be a function of various source, path, and site effects parameters. Although some of these parameters have been characterized through the analysis of small and moderate magnitude Pacific Northwest earthquakes, the question arises on whether these properties are appropriate in very large $(\mathbf{M}>9)$ earthquakes.

There are several significant issues that hinder our ability to predict CSZ ground shaking. First and foremost of the issues is the location of the megathrust rupture plane. Current estimates put the eastern edge just offshore of Washington and Oregon. Observations of near-field ground shaking in large events (M 7.5 to 8.5) worldwide have ranged considerably from low to very strong shaking with durations of one minute to several minutes. At 100 to $200 \mathrm{~km}$, which is a critical distance range for the major metropolitan areas of Vancouver, Seattle, and Portland, the structure and properties of the crust in which the seismic waves are propagating will play a significant role in controlling the levels of ground shaking, e.g., 1985 Mexico City.

In mitigating the ground shaking hazard in the Pacific Northwest particularly efforts to evaluate the current building inventory and for new design, it is imperative we provide an accurate characterization of the ground motions in terms of amplitudes, frequencies, and duration to engineers, public officials, and the general public. At this stage, we are still far short of that goal.

In this paper, I summarize the current assessments of CSZ strong motions in the Pacific Northwest and discuss their uncertainties and their implications to engineering practice and disaster response. 